\title{
Central and Eastern United States Seismic Source Characterization for Nuclear Facilities
}

\section{U.S.NRC United States Nuclear Regulatory Commissio Protecting People and the Environment}

U.S. Nuclear Regulatory Commission Office of Nuclear Regulatory Research Washington DC 20555 NUREG-2115

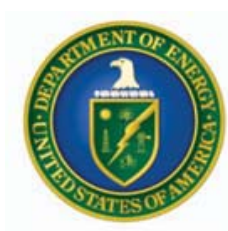

U.S. Department of Energy 1000 Independence Avenue SW

Washington, DC 20585

Report \# DOE/NE-0140

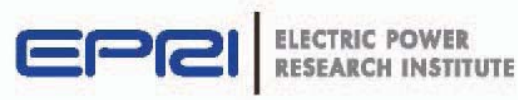

Electric Power Research Institute 3420 Hillview Avenue Palo Alto, CA 94304 Report \# 1021097 



\section{AVAILABILITY OF REFERENCE MATERIALS IN NRC PUBLICATIONS}

\section{NRC Reference Material}

As of November 1999, you may electronically access NUREG-series publications and other NRC records at NRC's Public Electronic Reading Room at http://www.nrc.gov/reading-rm.html.

Publicly released records include, to name a few, NUREG-series publications; Federal Register notices; applicant, licensee, and vendor documents and correspondence; NRC correspondence and internal memoranda; bulletins and information notices; inspection and investigative reports; licensee event reports; and Commission papers and their attachments.

NRC publications in the NUREG series, NRC regulations, and Title 10, Energy, in the Code of Federal Regulations may also be purchased from one of these two sources.

1. The Superintendent of Documents

U.S. Government Printing Office

Mail Stop SSOP

Washington, DC 20402-0001

Internet: bookstore.gpo.gov

Telephone: 202-512-1800

Fax: 202-512-2250

2. The National Technical Information Service Springfield, VA 22161-0002

www.ntis.gov

1-800-553-6847 or, locally, 703-605-6000

A single copy of each NRC draft report for comment is available free, to the extent of supply, upon written request as follows:

Address: U.S. Nuclear Regulatory Commission Office of Administration

Publications Branch Washington, DC 20555-0001

E-mail: DISTRIBUTION.SERVICES@NRC.GOV Facsimile: 301-415-2289

Some publications in the NUREG series that are posted at NRC's Web site address http://www.nrc.gov/reading-rm/doc-collections/nuregs are updated periodically and may differ from the last printed version. Although references to material found on a Web site bear the date the material was accessed, the material available on the date cited may subsequently be removed from the site.

\section{Non-NRC Reference Material}

Documents available from public and special technical libraries include all open literature items, such as books, journal articles, and transactions, Federal Register notices, Federal and State legislation, and congressional reports. Such documents as theses, dissertations, foreign reports and translations, and non-NRC conference proceedings may be purchased from their sponsoring organization.

Copies of industry codes and standards used in a substantive manner in the NRC regulatory process are maintained at-

The NRC Technical Library

Two White Flint North

11545 Rockville Pike

Rockville, MD 20852-2738

These standards are available in the library for reference use by the public. Codes and standards are usually copyrighted and may be purchased from the originating organization or, if they are American National Standards, from-

American National Standards Institute 11 West $42^{\text {nd }}$ Street

New York, NY 10036-8002

www.ansi.org

212-642-4900

Legally binding regulatory requirements are stated only in laws; NRC regulations; licenses, including technical specifications; or orders, not in

NUREG-series publications. The views expressed in contractor-prepared publications in this series are not necessarily those of the NRC.

The NUREG series comprises (1) technical and administrative reports and books prepared by the staff (NUREG-XXXX) or agency contractors

(NUREG/CR-XXXX), (2) proceedings of conferences (NUREG/CP-XXXX), (3) reports resulting from international agreements (NUREG/IA-XXXX), (4) brochures (NUREG/BR-XXXX), and (5) compilations of legal decisions and orders of the Commission and Atomic and Safety Licensing Boards and of Directors' decisions under Section 2.206 of NRC's regulations (NUREG-0750). 



\section{Central and Eastern United States Seismic Source Characterization for Nuclear Facilities}

\section{Cosponsors}

U.S. Department of Energy

1000 Independence Avenue SW

Washington, DC 20585

R. H. Lagdon, Jr.

Chief of Nuclear Safety

Office of the Under Secretary for Nuclear Security, S-5

M.E. Shields

Project Manager

Office of Nuclear Energy, NE-72

Electric Power Research Institute

3420 Hillview Avenue

Palo Alto, CA 94304

J. F. Hamel

Program Manager

Advanced Nuclear Technology

U.S. Nuclear Regulatory Commission

Office of Nuclear Regulatory Research

Washington DC 20555

R.G. Roche-Rivera

NRC Project Manager 


\section{DISCLAIMER OF WARRANTIES AND LIMITATION OF LIABILITIES}

\section{EPRI DISCLAIMER}

THIS DOCUMENT WAS PREPARED AS AN ACCOUNT OF WORK SPONSORED OR COSPONSORED BY THE ELECTRIC POWER RESEARCH INSTITUTE, INC. (EPRI). NEITHER EPRI, ANY MEMBER OF EPRI, ANY COSPONSOR BELOW, NOR ANY PERSON ACTING ON BEHALF OF ANY OF THEM:

(A) MAKES ANY WARRANTY OR REPRESENTATION WHATSOEVER, EXPRESS OR IMPLIED, (I) WITH RESPECT TO THE USE OF ANY INFORMATION, APPARATUS, METHOD, PROCESS, OR SIMILAR ITEM DISCLOSED IN THIS DOCUMENT, INCLUDING MERCHANTABILITY AND FITNESS FOR A PARTICULAR PURPOSE, OR (II) THAT SUCH USE DOES NOT INFRINGE ON OR INTERFERE WITH PRIVATELY OWNED RIGHTS, INCLUDING ANY PARTY'S INTELLECTUAL PROPERTY, OR (III) THAT THIS DOCUMENT IS SUITABLE TO ANY PARTICULAR USER'S CIRCUMSTANCE; OR

(B) ASSUMES RESPONSIBILITY FOR ANY DAMAGES OR OTHER LIABILITY WHATSOEVER (INCLUDING ANY CONSEQUENTIAL DAMAGES, EVEN IF EPRI OR ANY EPRI REPRESENTATIVE HAS BEEN ADVISED OF THE POSSIBILITY OF SUCH DAMAGES) RESULTING FROM YOUR SELECTION OR USE OF THIS DOCUMENT OR ANY INFORMATION, APPARATUS, METHOD, PROCESS, OR SIMILAR ITEM DISCLOSED IN THIS DOCUMENT.

\section{DOE DISCLAIMER}

THIS REPORT WAS PREPARED AS AN ACCOUNT OF WORK SPONSORED BY AN AGENCY OF THE UNITED STATES GOVERNMENT. NEITHER THE UNITED STATES GOVERNMENT NOR ANY AGENCY THEREOF, NOR ANY OF THEIR EMPLOYEES, MAKES ANY WARRANTY, EXPRESS OR IMPLIED, OR ASSUMES ANY LEGAL LIABILITY OR RESPONSIBILITY FOR THE ACCURACY, COMPLETENESS, OR USEFULNESS OF ANY INFORMATION, APPARATUS, PRODUCT, OR PROCESS DISCLOSED, OR REPRESENTS THAT ITS USE WOULD NOT INFRINGE PRIVATELY OWNED RIGHTS. REFERENCE HEREIN TO ANY SPECIFIC COMMERCIAL PRODUCT, PROCESS, OR SERVICE BY TRADE NAME, TRADEMARK, MANUFACTURER, OR OTHERWISE DOES NOT NECESSARILY CONSTITUTE OR IMPLY ITS ENDORSEMENT, RECOMMENDATION, OR FAVORING BY THE UNITED STATES GOVERNMENT OR ANY AGENCY THEREOF. THE VIEWS AND OPINIONS OF AUTHORS EXPRESSED HEREIN DO NOT NECESSARILY STATE OR REFLECT THOSE OF THE UNITED STATES GOVERNMENT OR ANY AGENCY THEREOF.

\section{NRC DISCLAIMER}

THIS REPORT WAS PREPARED AS AN ACCOUNT OF WORK SPONSORED BY AN AGENCY OF THE U.S. GOVERNMENT. NEITHER THE U.S. GOVERNMENT NOR ANY AGENCY THEREOF, NOR ANY EMPLOYEE, MAKES ANY WARRANTY, EXPRESSED OR IMPLIED, OR ASSUMES ANY LEGAL LIABILITY OR RESPONSIBILITY FOR ANY THIRD PARTY'S USE, OR THE RESULTS OF SUCH USE, OF ANY INFORMATION, APPARATUS, PRODUCT, OR PROCESS DISCLOSED IN THIS PUBLICATION, OR REPRESENTS THAT ITS USE BY SUCH THIRD PARTY WOULD NOT INFRINGE PRIVATELY OWNED RIGHTS. THE STATEMENTS, FINDINGS, CONCLUSIONS AND RECOMMENDATIONS ARE THOSE OF THE AUTHOR(S) AND DO NOT NECESSARILY REFLECT THE VIEW OF THE US NUCLEAR REGULATORY COMMISSION. 


\section{SPONSORS' ACKNOWLEDGMENTS}

The project sponsors would like to acknowledge the following individuals for directing the project:

Coppersmith Consulting, Inc.

2121 N. California Blvd., \#290

Walnut Creek, CA 94596

Technical Integration (TI) Lead

K.J. Coppersmith

Savannah River Nuclear Solutions, LLC

Savannah River Site

Building 730-4B, Room 313

Aiken, SC 29808

CEUS SSC Project Manager

L.A. Salomone

This document describes research sponsored by the Electric Power Research Institute (EPRI), U.S. Department of Energy (U.S. DOE) under Award Number DE-FG07-08ID14908, and the U.S. Nuclear Regulatory Commission (U.S. NRC) under Award Number NCR-04-09-144.

This publication is a corporate document that should be cited in the literature in the following manner:

Technical Report: Central and Eastern United States Seismic Source Characterization for Nuclear Facilities. EPRI, Palo Alto, CA, U.S. DOE, and U.S. NRC: 2012. 



\section{AUTHORS}

This document was prepared by the following investigators:

\begin{tabular}{|l|l|}
\hline Technical Integration Lead & Kevin J. Coppersmith \\
\hline Project Manager & Lawrence A. Salomone \\
\hline Technical Integration Team & Chris W. Fuller \\
& Laura L. Glaser \\
& Kathryn L. Hanson \\
& Ross D. Hartleb \\
& William R. Lettis \\
& Scott C. Lindvall \\
& Stephen M. McDuffie \\
& Robin K. McGuire \\
& Gerry L. Stirewalt \\
& Gabriel R. Toro \\
& Robert R. Youngs \\
\hline Database Manager & David L. Slayter \\
\hline Technical Support & Serkan B. Bozkurt \\
& Randolph J. Cumbest \\
& Valentina Montaldo Falero \\
& Roseanne C. Perman \\
& Allison M. Shumway \\
& Frank H. Syms \\
& Martitia (Tish) P. Tuttle, Paleoliquefaction Data \\
& Resource \\
\hline
\end{tabular}



This document has been reproduced from the best available copy. 



\section{ABSTRACT}

This report describes a new seismic source characterization (SSC) model for the Central and Eastern United States (CEUS). It will replace the Seismic Hazard Methodology for the Central and Eastern United States, EPRI Report NP-4726 (July 1986) and the Seismic Hazard Characterization of 69 Nuclear Plant Sites East of the Rocky Mountains, Lawrence Livermore National Laboratory Model, (Bernreuter et al., 1989). The objective of the CEUS SSC Project is to develop a new seismic source model for the CEUS using a Senior Seismic Hazard Analysis Committee (SSHAC) Level 3 assessment process. The goal of the SSHAC process is to represent the center, body, and range of technically defensible interpretations of the available data, models, and methods. Input to a probabilistic seismic hazard analysis (PSHA) consists of both seismic source characterization and ground motion characterization. These two components are used to calculate probabilistic hazard results (or seismic hazard curves) at a particular site. This report provides a new seismic source model.

\section{Results and Findings}

The product of this report is a regional CEUS SSC model. This model includes consideration of an updated database, full assessment and incorporation of uncertainties, and the range of diverse technical interpretations from the larger technical community. The SSC model will be widely applicable to the entire CEUS, so this project uses a ground motion model that includes generic variations to allow for a range of representative site conditions (deep soil, shallow soil, hard rock). Hazard and sensitivity calculations were conducted at seven test sites representative of different CEUS hazard environments.

\section{Challenges and Objectives}

The regional CEUS SSC model will be of value to readers who are involved in PSHA work, and who wish to use an updated SSC model. This model is based on a comprehensive and traceable process, in accordance with SSHAC guidelines in NUREG/CR-6372, Recommendations for Probabilistic Seismic Hazard Analysis: Guidance on Uncertainty and Use of Experts. The model will be used to assess the present-day composite distribution for seismic sources along with their characterization in the CEUS and uncertainty. In addition, this model is in a form suitable for use in PSHA evaluations for regulatory activities, such as Early Site Permit (ESPs) and Combined Operating License Applications (COLAs).

\section{Applications, Values, and Use}

Development of a regional CEUS seismic source model will provide value to those who (1) have submitted an ESP or COLA for Nuclear Regulatory Commission (NRC) review before 2011; (2) will submit an ESP or COLA for NRC review after 2011; (3) must respond to safety issues resulting from NRC Generic Issue 199 (GI-199) for existing plants and (4) will prepare PSHAs to meet design and periodic review requirements for current and future nuclear facilities. This work replaces a previous study performed approximately 25 years ago. Since that study was 
completed, substantial work has been done to improve the understanding of seismic sources and their characterization in the CEUS. Thus, a new regional SSC model provides a consistent, stable basis for computing PSHA for a future time span. Use of a new SSC model reduces the risk of delays in new plant licensing due to more conservative interpretations in the existing and future literature.

\section{Perspective}

The purpose of this study, jointly sponsored by EPRI, the U.S. Department of Energy (DOE), and the NRC was to develop a new CEUS SSC model. The team assembled to accomplish this purpose was composed of distinguished subject matter experts from industry, government, and academia. The resulting model is unique, and because this project has solicited input from the present-day larger technical community, it is not likely that there will be a need for significant revision for a number of years. See also Sponsors' Perspective for more details.

\section{Approach}

The goal of this project was to implement the CEUS SSC work plan for developing a regional CEUS SSC model. The work plan, formulated by the project manager and a technical integration team, consists of a series of tasks designed to meet the project objectives. This report was reviewed by a participatory peer review panel (PPRP), sponsor reviewers, the NRC, the U.S. Geological Survey, and other stakeholders. Comments from the PPRP and other reviewers were considered when preparing the report. The SSC model was completed at the end of 2011.

\section{Keywords}

Probabilistic seismic hazard analysis (PSHA)

Seismic source characterization (SSC)

Seismic source characterization model

Central and Eastern United States (CEUS) 


\section{CONTENTS}

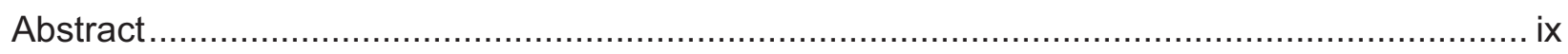

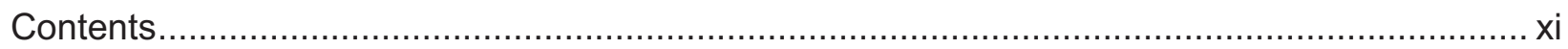

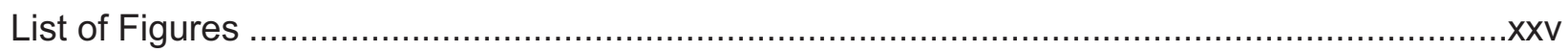

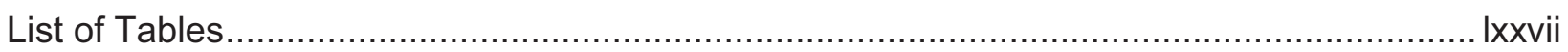

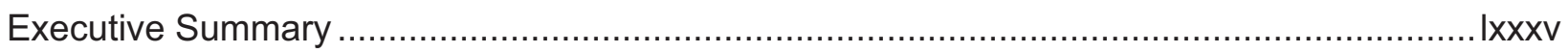

Participatory Peer Review Panel Final Report Dated October 24, 2011 ...............................xcv

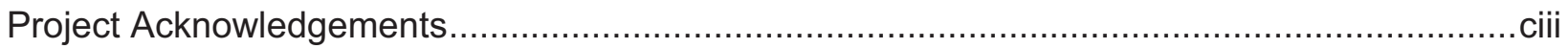

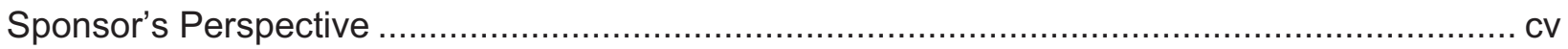

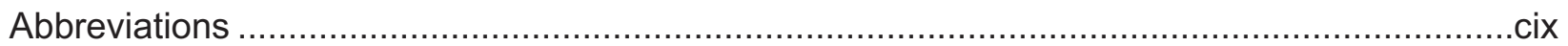

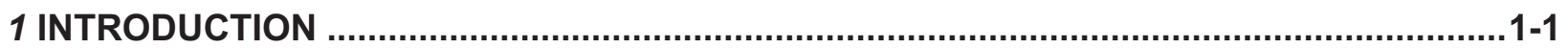

1.1 Background and History ..........................................................................

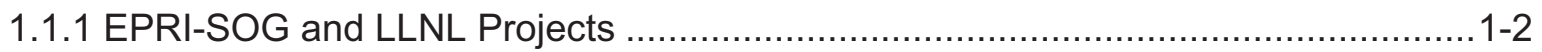

1.1.2 Development of the SSHAC Process .......................................................

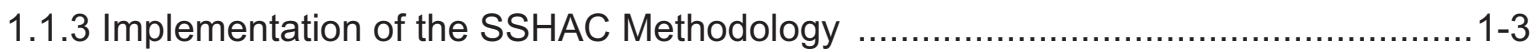

1.1.4 Regional SSC Model for Nuclear Facilities................................................ 1-3

1.1.5 Differences from USGS National Seismic Hazard Mapping Project.......................1-4

1.2 Purpose of the CEUS SSC Project ....................................................................

1.2.1 Implementation of SSHAC Level 3 Process .................................................. 1-6

1.2.2 Goals: Stability and Longevity .............................................................

1.2 .3 Interface with Ground Motion Models ...................................................... 1-8

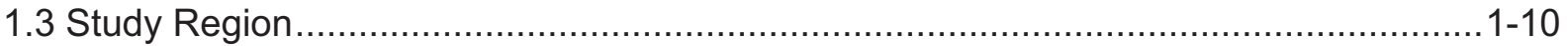

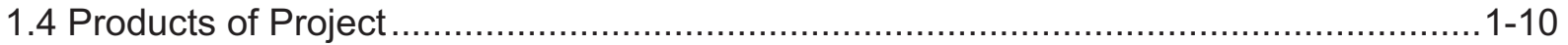

1.4.1 Seismic Source Model for Study Region ................................................... 1-10

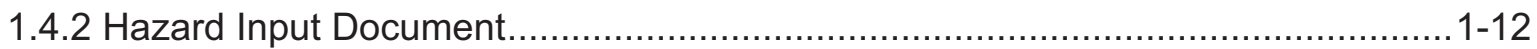

1.4.3 Documentation of Technical Bases for All Assessments .................................1-12

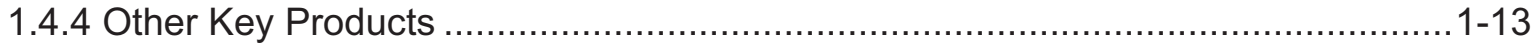

1.4.4.1 Data Evaluation and Data Summary Tables......................................... 1-13 
1.4.4.2 Database of Geologic, Geophysical, and Seismological Data.....................1-13

1.4.4.3 Earthquake Catalog with Uniform Moment Magnitudes...............................1-13

1.4.4.4 Updated Paleoseismicity Data and Guidance..........................................1-14

1.4.4.5 Recommendations for Future Applications of SSC Model...........................1-14

2 SSHAC LEVEL 3 ASSESSMENT PROCESS AND IMPLEMENTATION ............................. 2-1

2.1 Goals and Activities of a SSHAC Assessment Process ...............................................2-2

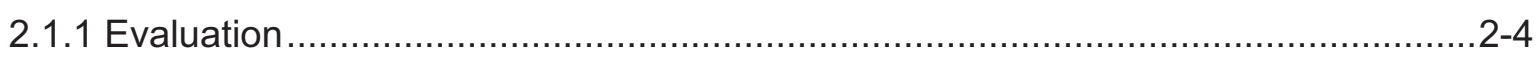

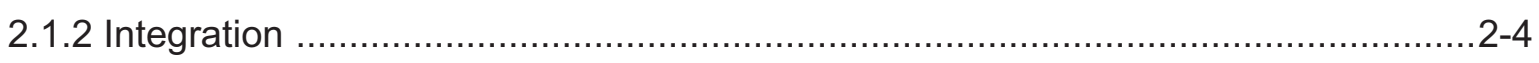

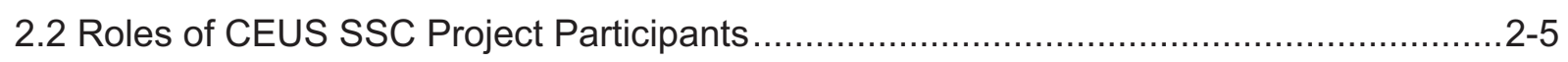

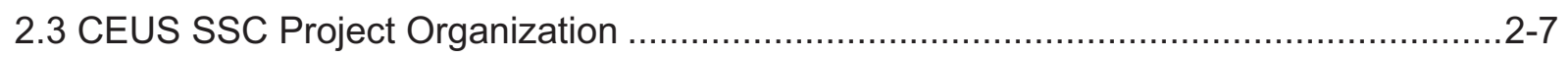

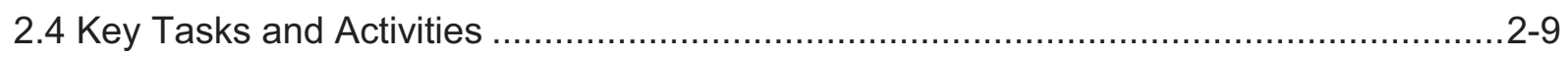

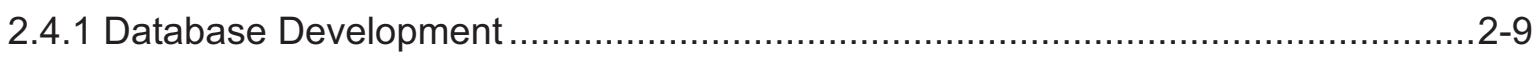

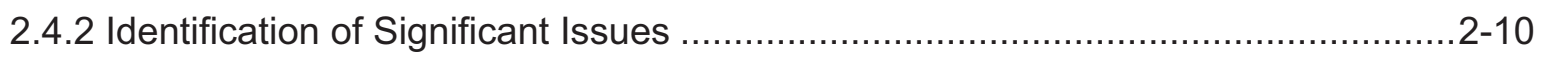

2.4.3 Workshop \#1—Key Issues and Available Data ............................................... 2-10

2.4.4 Workshop \#2-Alternative Interpretations ....................................................... 2-12

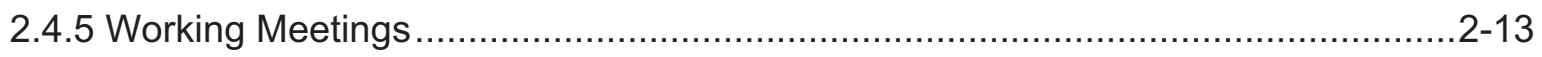

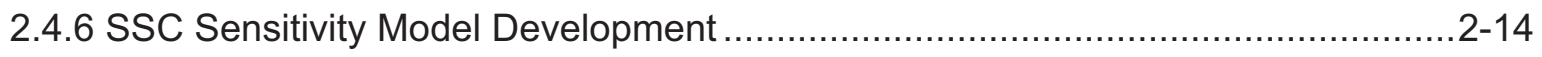

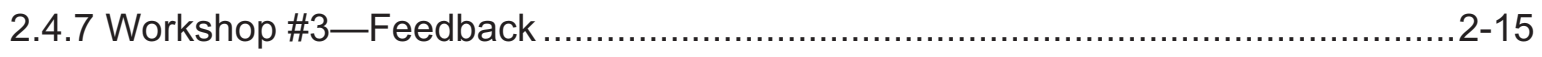

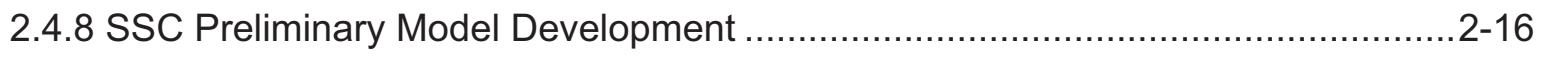

2.4.9 Finalization and Review of SSC Draft and Final Model .....................................2-17

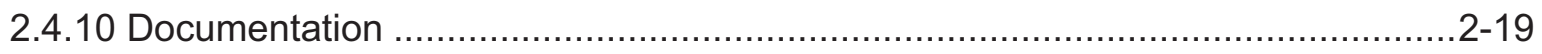

2.4.10.1 Development of the Hazard Input Document.........................................2-19

2.4.10.2 Development of Earlier Draft Report..................................................

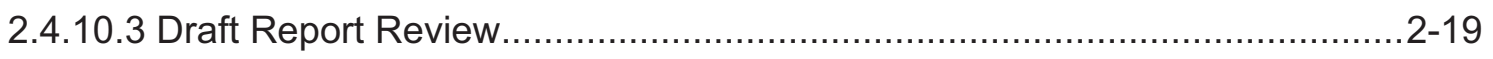

2.4.10.4 Final Report Development ............................................................2-20

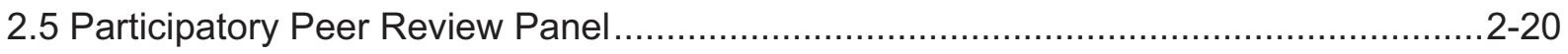

2.5.1 Roles and Responsibilities ..................................................................... 2-20

2.5.2 Reviews and Feedback .........................................................................2-20

2.5.3 Fulfillment of SSHAC-Prescribed Scope of Review of Both Technical and

Process Issues ......................................................................................

2.6 Consistency of CEUS SSC Assessment Process with SSHAC Guidelines ..................2-22

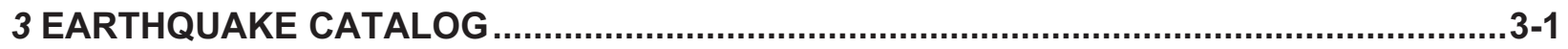

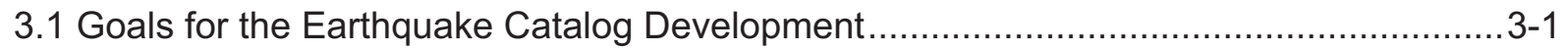

3.1.1 Completeness .........................................................................................

xii 


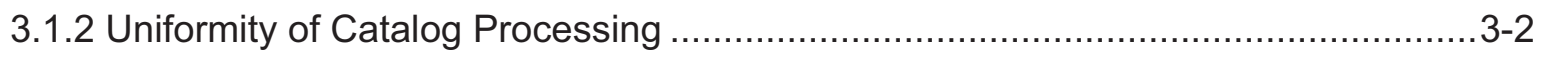

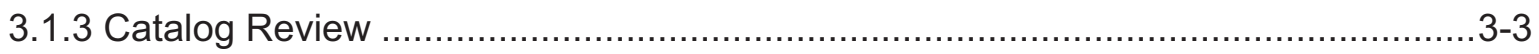

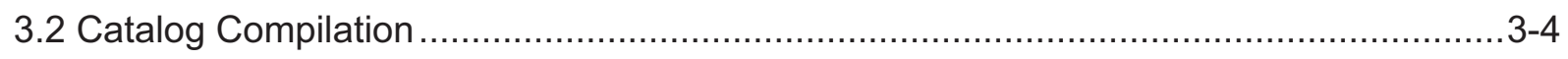

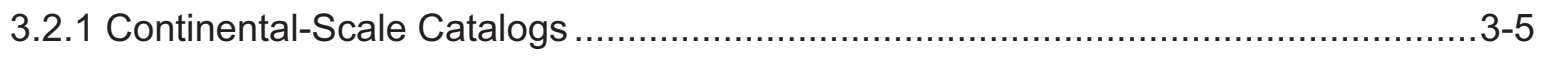

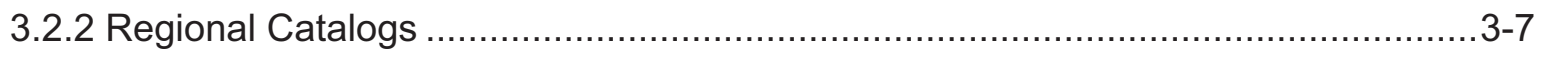

3.2.3 Catalogs from Special Studies ….........................................................

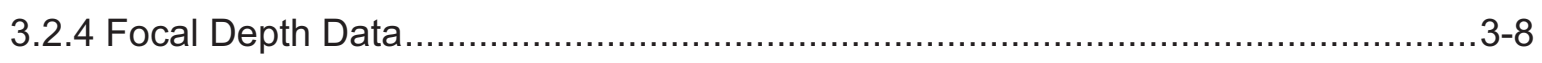

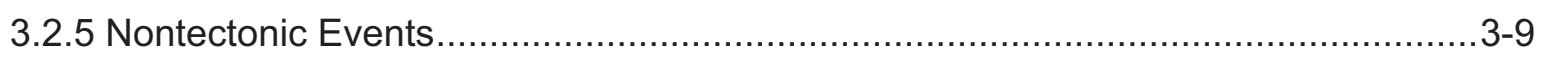

3.2.6 Identification of Unique Earthquake Entries .............................................. $3-9$

3.3 Development of a Uniform Moment Magnitude Earthquake Catalog ......................... 3-11

3.3.1 Approach for Uniform Magnitude and Unbiased Recurrence Estimation .............3-11

3.3.2 Estimation of E[M] for the CEUS SSC Project Catalog ................................. $3-19$

3.3.2.1 Effect of Magnitude Rounding on Statistical Tests .................................. -19

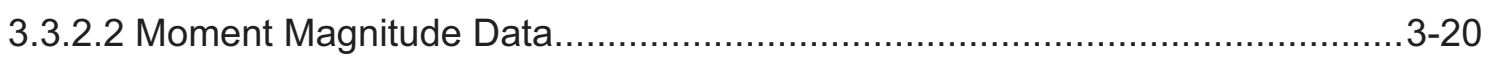

3.3.2.3 Estimation of $E[M]$ from Body-Wave Magnitudes ................................... $3-22$

3.3.2.4 Estimation of $E[M]$ from $M_{L}$ Magnitudes.......................................... $3-28$

3.3.2.5 Estimation of $E[M]$ from $M_{S}$ Magnitudes ............................................. $3-29$

3.3.2.6 Estimation of $E[M]$ from $M_{C}$ and $M_{D}$ Magnitudes................................. $3-30$

3.3.2.7 Estimation of $E[M]$ from the Logarithm of Felt Area ................................. $3-32$

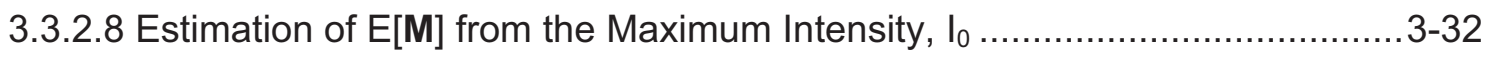

3.3.2.9 Uniform Moment Magnitude Catalog of $E[\mathbf{M}]$ and $N^{*}$ Values.....................3-36

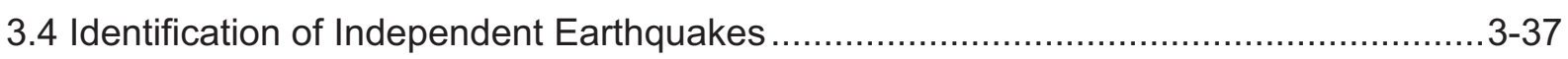

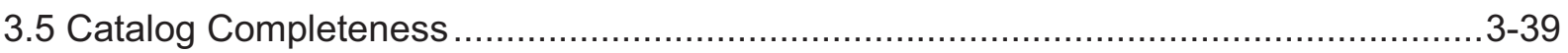

4 CONCEPTUAL SEISMIC SOURCE CHARACTERIZATION FRAMEWORK........................4-1

4.1 Needs for a Conceptual SSC Framework .......................................................... $4-2$

4.1.1 Logic Tree Approach to Representing Alternatives and Assessing

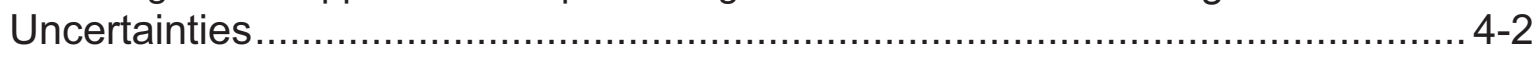

4.1.1.1 Examples of Logic Trees ............................................................... 4

4.1.1.2 Assigning Weights to Logic Tree Branches ......................................... 4-3

4.1.2 Data Identification and Evaluation ....................................................... 4

4.1.2.1 "Generic" Data Identification to Address Indicators of a Seismic Source ........4-5

4.1.2.2 Data Evaluation for Particular Seismic Sources: Data Evaluation and

Data Summary Tables ..........................................................................

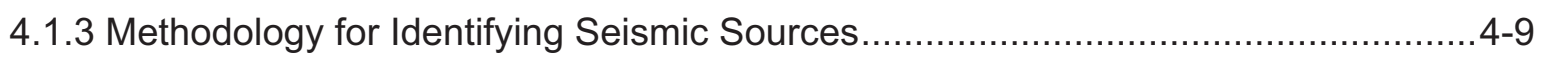


4.1.3.1 Hazard-Informed Approach

4.1.3.2 Conclusions Regarding the Hazard Significance of Various SSC Issues......4-13

4.1.3.3 Criteria for Defining Seismic Sources ............................................... $4-14$

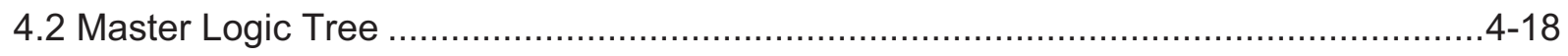

4.2.1 Description of Logic Tree Elements..................................................... $4-18$

4.2.2 RLME Source Logic Tree .................................................................... $4-20$

4.2.3 Mmax Zones Logic Tree ..................................................................... $4-22$

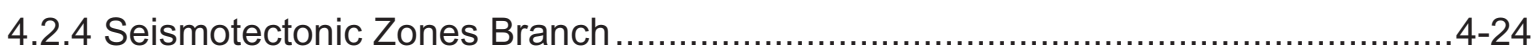

5 SSC MODEL: OVERVIEW AND METHODOLOGY.................................................... 5-1

5.1 Overview of Spatial and Temporal Models....................................................... $5-1$

5.1.1 Spatial Model Considerations .................................................................... $5-1$

5.1.2 Considerations Regarding Temporal Models ............................................ $5-3$

5.1 .3 Perspective on CEUS SSC Models ....................................................... $5-4$

5.2 Maximum Earthquake Magnitude Assessment .................................................. $5-5$

5.2.1 Approaches to Mmax Estimation in the CEUS ............................................. $5-6$

5.2.1.1 Bayesian Mmax Approach .............................................................. $5-8$

5.2.1.2 Kijko Approach to Mmax Assessment ...............................................5-17

5.2.1.3 Weights for the Alternative Mmax Approaches.................................... 5-20

5.2.1.4 Example Mmax Distributions .......................................................... 5-20

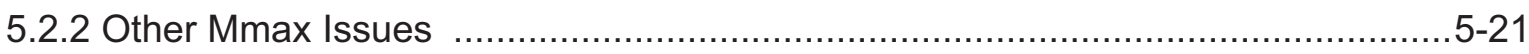

5.3 Earthquake Recurrence Assessment ....................................................................

5.3.1 Smoothing to Represent Spatial Stationarity ............................................ $5-22$

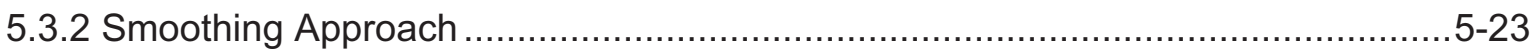

5.3.2.1 Development of Penalized-Likelihood Approach and Formulation ................5-23

5.3.2.2 Application of the Model and Specification of Model Parameters ..................5-36

5.3.2.3 Exploration of Model Results in Parameter Space ....................................5-40

5.3.2.4 Consideration of Constant b-Value Kernel Approaches ...............................5-42

5.3.2.5 Comparison to EPRI-SOG Approach.................................................. $5-45$

5.3.2.6 Assessment of the Lombardi Study .................................................. 5-46

5.3.3 Estimation of Recurrence for RLME Sources ............................................. 5-47

5.3.3.1 Estimation of Occurrence Rates for the Poisson Model ............................5-48

5.3.3.2 Estimation of Occurrence Rates for a Renewal Model .............................5-51

5.3.3.3 Incorporating Uncertainty in the Input .............................................5-52

5.3.3.4 RLME Magnitude Distribution ....................................................... $5-53$ 
5.4 Assessment of Future Earthquake Characteristics …….......................................5-54

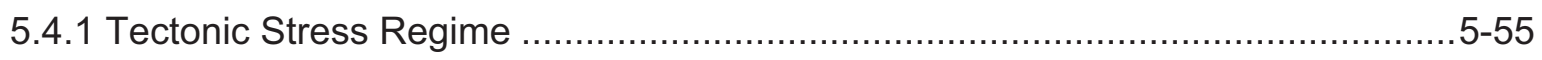

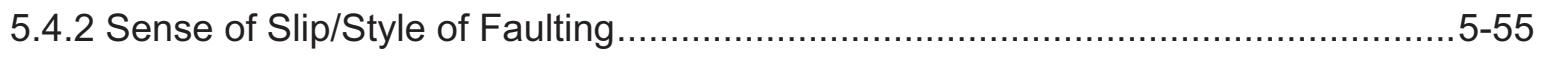

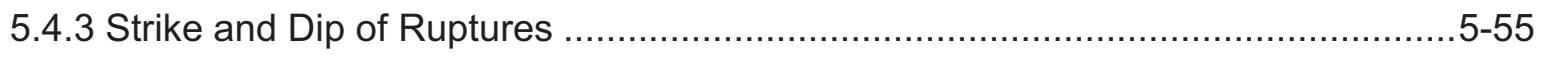

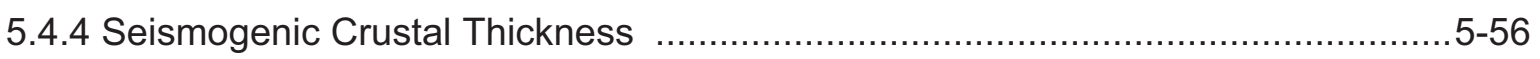

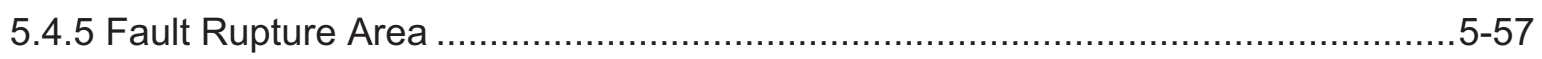

5.4.6 Rupture Length-to-Width Aspect Ratio ...............................................................5-57

5.4.7 Relationship of Rupture to Source Zone Boundaries ……................................ 5-58

5.5 Predicted Seismic Moment Rate ……....................................................................

6 SSC MODEL: RLME SOURCES AND MMAX ZONES BRANCH................................... 6-1

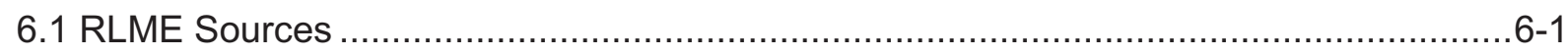

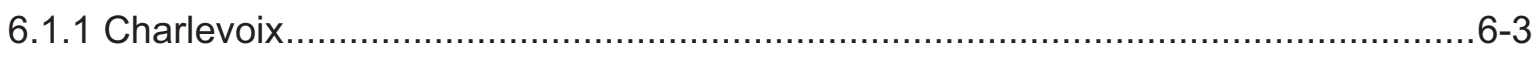

6.1.1.1 Evidence for Temporal Clustering ..........................................................

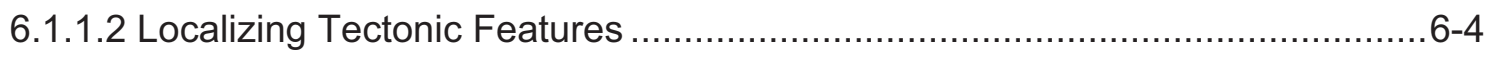

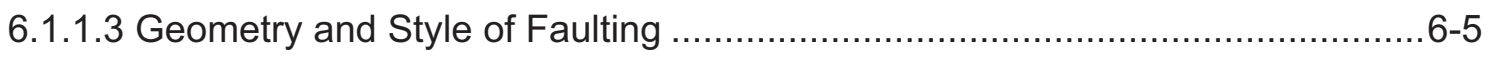

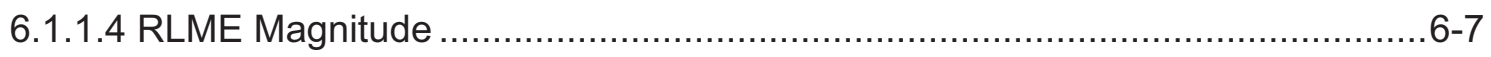

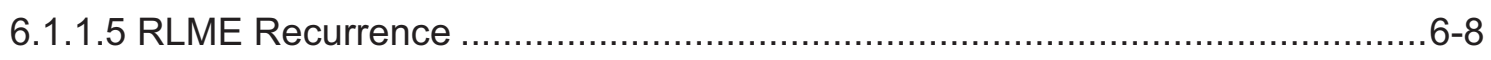

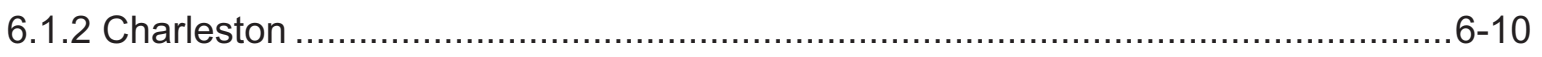

6.1.2.1 Evidence for Temporal Clustering .......................................................

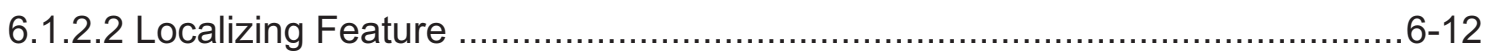

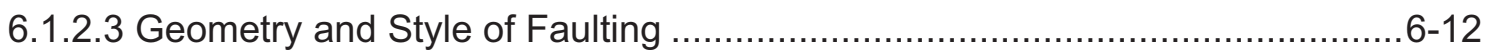

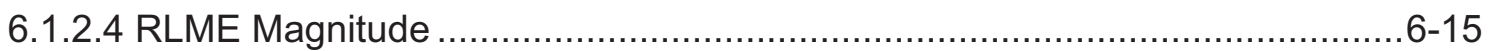

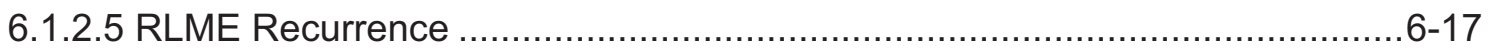

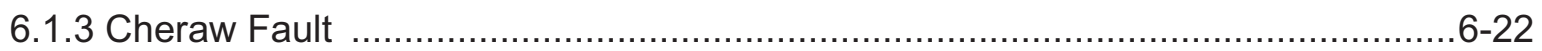

6.1.3.1 Evidence for Temporal Clustering.......................................................

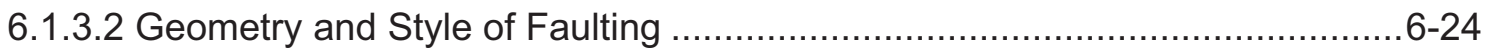

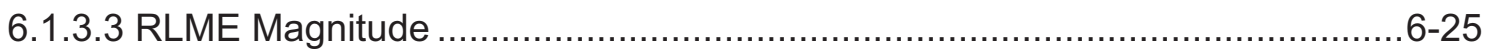

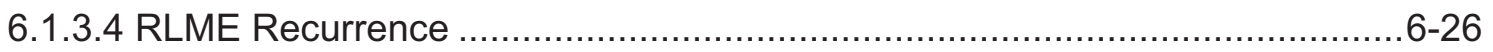

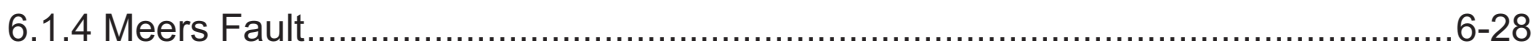

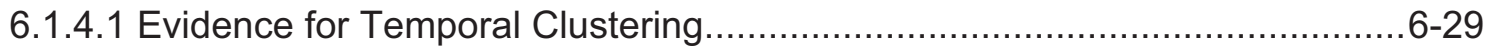

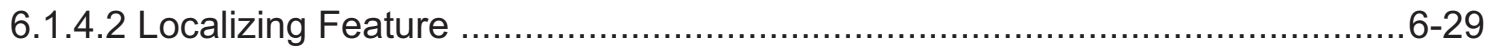

6.1.4.3 Geometry and Style of Faulting ….......................................................

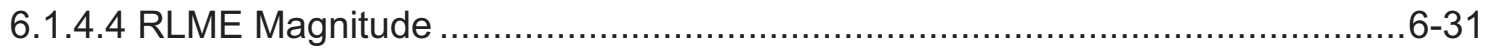

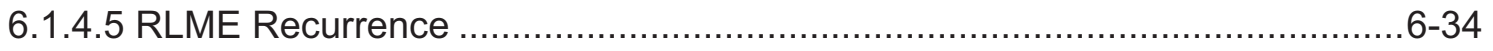


6.1.5 Reelfoot Rift-New Madrid Fault System ................................................ 6-35

6.1.5.1 Evidence for Temporal Clustering................................................ 6-40

6.1.5.2 Geometry and Style of Faulting ….................................................. 6 -42

6.1.5.3 RLME Magnitude ...................................................................... $6-44$

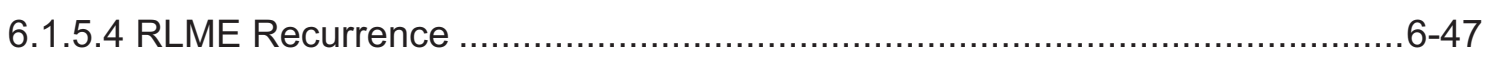

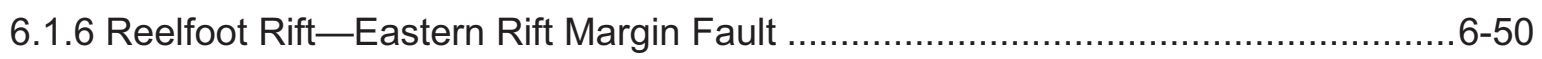

6.1.6.1 Evidence for Temporal Clustering...................................................... $6-53$

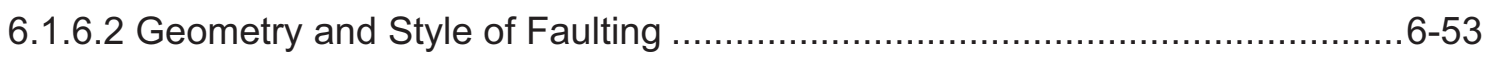

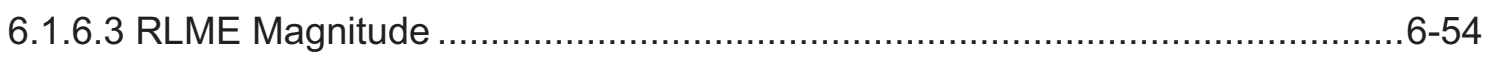

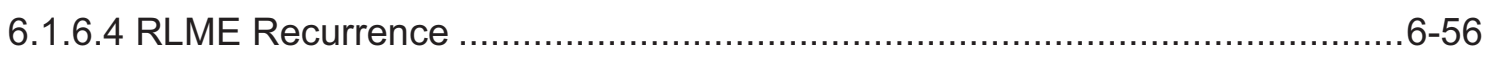

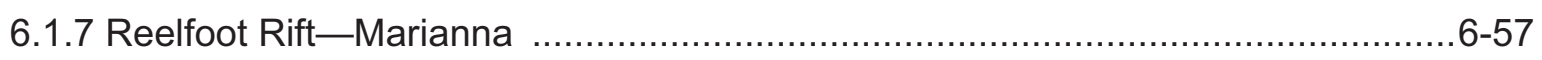

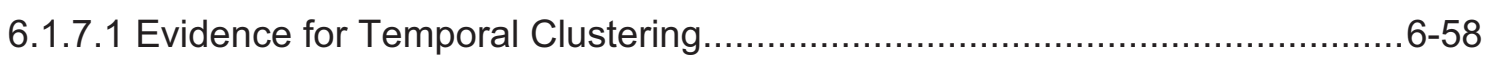

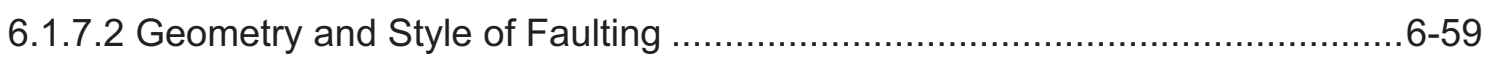

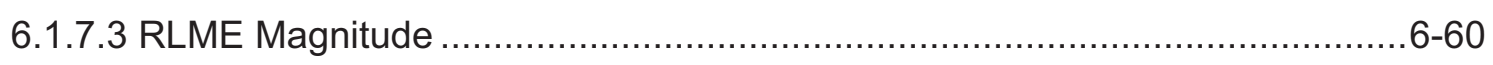

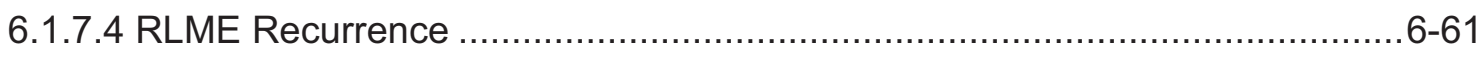

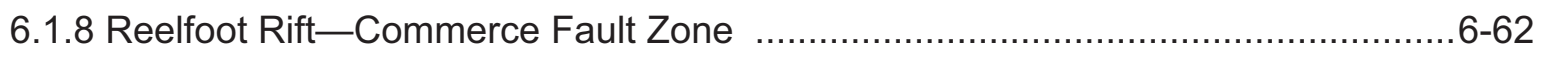

6.1.8.1 Evidence for Temporal Clustering.......................................................6-63

6.1.8.2 Geometry and Style of Faulting ................................................... 6-64

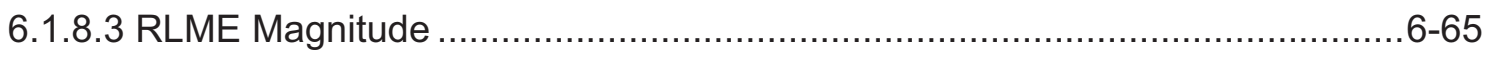

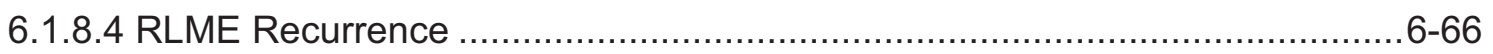

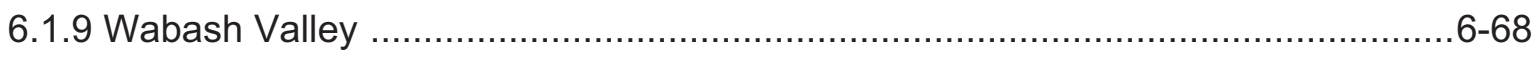

6.1.9.1 Evidence for Temporal Clustering..................................................6-69

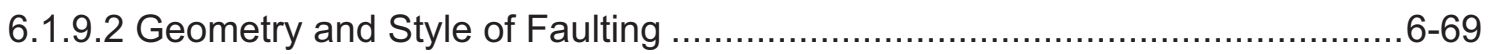

6.1.9.3 RLME Magnitude ........................................................................ $6-72$

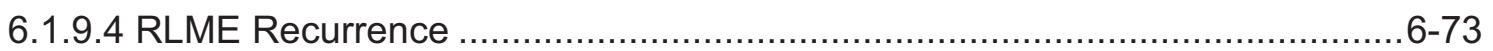

6.2 Mmax Distributed Seismicity Source Zones ........................................................ 6-74

6.2.1 Definition of Mmax Zones ..........................................................................

6.2.2 Criteria for Defining the MESE/NMESE Boundary ....................................6-75

6.3 Maximum Magnitude Distributions for Mmax Distributed Seismicity Sources..............6-76

6.3.1 Maximum Observed Earthquake Magnitude ................................................. $6-76$

6.3.2 Mmax Distributions ................................................................................. $6-77$

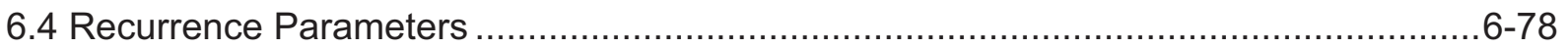

6.4.1 Rate and b-Value Maps for Single Zone and Two Zones...............................6-78

6.4.2 Comparison of Recurrence Parameters to Catalog......................................6-79 
7 SSC MODEL: SEISMOTECTONIC ZONES BRANCH ….................................................

7.1 Approaches and Data Used to Define Seismotectonic Zones .................................... 7-1

7.2 RLME Sources in the Seismotectonic Zones Branch..............................................

7.3 Seismotectonic Source Zones..........................................................................

7.3.1 St. Lawrence Rift Zone (SLR) .................................................................

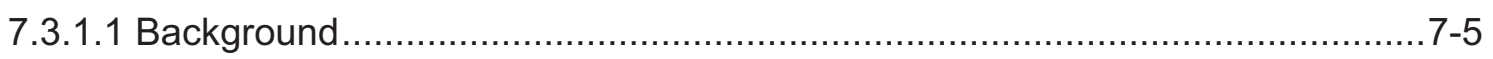

7.3.1.2 Basis for Defining Seismotectonic Zone ....................................................

7.3.1.3 Basis for Zone Geometry ....................................................................

7.3.1.4 Basis for Zone Mmax.........................................................................

7.3.1.5 Future Earthquake Characteristics ..............................................................

7.3.2 Great Meteor Hotspot Zone (GMH) ...........................................................

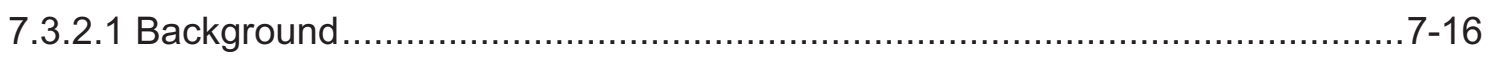

7.3.2.2 Basis for Defining Seismotectonic Zone ...................................................

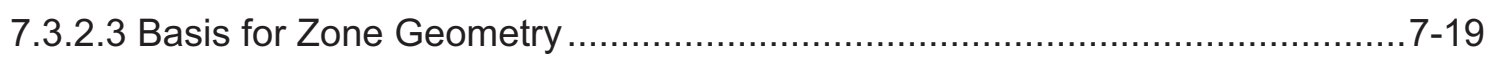

7.3.2.4 Basis for Zone Mmax.....................................................................

7.3.2.5 Future Earthquake Characteristics …………....................................

7.3.3 Northern Appalachian Zone (NAP) .........................................................

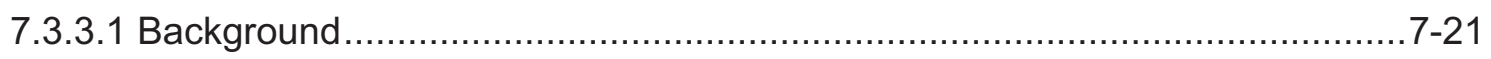

7.3.3.2 Basis for Defining Seismotectonic Zone ………...................................

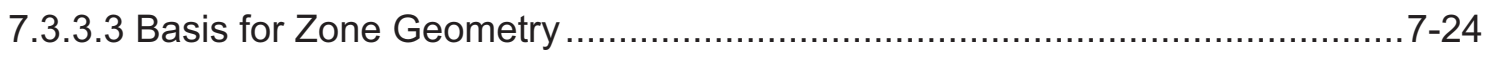

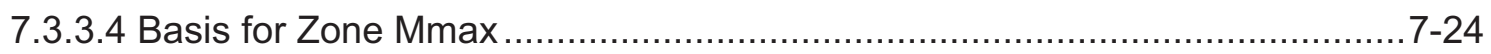

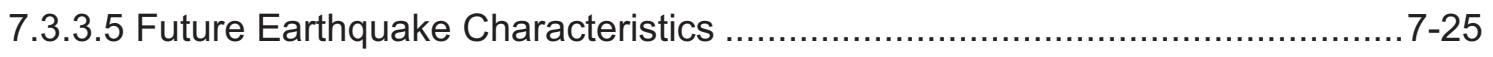

7.3.4 Paleozoic Extended Crust (PEZ) ………………..................................

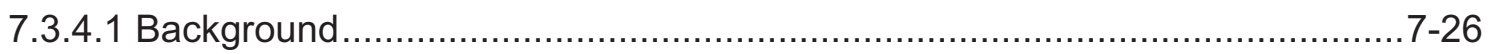

7.3.4.2 Basis for Defining Seismotectonic Zone ……......................................

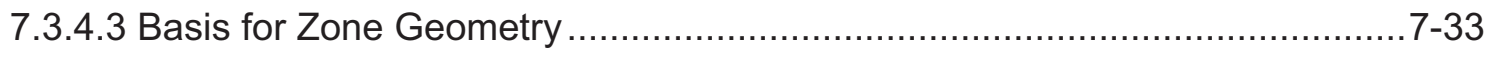

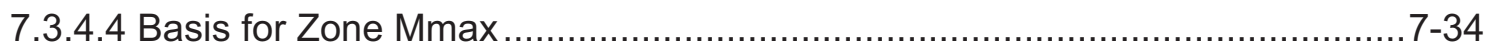

7.3.4.5 Future Earthquake Characteristics …………....................................

7.3.5 Ilinois Basin Extended Basement Zone (IBEB) ……................................... 7-37

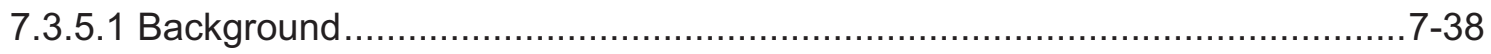

7.3.5.2 Basis for Defining Seismotectonic Zone ……......................................

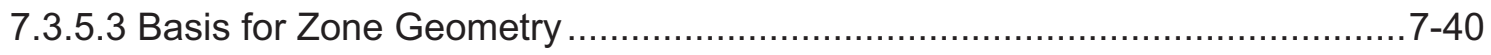

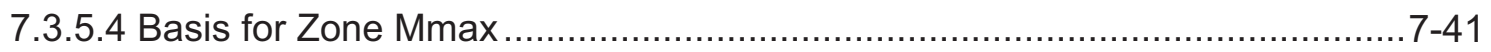

7.3.5.5 Future Earthquake Characteristics ......................................................

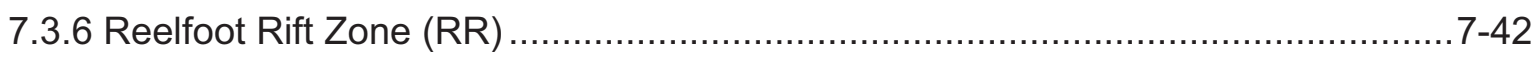




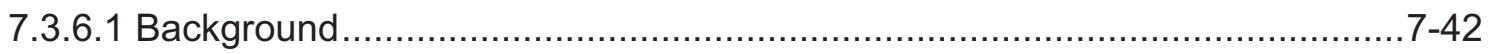

7.3.6.2 Basis for Defining Seismotectonic Zone …….......................................

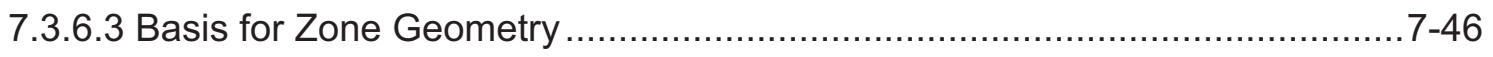

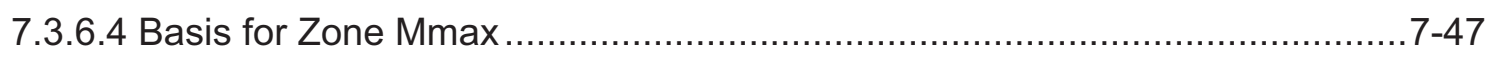

7.3.6.5 Future Earthquake Characteristics …………...................................

7.3.7 Extended Continental Crust-Atlantic Margin Zone (ECC-AM) ........................... 7-48

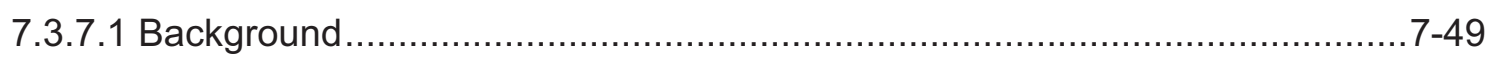

7.3.7.2 Basis for Defining Seismotectonic Zone ........................................................

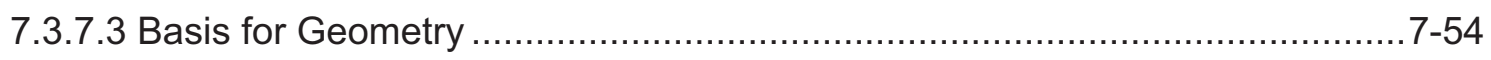

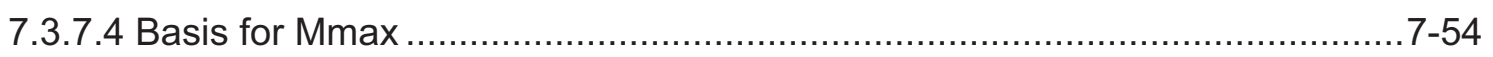

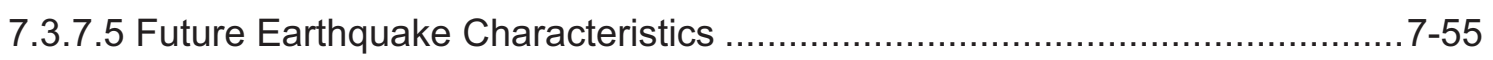

7.3.8 Atlantic Highly Extended Crust Zone (AHEX)...............................................

7.3.8.1 Basis for Defining Seismotectonic Zone ...................................................

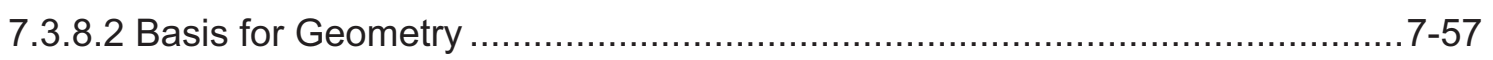

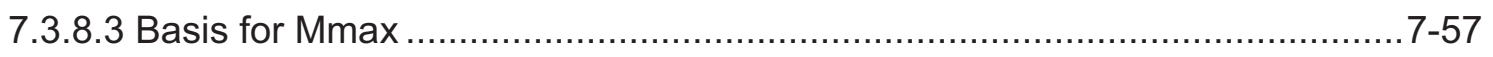

7.3.8.4 Future Earthquake Characteristics …………....................................

7.3.9 Extended Continental Crust-Gulf Coast Zone (ECC-GC) ................................ 7-58

7.3.9.1 Basis for Defining Seismotectonic Zone .................................................

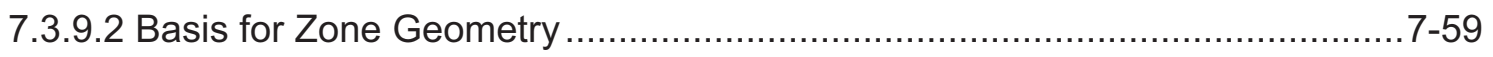

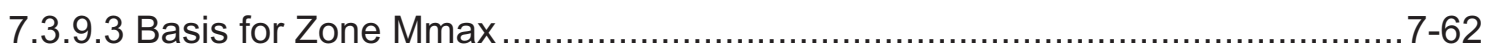

7.3.9.4 Future Earthquake Characteristics ………........................................

7.3.9.5 Possible Paleoliquefaction Features in Arkansas, Louisiana, and

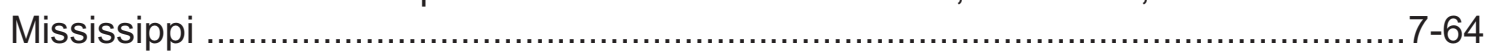

7.3.10 Gulf Coast Highly Extended Crust Zone (GHEX) ……................................. 7-65

7.3.10.1 Basis for Defining Seismotectonic Zone ……….................................

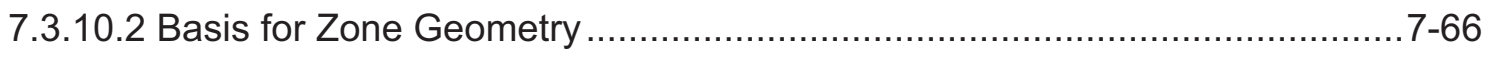

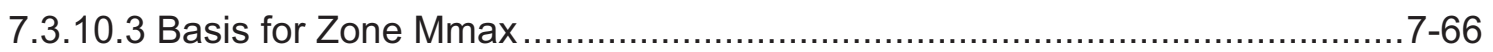

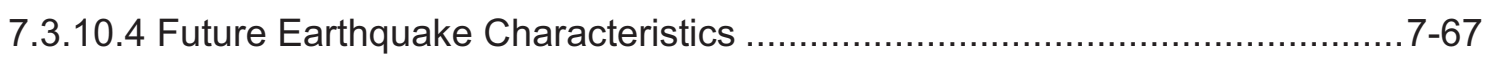

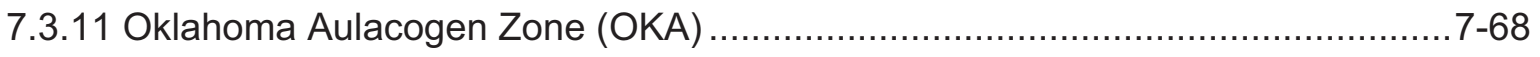

7.3.11.1 Basis for Defining Seismotectonic Zone …….........................................69

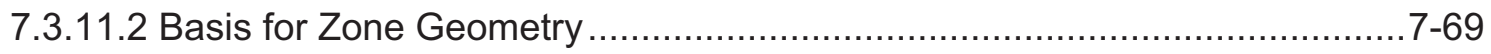

7.3.11.3 Basis for Zone Mmax...................................................................

7.3.11.4 Future Earthquake Characteristics ………..........................................

7.3.12 Midcontinent-Craton Zone (MidC) …….................................................... 7-70

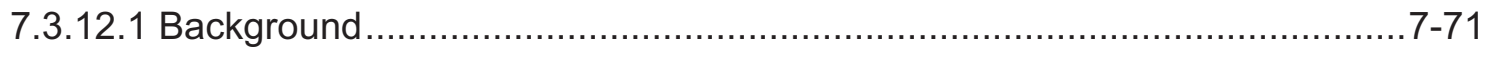


7.3.12.2 Basis for Defining Seismotectonic Zone ……...................................... 7-76

7.3.12.3 Basis for Zone Geometry ..............................................................

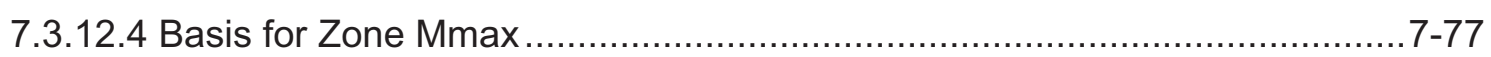

7.3.12.5 Future Earthquake Characteristics ...................................................

7.4 Maximum Magnitude Distributions for Seismotectonic Distributed Seismicity

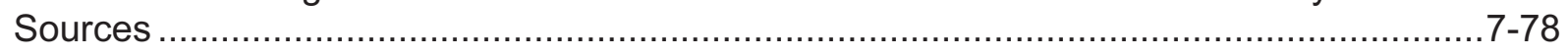

7.4.1 Maximum Observed Earthquake Magnitude ……………............................ 7-78

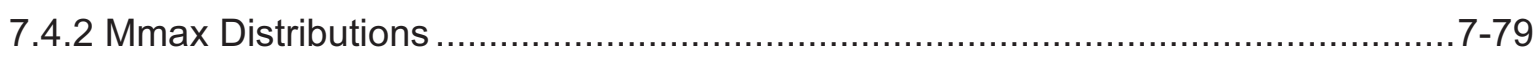

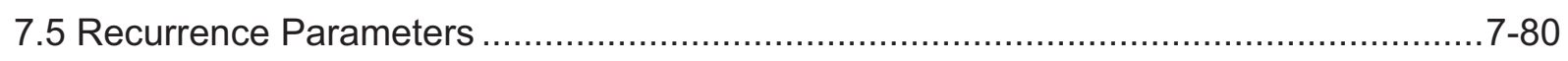

7.5.1 Rate and b-Value Maps for Single Zone and Two Zones.................................. 7-80

7.5.2 Comparison of Recurrence Parameters to Catalog.......................................... $7-80$

8 DEMONSTRATION HAZARD CALCULATIONS

8.1 Background on Demonstration Hazard Calculations ................................................. $8-1$

8.2 Demonstration Hazard Calculations ..................................................................... 8 -2

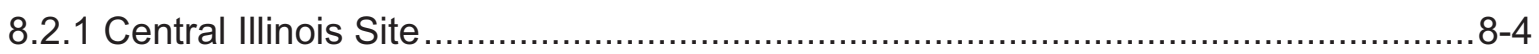

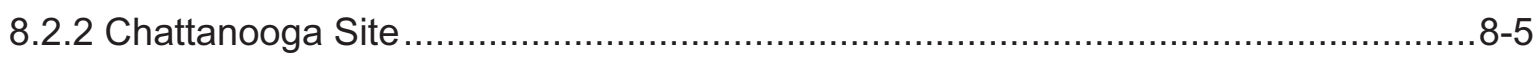

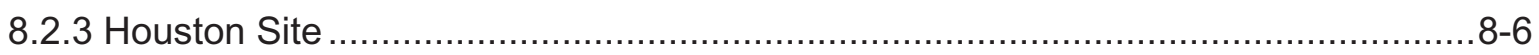

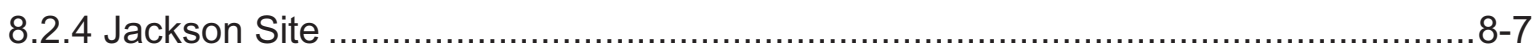

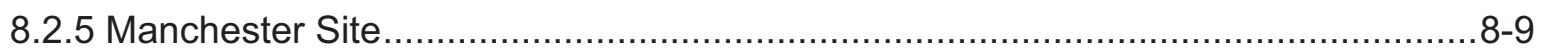

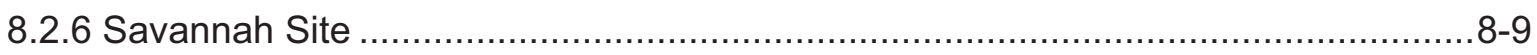

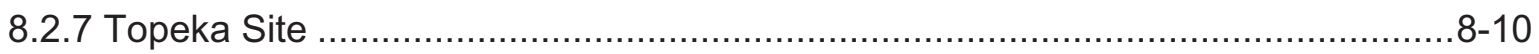

9 USE OF THE CEUS SSC MODEL IN PSHA

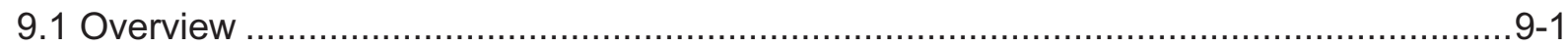

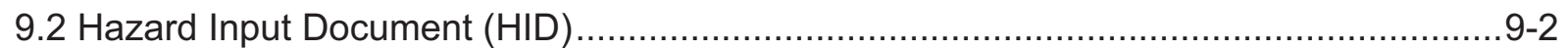

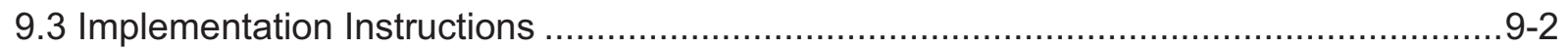

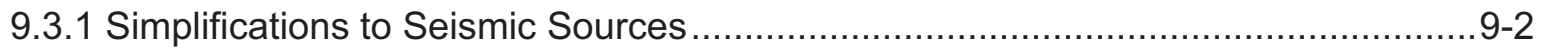

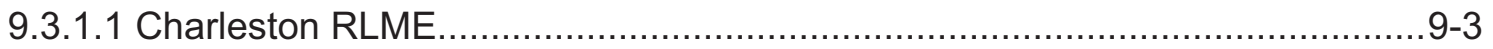

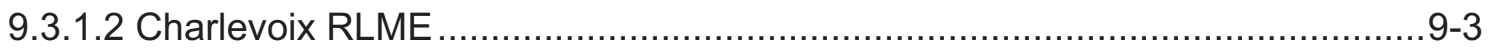

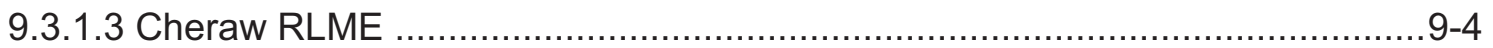

9.3.1.4 Commerce Fault Zone RLME .............................................................

9.3.1.5 Eastern Rift Margin North RLME .........................................................

9.3.1.6 Eastern Rift Margin South RLME.......................................................

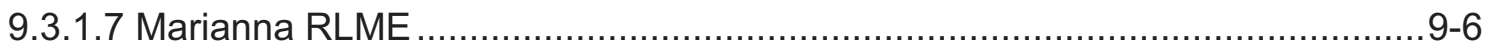

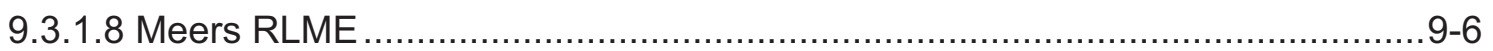


9.3.1.9 New Madrid Fault System RLME .................................................... 9-7

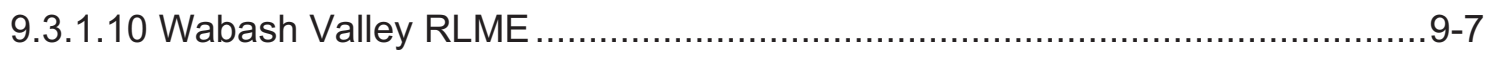

9.3.1.11 Background Sources.................................................................. $9-8$

9.3.2 Accessing the SSC Model and Components from the Website .......................... 9-8

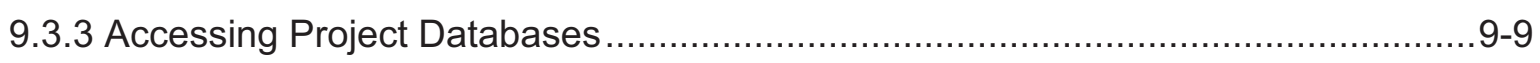

9.3.4 Use of SSC Model with Site-Specific Refinements ....................................... 9-10

9.4 Hazard Significance ................................................................................... $9-10$

9.4.1 Data Available to Evaluate the Precision of Seismic Hazard Estimates................9-10

9.4.2 Observed Imprecision in Seismic Hazard Estimates ....................................... 9-11

9.4.2.1 Area Seismic Sources................................................................ $9-11$

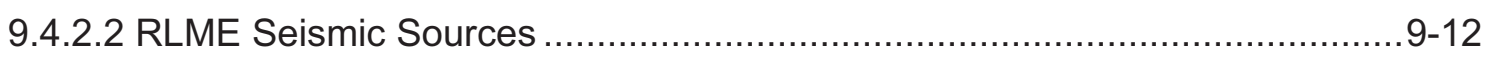

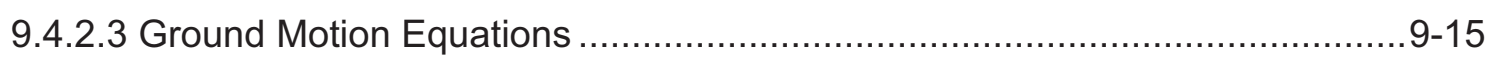

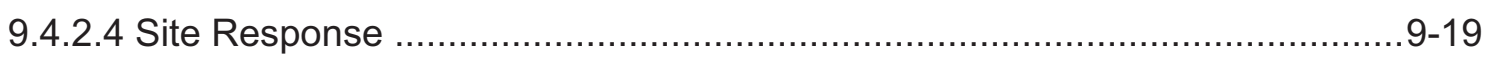

9.4.3 Conclusions on the Precision in Seismic Hazard Estimates ............................. 9-19

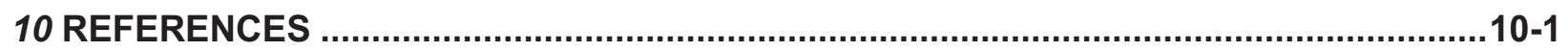

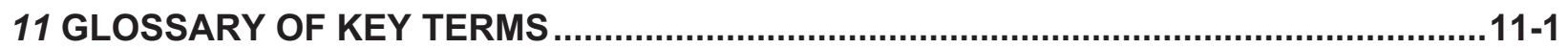

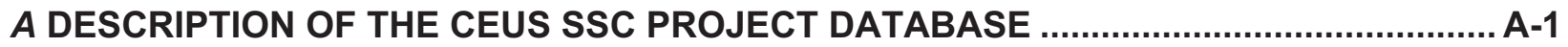

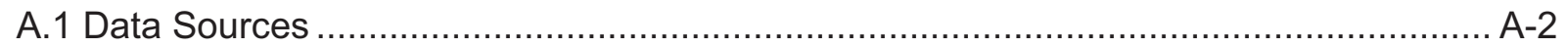

A.2 Project Database Design and Management ................................................. A-3

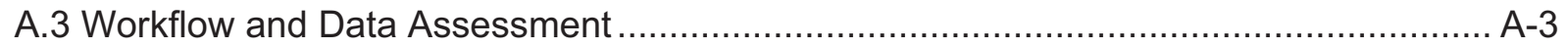

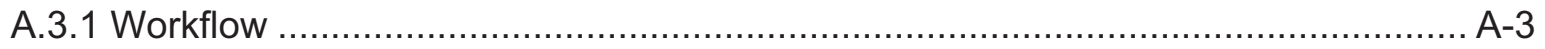

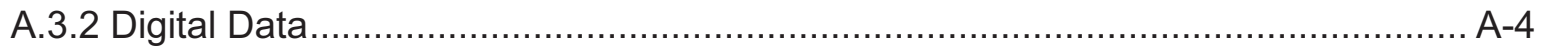

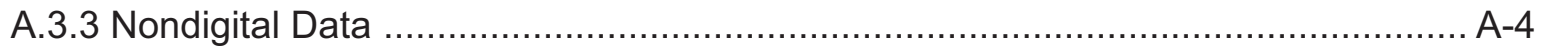

A.4 Use of Project Database in Model Development ….............................................. A-5

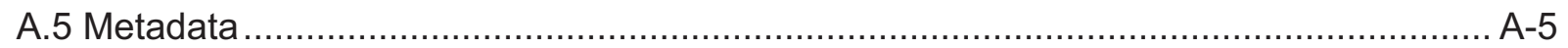

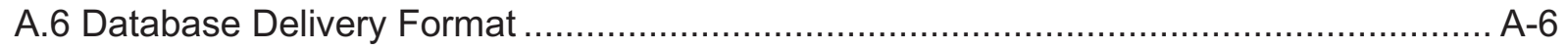

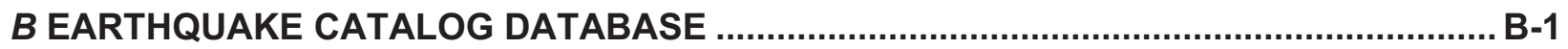

B.1 CEUS SSC Uniform Moment Magnitude Earthquake Catalog .............................. B-1

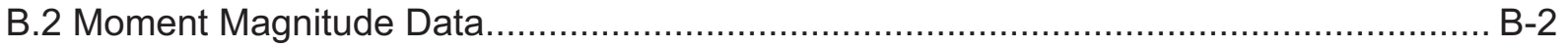

B.3 Approximate Moment Magnitude Data .................................................................. B-3

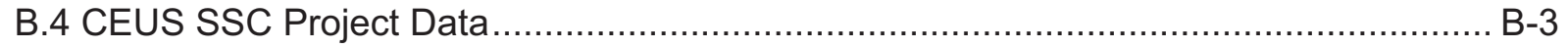


C DATA EVALUATION TABLES C-1

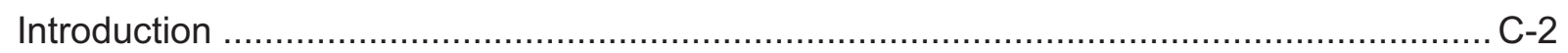

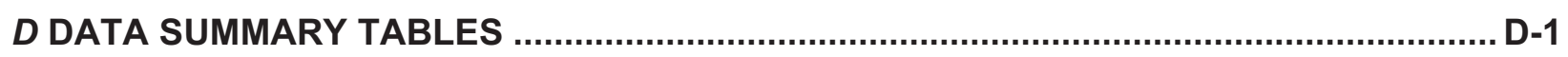

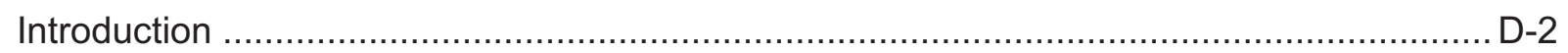

\section{E CEUS PALEOLIQUEFACTION DATABASE, UNCERTAINTIES ASSOCIATED WITH PALEOLIQUEFACTION DATA, AND GUIDANCE FOR SEISMIC SOURCE}

CHARACTERIZATION ................................................................................................... E-i

E.1 Development of the Paleoliquefaction Database ............................................. E-1

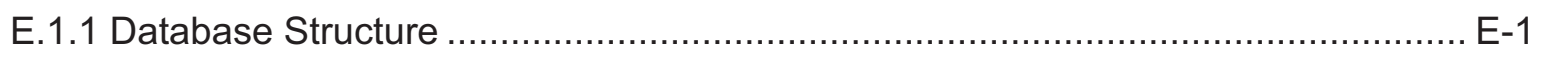

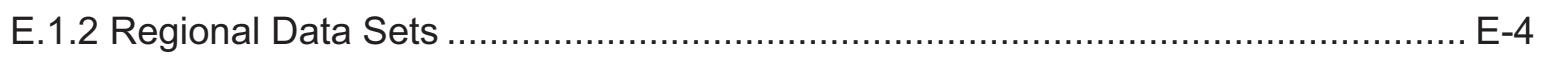

E.2 Uncertainties Associated with Paleoliquefaction Data ........................................ E-24

E.2.1 Collection of Paleoliquefaction Data .................................................. E-24

E.2.2 Uncertainties Related to Interpretation of Paleoliquefaction Data...................... E-35

E.2.3 Recommendations for Future Research ............................................. E-43

E.3 Guidance for the Use of Paleoliquefaction Data in Seismic Source

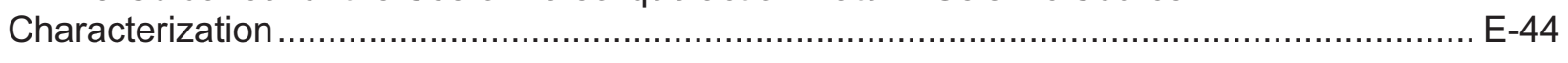

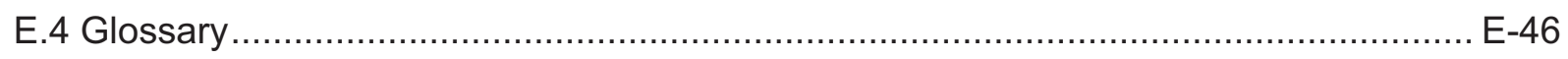

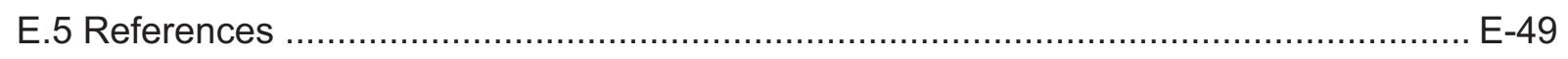

E.5.1 References Cited in Paleoliquefaction Database ...................................... E-49

E.5.2 References Cited in Appendix E ....................................................... E-54

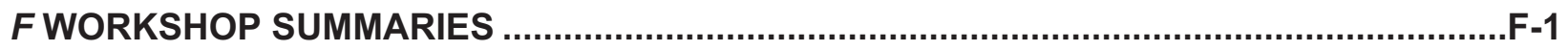

WORKSHOP 1: KEY ISSUES AND AVAILABLE DATA

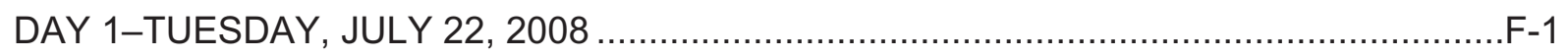

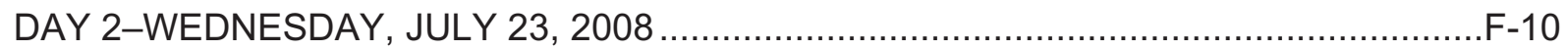

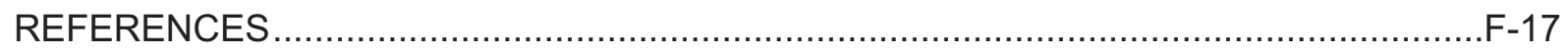

WORKSHOP 2: ALTERNATIVE INTERPRETATIONS

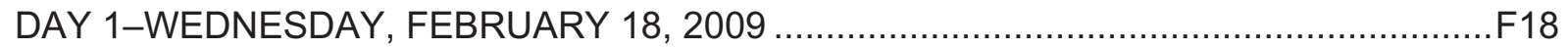

DAY 2-THURSDAY, FEBRUARY 19, 2009........................................................

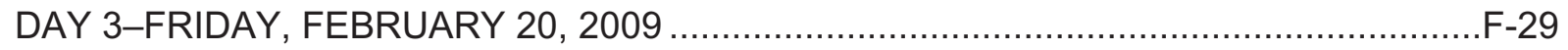

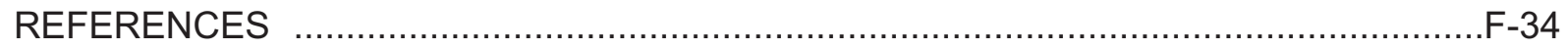

WORKSHOP 3: FEEDBACK

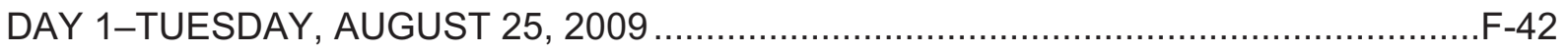

DAY 2-WEDNESDAY, AUGUST 26, 2009 ........................................................... 


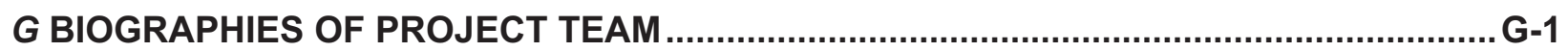

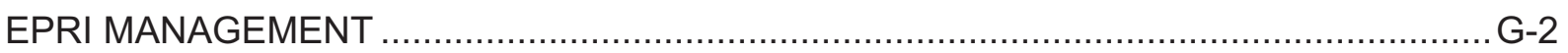

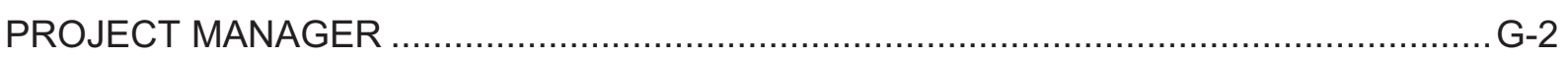

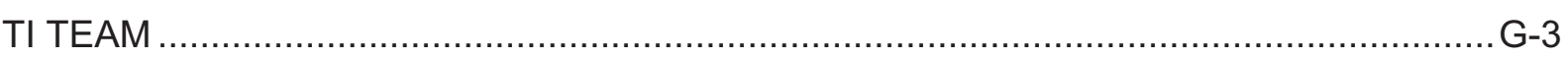

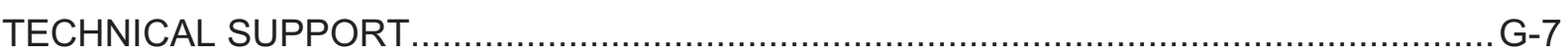

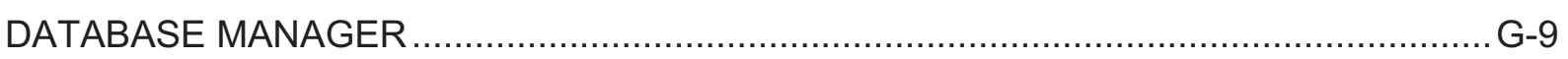

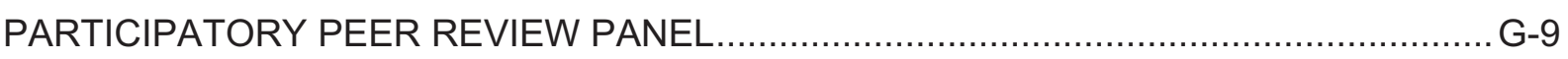

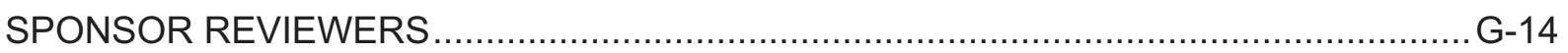

H CEUS SSC MODEL HAZARD INPUT DOCUMENT (HID) ......................................... $\mathrm{H}-1$

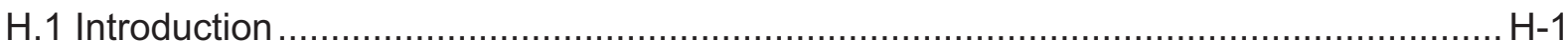

H.2 Seismic Source Model Structure and Master Logic Tree .................................... H-1

H.3 Mmax Zones Distributed Seismicity Sources ................................................ H-2

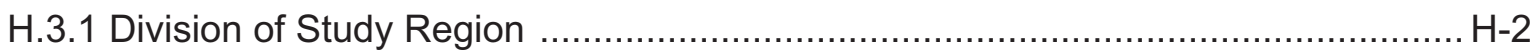

H.3.2 Location of Boundary of Mesozoic Extension …….................................... $\mathrm{H}-2$

H.3.3 Magnitude Interval Weights for Fitting Earthquake Occurrence Parameters ........ H-2

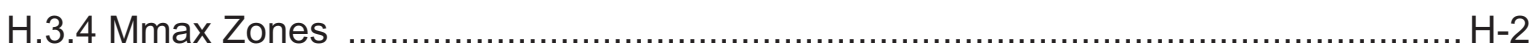

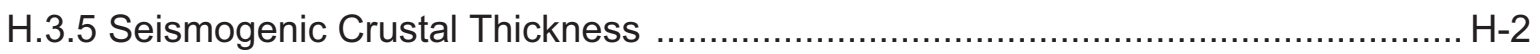

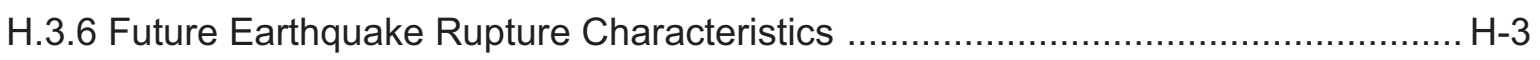

H.3.7 Assessment of Seismicity Rates .............................................................

H.3.8 Degree of Smoothing Applied in Defining Spatial Smoothing of Seismicity

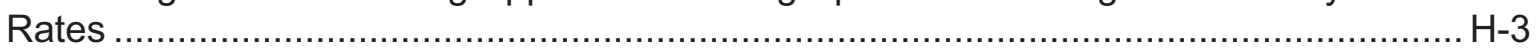

H.3.9 Uncertainty in Earthquake Recurrence Rates............................................. H-3

H.3.10 Uncertainty in Maximum Magnitude....................................................... H-4

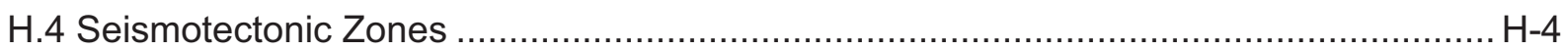

H.4.1 Alternative Zonation Models ................................................................. H-4

H.4.2 Magnitude Interval Weights for Fitting Earthquake Occurrence Parameters......... H-4

H.4.3 Seismotectonic Zones....................................................................... H-5

H.4.4 Seismogenic Crustal Thickness ............................................................

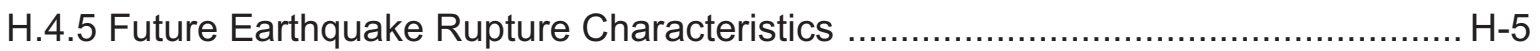

H.4.6 Assessment of Seismicity Rates ...........................................................

H.4.7 Degree of Smoothing Applied in Defining Spatial Smoothing of Seismicity

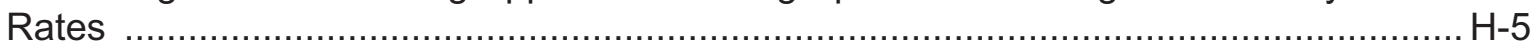

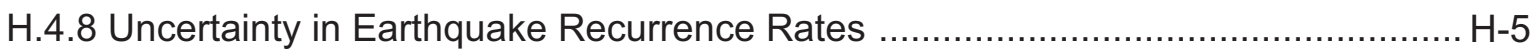

H.4.9 Uncertainty in Maximum Magnitude ...................................................... H-6

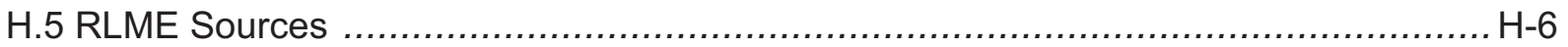

xxii 


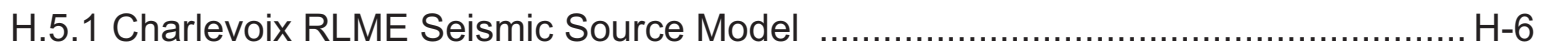

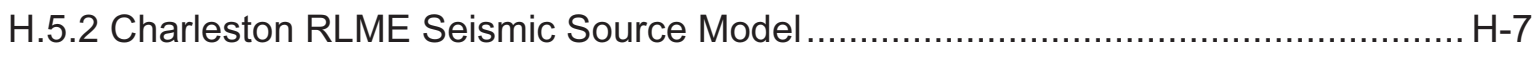

H.5.3 Cheraw RLME Seismic Source Model ........................................................

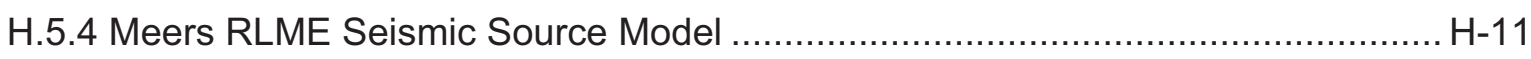

H.5.5 New Madrid Fault System RLME Seismic Source Model .............................. H-12

H.5.6 Eastern Rift Margin Fault RLME Seismic Source Model ................................ H-14

H.5.7 Marianna Zone RLME Seismic Source Model ....................................... H-15

H.5.8 Commerce Fault RLME Seismic Source Model........................................... H-16

H.5.9 Wabash Valley RLME Seismic Source Model ............................................ H-18

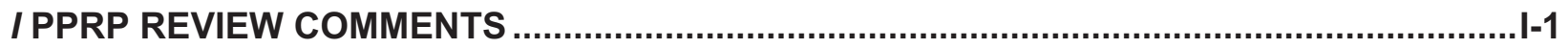

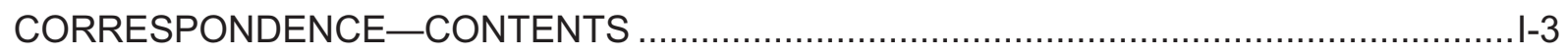

Participatory Peer Review Panel (PPRP) Letters ...................................................

Technical Integration (TI) Team and Project Manager (PM) Response to PPRP

Letters............................................................................................................

J MAGNITUDE-RECURRENCE MAPS FOR ALL REALIZATIONS AND ALL

SOURCE-ZONE CONFIGURATIONS ...................................................................................

K SCR DATABASE USED TO DEVELOP MMAX PRIOR DISTRIBUTIONS ........................ K-1

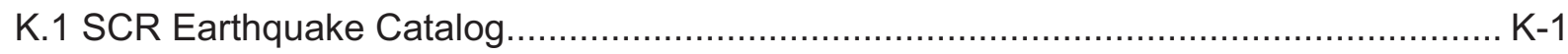

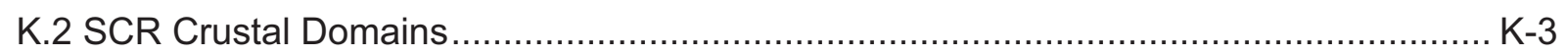

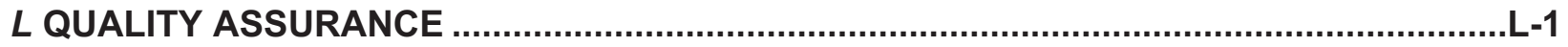

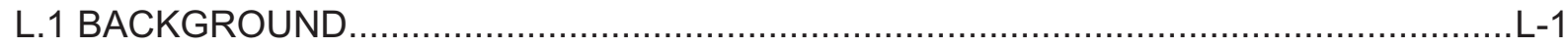

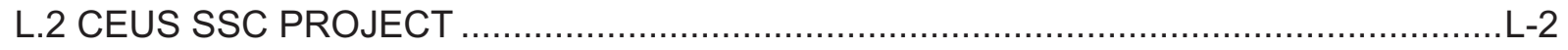

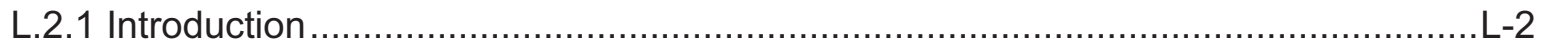

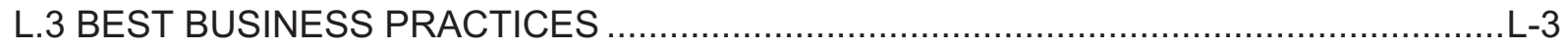

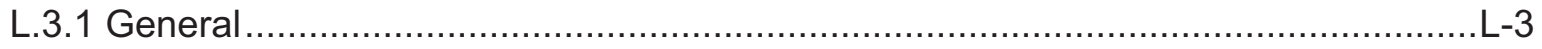

L.4 CEUS SSC EARTHQUAKE CATALOG DEVELOPMENT .......................................

L.4.1 External Review of Earthquake Catalog ....................................................

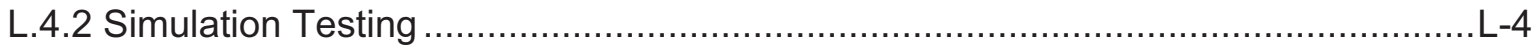

L.4.3 Checks for Consistency in Magnitude Conversion from Intensity ........................L-4

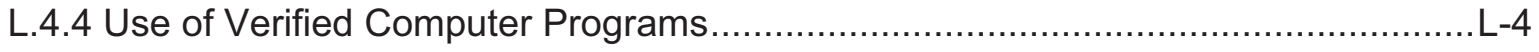

L.5 RECURRENCE ANALYSIS AND SPATIAL SMOOTHING .....................................-4

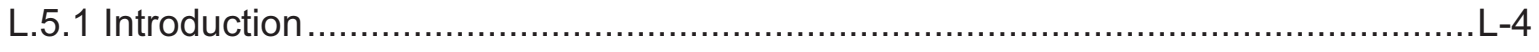

L.5.2 Recurrence Comparisons at the Source-Zone Level ......................................-5 
L.5.3 Recurrence Comparisons for Portions of a Source Zone ................................... -5

L.5.4 Examination of Recurrence Maps ......................................................... -5

L.5.5 Test with a Synthetic Catalog Homogeneous Seismicity ................................... -5

L.5.6 Test for the Adequacy of Eight Maps to Represent Epistemic Uncertainty ............. -6

L.6 HAZARD CALCULATION SOFTWARE .......................................................... 6

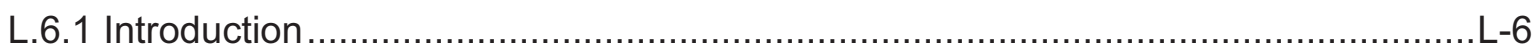

L.6.2 Test for the Treatment of Variable b ............................................................. 6

L.6.3 Test for the Treatment of Dipping Ruptures Within a Source Zone ......................... 6

L.6.4 Tests for Treatment of Epistemic Uncertainty from Sources that Make Small

Contribution to Hazard.......................................................................................... 


\section{LIST OF FIGURES}

Figure 1.3-1 Map showing the study area and test sites for the CEUS SSC Project.............1-15

Figure 2.3-1 CEUS SSC Project organization .......................................................... $2-33$

Figure 2.3-2 Lines of communication among the participants of the CEUS SSC Project........2-34

Figure 2.4-1 Essential activities associated with a SSHAC Level 3 or 4 project (Coppersmith et al., 2010).

Figure 3.2-1 Areal coverage of the primary earthquake catalog sources. Top: GSC catalog (Halchuk, 2009); bottom: USGS seismic hazard mapping catalog (Petersen et al., 2008). Red line denotes boundary of study region. Blue line denotes portion of each catalog used for development of project catalog.

Figure 3.2-2 Histogram of $\mathrm{M}_{\mathrm{L}}$ magnitudes from the GSC SHEEF catalog for the time period $1600-1899$ and the region east of longitude $-105^{\circ}$ and south of latitude $53^{\circ} \ldots \ldots .3-58$

Figure 3.2-3 Histogram of $M_{L}$ magnitudes from the GSC SHEEF catalog for the time period $1900-1929$ and the region east of longitude $-105^{\circ}$ and south of latitude $53^{\circ}$

Figure 3.2-4 Histogram of $M_{L}$ magnitudes from the GSC SHEEF catalog for the time period 1930-1979 and the region east of longitude $-105^{\circ}$ and south of latitude $53^{\circ}$

Figure 3.2-5 Histogram of $\mathrm{M}_{\mathrm{L}}$ magnitudes from the GSC SHEEF catalog for the time period 1980-2007 and the region east of longitude $-105^{\circ}$ and south of latitude $53^{\circ}$

Figure 3.2-6 Histogram of $\mathrm{M}_{\mathrm{L}}$ magnitudes from the revised catalog with $\mathrm{GSC}$ as the source for the time period 1928-1979.

Figure 3.2-7 Map of the CEUS SSC Project catalog showing earthquakes of uniform moment magnitude E[M] 2.9 and larger. Colored symbols denote earthquakes not contained in the USGS seismic hazard mapping catalog.

Figure 3.3-1 Illustration of equivalence of the $\mathrm{M}^{*}$ and $\mathrm{y}^{2}$ corrections to remove bias in earthquake recurrence relationships estimated from magnitudes with uncertainty

Figure 3.3-2 Approximate moment magnitudes from Atkinson (2004b) compared to values of $\mathrm{M}$ given in Table B-2 in Appendix $\mathrm{B}$ for earthquakes in common .....

Figure 3.3-3 Approximate moment magnitudes from Boatwright (1994) compared to values of $\mathrm{M}$ given in Table B-2 in Appendix B for earthquakes in common ....

Figure 3.3-4 Approximate moment magnitudes from Moulis (2002) compared to values of $\mathrm{M}$ given in Table $\mathrm{B}-2$ in Appendix $\mathrm{B}$ for earthquakes in common....

Figure 3.3-5 Difference between $M_{N}$ reported by the GSC and $M_{N}$ or $m_{L g(f)}$ reported by the Weston Observatory catalog as a function of time.

Figure 3.3-6 Spatial distribution of earthquakes with body-wave $\left(m_{b}, m_{b L g}, M_{N}\right)$ and $M$ magnitudes in the CEUS SSC Project catalog for the Midcontinent region. Color codes indicate the source of the body-wave magnitudes.

Figure 3.3-7 $m_{b}-M$ data for the earthquakes shown on Figure 3.3-6. Red curve shows the preferred offset fit $M=m_{b}-0.28$. 
Figure 3.3-8 Residuals from offset fit shown on Figure 3.3-7 plotted against earthquake year

Figure 3.3-9 Spatial distribution of earthquakes with body wave $\left(m_{b}, m_{b L g}, M_{N}\right)$ and $M$ magnitudes in the CEUS SSC Project catalog for the northeastern portion of the study region. Color codes indicate the source of the body-wave magnitudes.

Figure 3.3-10 $\mathrm{m}_{\mathrm{b}}-\mathrm{M}$ data for the earthquakes shown on Figure 3.3-9. Red curve shows the preferred offset fit $M=m_{b}-0.42$.

Figure 3.3-11 Residuals from offset fit shown on Figure 3.3-10 plotted against earthquake year

Figure 3.3-12 Residuals for GSC data from offset fit shown on Figure 3.3-10 plotted against earthquake year.

Figure 3.3-13 Residuals for WES data from offset fit shown on Figure 3.3-10 plotted against earthquake year.

Figure 3.3-14 Residuals for data from sources other than GSC or WES from offset fit shown on Figure 3.3-10 plotted against earthquake year

Figure 3.3-15 Difference between body-wave magnitudes reported by LDO and those by other sources as a function of year....

Figure 3.3-16 Spatial distribution of earthquakes with reported GSC body-wave magnitudes. Red and blue symbols indicate earthquakes with both $m_{b}$ and $M$ magnitudes for $m_{b} \geq 3.5$. Dashed line indicates the portion of the study region considered the "Northeast" for purposes of magnitude scaling.....

Figure 3.3-17 M- $m_{b}$ as a function of time for $m_{b}$ data from the GSC shown on Figure 3.316

Figure 3.3-18 Plot of magnitude differences $m_{b L g}-m(3 \mathrm{~Hz})$ for the OKO catalog.

Figure 3.3-19 Final $m_{b}-M$ data set. Vertical dashed lines indicate the magnitude range used to develop the scaling relationship. Diagonal line indicates a one-to-one correlation.

Figure 3.3-20 Spatial distribution of earthquakes in the CEUS SSC Project catalog with instrumental $\mathrm{M}_{\mathrm{L}}$ magnitudes

Figure 3.3-21 Spatial distribution of earthquakes in the CEUS SSC Project catalog with instrumental $\mathrm{M}_{\mathrm{L}}$ magnitudes and $\mathrm{M}$ magnitudes

Figure 3.3-22 $\mathrm{M}_{\mathrm{L}}-\mathrm{M}$ data from the CEUS SSC Project catalog and robust regression fit to the data

Figure 3.3-23 Relationship between $\mathrm{M}_{\mathrm{N}}$ and $\mathrm{M}_{\mathrm{L}}$ for the GSC data

Figure 3.3-24 Data from the northeastern portion of the study region with $M_{L}$ and $M_{C}$ or $M_{D}$ magnitude from catalog sources other than the GSC

Figure 3.3-25 Data from the northeastern portion of the study region with $M_{L}$ and $M$ magnitudes from sources other than the GSC....

Figure 3.3-26 Spatial distribution of earthquakes in the CEUS SSC Project catalog with $M_{S} \geq 3$ magnitudes

Figure 3.3-27 $\mathrm{M}_{\mathrm{S}}-\mathrm{M}$ data from the CEUS SSC Project catalog and quadratic polynomial fit to the data

Figure 3.3-28 Spatial distribution of earthquakes in the CEUS SSC Project catalog with $M_{C} \geq 2.5$ magnitudes

xxvi 
Figure 3.3-29 Spatial distribution of earthquakes in the CEUS SSC Project catalog with $\mathrm{M}_{\mathrm{C}} \geq 2.5$ and $\mathrm{M}$ magnitudes

Figure 3.3-30 Spatial distribution of earthquakes in the CEUS SSC Project catalog with $M_{D} \geq 3$ magnitudes

Figure 3.3-31 Spatial distribution of earthquakes in the CEUS SSC Project catalog with both $M_{D}$ and $M$ magnitudes

Figure 3.3-32 $\mathrm{M}_{\mathrm{C}}-\mathrm{M}$ data from the CEUS SSC Project catalog and linear regression fit to the data

Figure 3.3-33 Spatial distribution of earthquakes with reported $M_{C}$ and $M_{D}$ magnitudes.........3-96

Figure 3.3-34 Comparison of $M_{C}$ and $M_{D}$ magnitudes for the LDO and WES catalogs

Figure 3.3-35 Comparison of $M_{C}$ with $M_{D}$ for at least one of the two magnitude types reported in the OKO catalog

Figure 3.3-36 Comparison of $M_{C}$ with $M_{D}$ for at least one of the two magnitude types reported in the CERI catalog

Figure 3.3-37 Comparison of $M_{C}$ with $M_{D}$ for at least one of the two magnitude types reported in the SCSN catalog

Figure 3.3-38 Comparison of $M_{C}$ with $M_{D}$ for at least one of the two magnitude types reported in other catalogs for earthquakes in the Midcontinent portion of the study region ....

Figure 3.3-39 Relationship between $M$ and $M_{C}, M_{D}$, or $M_{L}$ for the Midcontinent portion of the study region.

Figure 3.3-40 Comparison of $M_{C}$ and $M_{D}$ magnitudes with $M_{L}$ magnitudes for the region between longitudes $105^{\circ} \mathrm{W}$ and $100^{\circ} \mathrm{W}$.

Figure 3.3-41 Comparison of $m_{b}$ magnitudes with $M_{L}$ magnitudes for the region between longitudes $105^{\circ} \mathrm{W}$ and $100^{\circ} \mathrm{W}$.....

Figure 3.3-42 Comparison of $m_{b}$ magnitudes with $M_{C}$ and $M_{D}$ magnitudes for the region between longitudes $105^{\circ} \mathrm{W}$ and $100^{\circ} \mathrm{W}$.

Figure 3.3-43 Spatial distribution of earthquake with $\ln (\mathrm{FA})$ in the CEUS SSC Project catalog

Figure 3.3-44 Catalog In(FA)-M data and fitted model.

Figure 3.3-45 Spatial distribution of earthquakes in the CEUS SSC Project catalog with reported values of $\mathrm{I}_{0}$

Figure 3.3-46 $\mathrm{I}_{0}$ and $\mathrm{M}$ data for earthquakes in the CEUS SSC Project catalog. Curves show locally weighted least-squares fit (Loess) to the data and the relationship published by Johnston (1996b).

Figure 3.3-47 $\mathrm{I}_{0}$ and $\mathrm{m}_{\mathrm{b}}$ data from the NCEER91 catalog. Plotted are the relationships between $I_{0}$ and $m_{b}$ developed by EPRI (1988) (EPRI-SOG) and Sibol et al. (1987)......3-110

Figure 3.3-48 Categorical model fits of $\mathrm{I}_{0}$ as a function and $\mathrm{M}$ for earthquakes in the CEUS SSC Project catalog

Figure 3.3-49 Results from proportional odds logistic model showing the probability of individual intensity classes as a function of $\mathrm{M}$.

Figure 3.3-50 Comparison of $\mathrm{I}_{0}$ and $\mathrm{m}_{\mathrm{b}}$ data from the CEUS SSC Project catalog for those earthquakes with reported values of $M$ (M set) and the full catalog (full set). Locally weighted least-squares fits to the two data sets are shown along with the 
relationship use to develop the EPRI (1988) catalog and the Sibol et al. (1987) relationship used in the NCEER91 catalog.

Figure 3.3-51 Linear fits to the data from Figure 3.3-50 for $\mathrm{I}_{0} \geq \mathrm{V}$

Figure 3.3-52 Comparison of $\mathrm{I}_{0}$ and $\mathrm{m}_{\mathrm{b}}$ data from the project, with $\mathrm{m}_{\mathrm{b}}$ adjusted for the difference in $m_{b}$ to $M$ scaling

Figure 3.3-53 Linear fits to the data from Figure 3.3-52 for $\mathrm{I}_{0} \geq \mathrm{V}$

Figure 3.3-54 Composite $\mathrm{I}_{0}-\mathrm{M}$ data set used for assessment of $\mathrm{I}_{0}$ scaling relationship

Figure 3.3-55 Linear and inverse sigmoid models fit to the project data for $\mathrm{I}_{0}>\mathrm{IV}$

Figure 3.4-1 Illustration of process used to identify clusters of earthquakes (from EPRI, 1988, Vol. 1): (a) local and extended time and distance windows, (b) buffer window, and (c) contracted window

Figure 3.4-2 Identification of secondary (dependent) earthquakes inside the cluster region through Poisson thinning (from EPRI, 1988, Vol. 1)....

Figure 3.4-3 Comparison of dependent event time and distance windows with results for individual clusters in the project catalog......

Figure 3.5-1 Earthquake catalog and catalog completeness regions used in EPRI-SOG (EPRI, 1988)

Figure 3.5-2 CEUS SSC Project earthquake catalog and modified catalog completeness regions

Figure 3.5-3 Plot of year versus location for the CEUS SSC Project earthquake catalog. Red lines indicate the boundaries of the catalog completeness time periods.

Figure 3.5-4 (1 of 7) "Stepp" plots of earthquake recurrence rate as a function of time for the individual catalog completeness regions shown on Figure 3.5-2.

Figure 3.5-4 (2 of 7) "Stepp" plots of earthquake recurrence rate as a function of time for the individual catalog completeness regions shown on Figure 3.5-2 ....

Figure 3.5-4 (3 of 7) "Stepp" plots of earthquake recurrence rate as a function of time for the individual catalog completeness regions shown on Figure 3.5-2....

Figure 3.5-4 (4 of 7) "Stepp" plots of earthquake recurrence rate as a function of time for the individual catalog completeness regions shown on Figure 3.5-2.

Figure 3.5-4 (5 of 7) "Stepp" plots of earthquake recurrence rate as a function of time for the individual catalog completeness regions shown on Figure 3.5-2

Figure 3.5-4 (6 of 7) "Stepp" plots of earthquake recurrence rate as a function of time for the individual catalog completeness regions shown on Figure 3.5-2....

Figure 3.5-4 (7 of 7) "Stepp" plots of earthquake recurrence rate as a function of time for the individual catalog completeness regions shown on Figure 3.5-2.

Figure 4.1.1-1 Example logic tree from the PEGASOS project (NAGRA, 2004) showing the assessment of alternative conceptual models on the logic tree. Each node of the logic tree represents an assessment that is uncertain. Alternative branches represent the alternative models or parameter values, and the weights associated with each branch reflect the TI Team's relative degree of belief that each branch is the correct model or parameter value.

Figure 4.1.1-2 Example logic tree from the PVHA-U (SNL, 2008) project showing the treatment of alternative conceptual models in the logic tree

Xxviii 
Figure 4.2.1-1 Master logic tree showing the Mmax zones and seismotectonic zones alternative conceptual models for assessing the spatial and temporal characteristics of future earthquake sources in the CEUS.

Figure 4.2.2-1 Example of a logic tree for RLME sources. Shown is the tree for the Marianna RLME source.

Figure 4.2.2-2 Map showing RLME sources, some with alternative source geometries (discussed in Section 6.1).

Figure 4.2.3-1 Logic tree for the Mmax zones branch of the master logic tree.....

Figure 4.2.3-2 Subdivision used in the Mmax zones branch of the master logic tree. Either the region is considered one zone for purposes of Mmax or the region is divided into two zones as shown: a Mesozoic-and-younger extension (MESE) zone and a non-Mesozoic-and-younger zone (NMESE). In this figure the "narrow" MESE zone is shown

Figure 4.2.3-3 Subdivision used in the Mmax zones branch of the master logic tree.

Either the region is considered one zone for purposes of Mmax or the region is divided into two zones as shown: a Mesozoic-and-younger extension (MESE) zone and a non-Mesozoic-and-younger zone (NMESE). In this figure the "wide" MESE zone is shown

Figure 4.2.4-1(a) Logic tree for the seismotectonic zones branch of the master logic tree .....4-48

Figure 4.2.4-1(b) Logic tree for the seismotectonic zones branch of the master logic tree .....4-49

Figure 4.2.4-2 Seismotectonic zones shown in the case where the Rough Creek Graben is not part of the Reelfoot Rift (RR), and the Paleozoic Extended Zone is narrow (PEZ-N)

Figure 4.2.4-3 Seismotectonic zones shown in the case where the Rough Creek Graben is part of the Reelfoot Rift (RR-RCG), and the Paleozoic Extended Zone is narrow (PEZ-N)

Figure 4.2.4-4 Seismotectonic zones shown in the case where the Rough Creek Graben is not part of the Reelfoot Rift (RR), and the Paleozoic Extended Crust is wide (PEZ-W)

Figure 4.2.4-5 Seismotectonic zones shown in the case where the Rough Creek Graben is part of the Reelfoot Rift (RR-RCG), and the Paleozoic Extended Crust is wide (PEZ-W)

Figure 5.2.1-1 Diagrammatic illustration of the Bayesian Mmax approach showing (a) the prior distribution, (b) the likelihood function, and (c) the posterior distribution. The posterior distribution is represented by a discrete distribution (d) for implementation in hazard analysis.

Figure 5.2.1-2 Diagrammatic illustration of the Bayesian Mmax approach showing (a) the prior distribution, (b) the likelihood function, and (c) the posterior distribution. The posterior distribution is represented by a discrete distribution (d) for implementation in hazard analysis.

Figure 5.2.1-3 Median values of $m_{\max -o b s}$ as a function of maximum magnitude, $m^{u}$, and sample size $N$, the number of earthquakes $\geq M 4.5$.

Figure 5.2.1-4 Histograms of $m_{\max -o b s}$ for extended and non-extended superdomains 
Figure 5.2.1-5 Histograms of $m_{\max -o b s}$ for Mesozoic-and-younger extended (MESE) superdomains and for older extended and non-extended (NMESE) superdomains ........5-76

Figure 5.2.1-6 Histograms of $m_{\max -o b s}$ for Mesozoic-and-younger extended (MESE) superdomains and for older extended and non-extended (NMESE) superdomains using age of most recent extension for the age classification

Figure 5.2.1-7 Histograms of $m_{\max -o b s}$ for Mesozoic-and-younger extended (MESE) superdomains and for older extended and non-extended (NMESE) superdomains using final sets indicated by asterisks in Tables 5.2.1-1 and 5.2.1-2 ....

Figure 5.2.1-8 Histograms of $m_{\max -o b s}$ for combined (COMB) superdomains using final sets indicated by asterisks in Table 5.2.1-3

Figure 5.2.1-9 Bias adjustments from $m_{\max -o b s}$ to $m^{u}$ for the three sets of superdomain analysis results presented in Table 5.2.1-4.

Figure 5.2.1-10 Results of simulations of estimates of Mmax using the Bayesian approach for earthquake catalogs ranging in size from 1 to 1,000 earthquakes. True Mmax is set at the mean of the prior distribution.

Figure 5.2.1-11 Comparison of the Kijko (2004) estimates of $m^{u}$ for given values of $m_{\max -o b s}$ and $N$, the number of earthquakes of magnitude $\geq 4.5$. Also shown is the median value of $m_{\max -o b s}$ for given $m^{u}$ obtained using Equation 5.2.1-2.....

Figure 5.2.1-12 Behavior of the cumulative probability function for $m^{u}$ (Equation 5.2.1-9) for the K-S-B estimator and a value of $m_{\max -o b s}$ equal to 6 .

Figure 5.2.1-13 Example Mmax distribution assessed for the Mesozoic-and-younger extended Mmax zone for the case where the zone is "narrow" (MESE-N). Distributions are shown for the Kijko approach and for the Bayesian approach using either the Mesozoic-and-younger extended prior distribution or the composite prior distribution. The final composite Mmax distribution, which incorporates the relative weights, is shown by the red probability distribution.

Figure 5.2.1-14 Example Mmax distribution assessed for the Northern Appalachian seismotectonic zone (NAP). Distributions are shown for the Kijko approach and for the Bayesian approach using either the Mesozoic-and-younger extended prior distribution or the composite prior distribution. Note that the Kijko results are shown in this example for illustration, even though they have zero weight. The final composite Mmax distribution, which incorporates the relative weights, is shown by the red probability distribution.

Figure 5.3.2-1 Likelihood function for rate per unit area in a Poisson process, for multiple values of the earthquake count $N$ : (a) arithmetic scale, and (b) logarithmic scale used to illustrate decreasing COV as $\mathrm{N}$ increases

Figure 5.3.2-2 Likelihood function for $b$-value of an exponential magnitude distribution, for multiple values of the earthquake count $N$. The value of $b$ is normalized by the maximum-likelihood estimate, which is derived from Equation 5.3.2-5.

Figure 5.3.2-3 Histogram of magnitudes in the earthquake catalog used in this section. The minimum magnitude shown (M 2.9) is the lowest magnitude used in these recurrence calculations. 
Figure 5.3.2-4 Objectively determined values of the penalty function for $\ln ($ rate) for Case A magnitude weights. Source zones are sorted from smallest to largest. See list of abbreviations for full source-zone names.

Figure 5.3.2-5 Objectively determined values of the penalty function for beta for Case A magnitude weights

Figure 5.3.2-6 Objectively determined values of the penalty function for $\ln ($ rate) for Case $B$ magnitude weights

Figure 5.3.2-7 Objectively determined values of the penalty function for beta for Case B magnitude weights. Source zones are sorted from smallest to largest.

Figure 5.3.2-8 Objectively determined values of the penalty function for $\ln ($ rate) for Case E magnitude weights

Figure 5.3.2-9 Objectively determined values of the penalty function for beta for Case $E$ magnitude weights. Source zones are sorted from smallest to largest.

Figure 5.3.2-10 Mean map of rate and $b$-value for ECC-AM calculated using Case A magnitude weights

Figure 5.3.2-11 Mean map of rate and $b$-value for ECC-GC calculated using Case A magnitude weights

Figure 5.3.2-12 Mean map of rate and $b$-value for ECC-AM calculated using Case B magnitude weights

Figure 5.3.2-13 Mean map of rate and $b$-value for ECC-GC calculated using Case B magnitude weights

Figure 5.3.2-14 Mean map of rate and $b$-value for ECC-AM calculated using Case E magnitude weights

Figure 5.3.2-15 Mean map of rate and $b$-value for ECC-GC calculated using Case E magnitude weights

Figure 5.3.2-16 Sensitivity of seismic hazard at Manchester site to the strength of the prior on $\mathrm{b}$

Figure 5.3.2-17 Sensitivity of seismic hazard at Topeka site to the strength of the prior on $\mathrm{b}$

Figure 5.3.2-18 Sensitivity of seismic hazard at Manchester site to the choice of magnitude weights

Figure 5.3.2-19 Sensitivity of seismic hazard at Topeka site to the choice of magnitude weights

Figure 5.3.2-20 Sensitivity of seismic hazard from source NAP at Manchester site to the eight alternative recurrence maps for Case B magnitude weights.

Figure 5.3.2-21 Sensitivity of seismic hazard from source MID-C-A at Topeka site to the eight alternative recurrence maps for Case B magnitude weights.

Figure 5.3.2-22 Mean recurrence-parameter map for the study region under the highest weighted source-zone configuration in the master logic tree. See Sections 6.3 and 7.5 for all mean maps.

Figure 5.3.2-23 Map of the uncertainty in the estimated recurrence parameters, expressed as the coefficient of variation of the rate (left) and the standard deviation of the $b$-value (right) for the study region, under the highest weighted source-zone configuration in the master logic tree. See Appendix $\mathrm{J}$ for all maps of uncertainty..... 
Figure 5.3.2-24 First of eight equally likely realizations of the recurrence-parameter map for the study region under the highest weighted source-zone configuration in the master logic tree. See Appendix $\mathrm{J}$ for maps of all realizations for all source-zone configurations.

Figure 5.3.2-25 Eighth of eight equally likely realizations of the recurrence-parameter map for the study region under the highest weighted source-zone configuration in the master logic tree. See Appendix $\mathrm{J}$ for maps of all realizations for all source-zone configurations.

Figure 5.3.2-26 Map of geographic areas considered in the exploration of model results.....5-111

Figure 5.3.2-27 Comparison of model-predicted earthquake counts for the USGS Eastern Tennessee area using Case A magnitude weights. The error bars represent the $16 \%-84 \%$ uncertainty associated with the data, computed using the Weichert (1980) procedure.

Figure 5.3.2-28 Comparison of model-predicted earthquake counts for the USGS Eastern Tennessee area using Case B magnitude weights.

Figure 5.3.2-29 Comparison of model-predicted earthquake counts for the USGS Eastern Tennessee area using Case E magnitude weights.

Figure 5.3.2-30 Comparison of model-predicted earthquake counts for the central New England area using Case A magnitude weights

Figure 5.3.2-31 Comparison of model-predicted earthquake counts for the central New England area using Case B magnitude weights

Figure 5.3.2-32 Comparison of model-predicted earthquake counts for the central New England area using Case E magnitude weights

Figure 5.3.2-33 Comparison of model-predicted earthquake counts for the Nemaha Ridge area using Case A magnitude weights

Figure 5.3.2-34 Comparison of model-predicted earthquake counts for the Nemaha Ridge area using Case B magnitude weights

Figure 5.3.2-35 Comparison of model-predicted earthquake counts for the Nemaha Ridge area using Case E magnitude weights

Figure 5.3.2-36 Comparison of model-predicted earthquake counts for the Miami, FL, area using Case A magnitude weights...

Figure 5.3.2-37 Comparison of model-predicted earthquake counts for the Miami, FL, area using Case $B$ magnitude weights

Figure 5.3.2-38 Comparison of model-predicted earthquake counts for the Miami, FL, area using Case $\mathrm{E}$ magnitude weights.

Figure 5.3.2-39 Comparison of model-predicted earthquake counts for the St. Paul, MN, area using Case A magnitude weights

Figure 5.3.2-40 Comparison of model-predicted earthquake counts for the St. Paul, MN, area using Case $B$ magnitude weights

Figure 5.3.2-41 Comparison of model-predicted earthquake counts for the St. Paul, MN, area using Case $\mathrm{E}$ magnitude weights

Figure 5.3.2-42 Recurrence parameters for the ECC-AM, MID-C-A, and NAP seismotectonic source zones and Case A magnitude weights computed using an objective adaptive kernel approach.

xxxii 
Figure 5.3.3-1 Likelihood distribution for rate parameter $\lambda$ derived using Equation 5.3.3-1 for $\mathrm{N}=2$ and $\mathrm{T}=2,000$ years. Top: normalized probability density function for $\lambda$. Bottom: resulting cumulative distribution function. Dashed lines show the cumulative probability levels for the Miller and Rice (1983) discrete approximation of a continuous probability distribution.

Figure 5.3.3-2 Uncertainty distributions for the age of Charleston RLMEs

Figure 5.4.4-1 Spatial distribution of earthquakes in the CEUS SSC Project catalog. Solid lines indicate the boundaries of the seismotectonic source zones (narrow interpretation).

Figure 5.4.4-2 Spatial distribution of earthquakes in the CEUS SSC Project catalog with good quality depth determinations used for assessing crustal thickness. Solid lines indicate the boundaries of the seismotectonic source zones (narrow interpretation).....5-131

Figure 5.4.4-3 Distribution of better-quality focal depths in Mmax source zones.

Figure 5.4.4-4 (1 of 3) Distribution of better-quality focal depths in seismotectonic source zones

Figure 5.4.4-4 (2 of 3) Distribution of better-quality focal depths in seismotectonic source zones......

Figure 5.4.4-4 (3 of 3) Distribution of better-quality focal depths in seismotectonic source zones.

Figure 6.1-1 Map showing the RLME sources characterized in the CEUS SSC model. Detailed alternatives to the source geometries are shown on figures associated with each RLME discussion.

Figure 6.1-2a Map showing the RLME sources and seismicity from the CEUS SSC earthquake catalog. Some of the RLMEs occur in regions of elevated seismicity, but others do not.

Figure 6.1-2b Close-up of the Wabash Valley and New Madrid/Reelfoot Rift RLME sources and seismicity from the CEUS SSC earthquake catalog. Some of the RLMEs occur in regions of elevated seismicity, but others do not.

Figure 6.1.1-1 Logic tree for the Charlevoix RLME source

Figure 6.1.1-2 Seismicity and tectonic features of the Charlevoix RLME

Figure 6.1.1-3 Magnetic and gravity anomaly maps of the Charlevoix RLME

Figure 6.1.2-1a Logic tree for the Charleston RLME source

Figure 6.1.2-1b Logic tree for the Charleston RLME source 6-118

Figure 6.1.2-2 Charleston RLME source zones with (a) total magnetic anomaly and (b) residual isostatic gravity data

Figure 6.1.2-3 Postulated faults and tectonic features in the Charleston region

Figure 6.1.2-4 Postulated faults and tectonic features in the local Charleston area 6-121

Figure 6.1.2-5a Postulated faults and tectonic features in the Charleston region with Charleston RLME source zones

Figure 6.1.2-5b Postulated faults and tectonic features in the local Charleston area with Charleston RLME source zones

Figure 6.1.2-6 Schematic diagram showing contemporary, maximum, and minimum constraining age sample locations 
Figure 6.1.2-7 Charleston space-time diagram of earthquakes interpreted from paleoliquefaction, contemporary-ages-only scenario

Figure 6.1.2-8 Charleston space-time diagram of earthquakes interpreted from paleoliquefaction, all-ages scenario

Figure 6.1.2-9 Distribution of liquefaction from earthquake A, contemporary-ages-only scenario

Figure 6.1.2-10 Distribution of liquefaction from earthquake B, contemporary-ages-only scenario

Figure 6.1.2-11 Distribution of liquefaction from earthquake $C$, contemporary-ages-only scenario

Figure 6.1.2-12 Distribution of liquefaction from earthquake D, contemporary-ages-only scenario

Figure 6.1.2-13 Distribution of liquefaction from earthquake $E$, contemporary-ages-only scenario

Figure 6.1.2-14 Distribution of liquefaction from earthquake A, all-ages scenario

Figure 6.1.2-15 Distribution of liquefaction from earthquake $B$, all-ages scenario 6-133

Figure 6.1.2-16 Distribution of liquefaction from earthquake $C$, all-ages scenario

Figure 6.1.2-17 Distribution of liquefaction from earthquake $D$, all-ages scenario

Figure 6.1.2-18 Distribution of liquefaction from earthquake $\mathrm{E}$, all-ages scenario. 6-136

Figure 6.1.2-19 Uncertainty distributions for the age of Charleston RLMEs

Figure 6.1.3-1 Logic tree for the Cheraw fault RLME source.

Figure 6.1.3-2 Map (c) and hillshade relief images (a, b, and d) showing location of mapped Cheraw fault, possible northeast extension, and paleoseismic locality....

Figure 6.1.3-3 Cheraw RLME source relative to (a) total magnetic anomaly and (b) residual isostatic gravity data

Figure 6.1.4-1 Meers fault location

Figure 6.1.4-2 Logic tree for the Meers fault source.

Figure 6.1.5-1 Logic tree for the NMFS RLME source $6-143$

Figure 6.1.5-2 Map showing seismicity and major subsurface structural features in the New Madrid region

Figure 6.1.5-3 Map showing geomorphic and near-surface tectonic features in the New Madrid region and locations of NMFS RLME fault sources

Figure 6.1.5-4 Rupture segments (a) and models (b) for the New Madrid faults from Johnston and Schweig (1996) and (c) the NMFS RLME fault sources

Figure 6.1.5-5 Map of NMSZ showing estimated ages and measured sizes of liquefaction features

Figure 6.1.5-6 Earthquake chronology for NMSZ from dating and correlation of liquefaction features at sites (listed at top) along N-S transect across region.

Figure 6.1.5-7 Probability distributions for the age of the AD 900 and AD 1450 NMFS RLMEs

Figure 6.1.5-8 Liquefaction fields for the 1811-1812, AD 1450, and AD 900 earthquakes as interpreted from spatial distribution and stratigraphy of sand blows 
Figure 6.1.6-1a Logic tree for the Reelfoot Rift-Eastern Rift Margin South RLME source.

Two options for the southern extent of the ERM-S are considered: ERM-SCC includes the Crittenden County fault zone, and ERM-SRP includes the postulated zone of deformation based on fault picks identified in a high-resolution seismic profile along the Mississippi River.

Figure 6.1.6-1b Logic tree for the Reelfoot Rift-Eastern Rift Margin North RLME source.....6-152

Figure 6.1.6-2 Map showing structural features and paleoseismic investigation sites along the eastern margin of the Reelfoot rift. The inset map shows the locations of inferred basement faults that border and cross the Reelfoot rift (Csontos et al., 2008) and the inferred Joiner Ridge-Meeman-Shelby fault (JR-MSF; Odum et al., 2010).

Figure 6.1.6-3 Maps showing surficial geology and locations of subsurface investigations at (a) Meeman-Shelby Forest State Park locality and (b) Union City site (MSF and UC on Figure 6.1.6-2). Modified from Cox et al. (2006) and Odum et al. (2010).....

Figure 6.1.6-4 Figure showing the timing of events along the eastern Reelfoot rift margin. Modified from Cox (2009).

Figure 6.1.7-1 Logic tree for the Reelfoot rift-Marianna RLME source 6-156

Figure 6.1.7-2 Map showing tectonic features and locations of paleoliquefaction sites in the vicinity of Marianna, Arkansas

Figure 6.1.7-3 Map showing liquefaction features near Daytona Beach lineament southwest of Marianna, Arkansas

Figure 6.1.8-1 Logic tree for the Commerce Fault Zone RLME source

Figure 6.1.8-2 Map showing tectonic features, seismicity, and paleoseismic localities along the Commerce Fault Zone RLME source

Figure 6.1.8-3 Location of the Commerce geophysical lineament and Commerce Fault Zone RLME source relative to the (a) regional magnetic anomaly map and (b) regional gravity anomaly map

Figure 6.1.8-4 Space-time diagram showing constraints on the location and timing of late Pleistocene and Holocene paleoearthquakes that may be associated with the Commerce Fault Zone RLME source

Figure 6.1.9-1 Logic tree for the Wabash Valley RLME source

Figure 6.1.9-2 Map showing seismicity, subsurface structural features, paleoearthquake energy centers, and postulated neotectonic deformation in the Wabash Valley region of southern Illinois and southern Indiana

Figure 6.1.9-3 Wabash Valley RLME source relative to (a) magnetic anomaly, and (b) residual isostatic gravity data

Figure 6.2-1 Map showing the two Mmax zones for the "narrow" interpretation of the Mesozoic-and-younger extended zone.

Figure 6.2-2 Map showing the two Mmax zones for the "wide" interpretation of the Mesozoic-and-younger extended zone.

Figure 6.3.1-1 Distributions for $m_{\text {max-obs }}$ for the Mmax distributed seismicity source zones .. 6-168

Figure 6.3.2-1 Mmax distributions for the study region treated as a single Mmax zone

Figure 6.3.2-2 Mmax distributions for the MESE-N Mmax zone 
Figure 6.3.2-3 Mmax distributions for the MESE-W Mmax zone

Figure 6.3.2-4 Mmax distributions for the NMESE-N Mmax zone

Figure 6.3.2-5 Mmax distributions for the NMESE-W Mmax zone $6-173$

Figure 6.4.1-1 Mean map of rate and $b$-value for the study region under the source-zone configuration, with no separation of Mesozoic extended and non-extended; Case A magnitude weights

Figure 6.4.1-2 Mean map of rate and b-value for the study region under the source-zone configuration, with no separation of Mesozoic extended and non-extended; Case B magnitude weights

Figure 6.4.1-3 Mean map of rate and b-value for the study region under the source-zone configuration, with no separation of Mesozoic extended and non-extended; Case E magnitude weights

Figure 6.4.1-4 Mean map of rate and b-value for the study region under the source-zone configuration, with separation of Mesozoic extended and non-extended, narrow geometry for MESE; Case A magnitude weights

Figure 6.4.1-5 Mean map of rate and b-value for the study region under the source-zone configuration, with separation of Mesozoic extended and non-extended, narrow geometry for MESE; Case B magnitude weights

Figure 6.4.1-6 Mean map of rate and b-value for the study region under the source-zone configuration, with separation of Mesozoic extended and non-extended, narrow geometry for MESE; Case E magnitude weights

Figure 6.4.1-7 Mean map of rate and b-value for the study region under the source-zone configuration, with separation of Mesozoic extended and non-extended, wide geometry for MESE; Case A magnitude weights

Figure 6.4.1-8 Mean map of rate and b-value for the study region under the source-zone configuration, with separation of Mesozoic extended and non-extended, wide geometry for MESE; Case B magnitude weights

Figure 6.4.1-9 Mean map of rate and b-value for the study region under the source-zone configuration, with separation of Mesozoic extended and non-extended, wide geometry for MESE; Case E magnitude weights

Figure 6.4.2-1 Comparison of model-predicted earthquake counts for study region using Case A magnitude weights. The error bars represent the $16 \%-84 \%$ uncertainty associated with the data, computed using the Weichert (1980) procedure.

Figure 6.4.2-2 Comparison of model-predicted earthquake counts for study region using Case B magnitude weights. The error bars represent the $16 \%-84 \%$ uncertainty associated with the data, computed using the Weichert (1980) procedure

Figure 6.4.2-3 Comparison of model-predicted earthquake counts for study region using Case $\mathrm{E}$ magnitude weights. The error bars represent the $16 \%-84 \%$ uncertainty associated with the data, computed using the Weichert (1980) procedure.

Figure 6.4.2-4 Comparison of model-predicted earthquake counts for MESE-N using Case A magnitude weights. The error bars represent the $16 \%-84 \%$ uncertainty associated with the data, computed using the Weichert (1980) procedure.

Figure 6.4.2-5 Comparison of model-predicted earthquake counts for MESE-N using Case B magnitude weights. The error bars represent the $16 \%-84 \%$ uncertainty associated with the data, computed using the Weichert (1980) procedure. 
Figure 6.4.2-6 Comparison of model-predicted earthquake counts for MESE-N using Case $\mathrm{E}$ magnitude weights. The error bars represent the $16 \%-84 \%$ uncertainty associated with the data, computed using the Weichert (1980) procedure.

Figure 6.4.2-7 Comparison of model-predicted earthquake counts for MESE-W using Case A magnitude weights. The error bars represent the $16 \%-84 \%$ uncertainty associated with the data, computed using the Weichert (1980) procedure.

Figure 6.4.2-8 Comparison of model-predicted earthquake counts for MESE-W using Case B magnitude weights. The error bars represent the $16 \%-84 \%$ uncertainty associated with the data, computed using the Weichert (1980) procedure.

Figure 6.4.2-9 Comparison of model-predicted earthquake counts for MESE-W using Case $\mathrm{E}$ magnitude weights. The error bars represent the $16 \%-84 \%$ uncertainty associated with the data, computed using the Weichert (1980) procedure.

Figure 6.4.2-10 Comparison of model-predicted earthquake counts for NMESE-N using Case A magnitude weights. The error bars represent the $16 \%-84 \%$ uncertainty associated with the data, computed using the Weichert (1980) procedure.

Figure 6.4.2-11 Comparison of model-predicted earthquake counts for NMESE-N using Case B magnitude weights. The error bars represent the $16 \%-84 \%$ uncertainty associated with the data, computed using the Weichert (1980) procedure.

Figure 6.4.2-12 Comparison of model-predicted earthquake counts for NMESE-N using Case $\mathrm{E}$ magnitude weights. The error bars represent the $16 \%-84 \%$ uncertainty associated with the data, computed using the Weichert (1980) procedure.

Figure 6.4.2-13 Comparison of model-predicted earthquake counts for NMESE-W using Case A magnitude weights. The error bars represent the $16 \%-84 \%$ uncertainty associated with the data, computed using the Weichert (1980) procedure.

Figure 6.4.2-14 Comparison of model-predicted earthquake counts for NMESE-W using Case B magnitude weights. The error bars represent the $16 \%-84 \%$ uncertainty associated with the data, computed using the Weichert (1980) procedure.

Figure 6.4.2-15 Comparison of model-predicted earthquake counts for NMESE-W using Case $\mathrm{E}$ magnitude weights. The error bars represent the $16 \%-84 \%$ uncertainty associated with the data, computed using the Weichert (1980) procedure.

Figure 7.1-1 Seismotectonic zones shown in the case where the Rough Creek graben is not part of the Reelfoot rift (RR) and the Paleozoic Extended Crust is narrow (PEZN)

Figure 7.1-2 Seismotectonic zones shown in the case where the Rough Creek graben is part of the Reelfoot rift (RR_RCG) and the Paleozoic Extended Crust is narrow (PEZ-N)

Figure 7.1-3 Seismotectonic zones shown in the case where the Rough Creek graben is not part of the Reelfoot rift (RR) and the Paleozoic Extended Crust is wide (PEZ-W) 7-85

Figure 7.1-4 Seismotectonic zones shown in the case where the Rough Creek graben is part of the Reelfoot rift (RR_RCG) and the Paleozoic Extended Crust is wide (PEZW).

Figure 7.1-5 Example of comparing seismotectonic zones with magnetic map developed as part of the CEUS SSC Project.

Figure 7.1-6 Example of comparing seismotectonic zones with isostatic gravity map developed as part of the CEUS SSC Project 
Figure 7.1-7 Map of seismicity based on the earthquake catalog developed for the CEUS SSC Project.

Figure 7.1-8 Map showing example comparison of seismotectonic zones with seismicity. Note the non-uniform spatial distribution of seismicity within the zones. Spatial smoothing of $a$ - and $b$-values accounts for these spatial variations.

Figure 7.3-1 Logic tree for the seismotectonic zones branch of the master logic tree.....

Figure 7.3.1-1 Significant earthquakes and paleoseismology of the SLR seismotectonic zone

Figure 7.3.1-2 Tectonic features of the SLR seismotectonic zone

Figure 7.3.1-3 Magnetic and gravity anomaly maps of the SLR seismotectonic zone

Figure 7.3.2-1 Significant earthquakes and paleoseismic study area in the region of the $\mathrm{GMH}$ seismotectonic zone

Figure 7.3.2-2 Igneous rocks attributed to the $\mathrm{GMH}$ seismotectonic zone 7-96

Figure 7.3.2-3 Relocated hypocentral depths and crustal depth of the $\mathrm{GMH}$ seismotectonic zone.

Figure 7.3.2-4 Magnetic and gravity anomaly maps of the GMH seismotectonic zone

Figure 7.3.3-2 Magnetic and gravity anomaly maps of the NAP seismotectonic zone $7-100$

Figure 7.3.4-1 Seismicity and tectonic features of the PEZ seismotectonic zone.

Figure 7.3.5-1 Map showing seismicity, subsurface Paleozoic and basement structures, and postulated energy centers for prehistoric earthquakes

Figure 7.3.5-2 Map showing alternative boundaries for Precambrian (proto-Illinois basin) rift basins

Figure 7.3.5-3 Maps showing the IBEB source zone boundaries, seismicity, and prehistoric earthquake centers relative to (a) regional magnetic anomalies and (b) regional gravity anomalies

Figure 7.3.6-1 Map of seismicity and geomorphic features and faults showing evidence for Quaternary neotectonic deformation and reactivation. Inset map shows basement structures associated with the Reelfoot rift.

Figure 7.3.6-2 Maps showing geophysical anomalies in the Reelfoot rift region ................. 7-107

Figure 7.3.7-1 Mesozoic basins within the ECC-AM zone ......................................... $7-108$

Figure 7.3.7-2 Seismicity within the ECC-AM and AHEX zones...................................... $7-109$

Figure 7.3.7-3 Magnetic and gravity data for ECC-AM and AHEX zones............................ 7-110

Figure 7.3.7-4 Estimated locations of the 1755 M 6.1 Cape Ann earthquake .....................7-111

Figure 7.3.8-1 Correlation of interpreted transitional crust with the East Coast magnetic anomaly

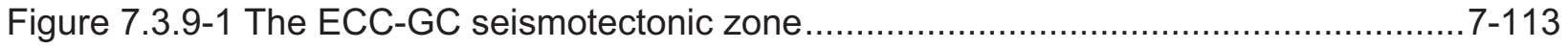

Figure 7.3.10-1 The GHEX seismotectonic zone................................................... $7-114$

Figure 7.3.11-1 The OKA seismotectonic zone and regional gravity and magnetic data ......7-115

Figure 7.3.12-1 Simplified tectonic map showing the distribution of principal basement faults, rifts, and sutures in the Midcontinent 
Figure 7.3.12-2 Maps showing major basement structural features relative to (a) regional magnetic anomalies and (b) regional gravity anomalies ...................................... $7-117$

Figure 7.3.12-3 Seismic zones and maximum observed earthquakes in the MidC zone ......7-118 Figure 7.3.12-4 Alternative MidC source zone configurations ......................................... $7-119$

Figure 7.4.1-1 (1 of 3) Distributions for $m_{\max -o b s}$ for the seismotectonic distributed

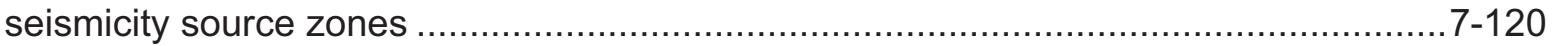

Figure 7.4.1-1 (2 of 3) Distributions for $m_{\max -o b s}$ for the seismotectonic distributed seismicity source zones

Figure 7.4.1-1 (3 of 3) Distributions for $m_{\max -o b s}$ for the seismotectonic distributed

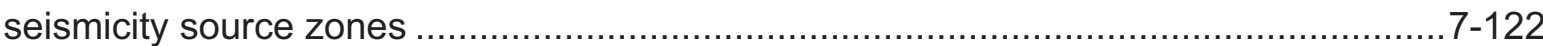

Figure 7.4.2-1 Mmax distributions for the AHEX seismotectonic zone ........................... $7-123$

Figure 7.4.2-2 Mmax distributions for the ECC_AM seismotectonic zone ......................... $7-124$

Figure 7.4.2-3 Mmax distributions for the ECC_GC seismotectonic zone .........................7-125

Figure 7.4.2-4 Mmax distributions for the GHEX seismotectonic zone ........................... $7-126$

Figure 7.4.2-5 Mmax distributions for the GMH seismotectonic zone........................... $7-127$

Figure 7.4.2-6 Mmax distributions for the IBEB seismotectonic zone...........................7-128

Figure 7.4.2-7 Mmax distributions for the MidC-A seismotectonic zone ............................7-129

Figure 7.4.2-8 Mmax distributions for the MidC-B seismotectonic zone ............................ 7-130

Figure 7.4.2-9 Mmax distributions for the MidC-C seismotectonic zone ...........................7-131

Figure 7.4.2-10 Mmax distributions for the MidC-D seismotectonic zone...........................7-132

Figure 7.4.2-11 Mmax distributions for the NAP seismotectonic zone ............................ 7-133

Figure 7.4.2-12 Mmax distributions for the OKA seismotectonic zone ..............................7-134

Figure 7.4.2-13 Mmax distributions for the PEZ_N seismotectonic zone .......................... 7-135

Figure 7.4.2-14 Mmax distributions for the PEZ_W seismotectonic zone...........................7-136

Figure 7.4.2-15 Mmax distributions for the RR seismotectonic zone.............................. $7-137$

Figure 7.4.2-16 Mmax distributions for the RR_RCG seismotectonic zone........................7-138

Figure 7.4.2-17 Mmax distributions for the SLR seismotectonic zone .............................. 7-139

Figure 7.5.1-1 Mean map of rate and $b$-value for the study region under the source-zone configuration with narrow interpretation of PEZ, Rough Creek graben associated with Midcontinent; Case A magnitude weights....

Figure 7.5.1-2 Mean map of rate and $b$-value for the study region under the source-zone configuration with narrow interpretation of PEZ, Rough Creek graben associated with Midcontinent; Case B magnitude weights

Figure 7.5.1-3 Mean map of rate and $b$-value for the study region under the source-zone configuration with narrow interpretation of PEZ, Rough Creek graben associated with Midcontinent; Case E magnitude weights

Figure 7.5.1-4 Mean map of rate and $b$-value for the study region under the source-zone configuration with narrow interpretation of PEZ, Rough Creek graben associated with Reelfoot rift; Case A magnitude weights. 
Figure 7.5.1-5 Mean map of rate and $b$-value for the study region under the source-zone configuration with narrow interpretation of PEZ, Rough Creek graben associated with Reelfoot rift; Case B magnitude weights.

Figure 7.5.1-6 Mean map of rate and $b$-value for the study region under the source-zone configuration with narrow interpretation of PEZ, Rough Creek graben associated with Reelfoot rift; Case E magnitude weights

Figure 7.5.1-7 Mean map of rate and $b$-value for the study region under the source-zone configuration with wide interpretation of PEZ, Rough Creek graben associated with Midcontinent; Case A magnitude weights

Figure 7.5.1-8 Mean map of rate and $b$-value for the study region under the source-zone configuration with wide interpretation of PEZ, Rough Creek graben associated with Midcontinent; Case B magnitude weights

Figure 7.5.1-9 Mean map of rate and $b$-value for the study region under the source-zone configuration with wide interpretation of PEZ, Rough Creek graben associated with Midcontinent; Case E magnitude weights

Figure 7.5.1-10 Mean map of rate and $b$-value for the study region under the sourcezone configuration with wide interpretation of PEZ, Rough Creek graben associated with Reelfoot rift; Case A magnitude weights

Figure 7.5.1-11 Mean map of rate and $b$-value for the study region under the sourcezone configuration with wide interpretation of PEZ, Rough Creek graben associated with Reelfoot rift; Case B magnitude weights....

Figure 7.5.1-12 Mean map of rate and $b$-value for the study region under the sourcezone configuration with wide interpretation of PEZ, Rough Creek graben associated with Reelfoot rift; Case E magnitude weights.

Figure 7.5.2-1 Comparison of model-predicted earthquake counts for AHEX using Case A magnitude weights. No earthquake counts are shown because this source zone contains no seismicity.

Figure 7.5.2-2 Comparison of model-predicted earthquake counts for AHEX using Case $B$ magnitude weights. No earthquake counts are shown because this source zone contains no seismicity..

Figure 7.5.2-3 Comparison of model-predicted earthquake counts for AHEX using Case $E$ magnitude weights. No earthquake counts are shown because this source zone contains no seismicity.

Figure 7.5.2-4 Comparison of model-predicted earthquake counts for ECC_AM using Case A magnitude weights. The error bars represent the $16 \%-84 \%$ uncertainty associated with the data, computed using the Weichert (1980) procedure.

Figure 7.5.2-5 Comparison of model-predicted earthquake counts for ECC_AM using Case B magnitude weights. Error bars as in Figure 7.5.2-4.

Figure 7.5.2-6 Comparison of model-predicted earthquake counts for ECC_AM using Case $\mathrm{E}$ magnitude weights. Error bars as in Figure 7.5.2-4.

Figure 7.5.2-7 Comparison of model-predicted earthquake counts for ECC_GC using Case A magnitude weights. Error bars as in Figure 7.5.2-4.

Figure 7.5.2-8 Comparison of model-predicted earthquake counts for ECC_GC using Case B magnitude weights. Error bars as in Figure 7.5.2-4.

Figure 7.5.2-9 Comparison of model-predicted earthquake counts for ECC_GC using Case $\mathrm{E}$ magnitude weights. Error bars as in Figure 7.5.2-4. 
Figure 7.5.2-10 Comparison of model-predicted earthquake counts for GHEX using Case A magnitude weights. Error bars as in Figure 7.5.2-4.

Figure 7.5.2-11 Comparison of model-predicted earthquake counts for GHEX using Case B magnitude weights. Error bars as in Figure 7.5.2-4.

Figure 7.5.2-12 Comparison of model-predicted earthquake counts for GHEX using Case $\mathrm{E}$ magnitude weights. Error bars as in Figure 7.5.2-4.

Figure 7.5.2-13 Comparison of model-predicted earthquake counts for $\mathrm{GMH}$ using Case A magnitude weights. Error bars as in Figure 7.5.2-4.

Figure 7.5.2-14 Comparison of model-predicted earthquake counts for $\mathrm{GMH}$ using Case B magnitude weights. Error bars as in Figure 7.5.2-4.

Figure 7.5.2-15 Comparison of model-predicted earthquake counts for $\mathrm{GMH}$ using Case E magnitude weights. Error bars as in Figure 7.5.2-4.

Figure 7.5.2-16 Comparison of model-predicted earthquake counts for IBEB using Case A magnitude weights. Error bars as in Figure 7.5.2-4.

Figure 7.5.2-17 Comparison of model-predicted earthquake counts for IBEB using Case $B$ magnitude weights. Error bars as in Figure 7.5.2-4.

Figure 7.5.2-18 Comparison of model-predicted earthquake counts for IBEB using Case E magnitude weights. Error bars as in Figure 7.5.2-4.

Figure 7.5.2-19 Comparison of model-predicted earthquake counts for MidC-A using Case A magnitude weights. Error bars as in Figure 7.5.2-4.

Figure 7.5.2-20 Comparison of model-predicted earthquake counts for MidC-A using Case B magnitude weights. Error bars as in Figure 7.5.2-4.

Figure 7.5.2-21 Comparison of model-predicted earthquake counts for MidC-A using Case $\mathrm{E}$ magnitude weights. Error bars as in Figure 7.5.2-4.

Figure 7.5.2-22 Comparison of model-predicted earthquake counts for MidC-B using Case A magnitude weights. Error bars as in Figure 7.5.2-4.

Figure 7.5.2-23 Comparison of model-predicted earthquake counts for MidC-B using Case B magnitude weights. Error bars as in Figure 7.5.2-4.

Figure 7.5.2-24 Comparison of model-predicted earthquake counts for MidC-B using Case $\mathrm{E}$ magnitude weights. Error bars as in Figure 7.5.2-4.

Figure 7.5.2-25 Comparison of model-predicted earthquake counts for MidC-C using Case A magnitude weights. Error bars as in Figure 7.5.2-4.

Figure 7.5.2-26 Comparison of model-predicted earthquake counts for MidC-C using Case B magnitude weights. Error bars as in Figure 7.5.2-4.

Figure 7.5.2-27 Comparison of model-predicted earthquake counts for MidC-C using Case $\mathrm{E}$ magnitude weights. Error bars as in Figure 7.5.2-4.

Figure 7.5.2-28 Comparison of model-predicted earthquake counts for MidC-D using Case A magnitude weights. Error bars as in Figure 7.5.2-4.

Figure 7.5.2-29 Comparison of model-predicted earthquake counts for MidC-D using Case B magnitude weights. Error bars as in Figure 7.5.2-4.

Figure 7.5.2-30 Comparison of model-predicted earthquake counts for MidC-D using Case E magnitude weights. Error bars as in Figure 7.5.2-4.

Figure 7.5.2-31 Comparison of model-predicted earthquake counts for NAP using Case A magnitude weights. Error bars as in Figure 7.5.2-4. 
Figure 7.5.2-32 Comparison of model-predicted earthquake counts for NAP using Case

B magnitude weights. Error bars as in Figure 7.5.2-4.

Figure 7.5.2-33 Comparison of model-predicted earthquake counts for NAP using Case $\mathrm{E}$ magnitude weights. Error bars as in Figure 7.5.2-4.

Figure 7.5.2-34 Comparison of model-predicted earthquake counts for OKA using Case A magnitude weights. Error bars as in Figure 7.5.2-4.

Figure 7.5.2-35 Comparison of model-predicted earthquake counts for OKA using Case B magnitude weights. Error bars as in Figure 7.5.2-4.

Figure 7.5.2-36 Comparison of model-predicted earthquake counts for OKA using Case E magnitude weights. Error bars as in Figure 7.5.2-4.

Figure 7.5.2-37 Comparison of model-predicted earthquake counts for PEZ_N using Case A magnitude weights. Error bars as in Figure 7.5.2-4.

Figure 7.5.2-38 Comparison of model-predicted earthquake counts for PEZ_N using Case B magnitude weights. Error bars as in Figure 7.5.2-4.

Figure 7.5.2-39 Comparison of model-predicted earthquake counts for PEZ_N using Case $\mathrm{E}$ magnitude weights. Error bars as in Figure 7.5.2-4.

Figure 7.5.2-40 Comparison of model-predicted earthquake counts for PEZ_W using Case A magnitude weights. Error bars as in Figure 7.5.2-4.

Figure 7.5.2-41 Comparison of model-predicted earthquake counts for PEZ_W using Case B magnitude weights. Error bars as in Figure 7.5.2-4.

Figure 7.5.2-42 Comparison of model-predicted earthquake counts for PEZ_W using Case $\mathrm{E}$ magnitude weights. Error bars as in Figure 7.5.2-4.

Figure 7.5.2-43 Comparison of model-predicted earthquake counts for RR using Case A magnitude weights. Error bars as in Figure 7.5.2-4.

Figure 7.5.2-44 Comparison of model-predicted earthquake counts for RR using Case $B$ magnitude weights. Error bars as in Figure 7.5.2-4.

Figure 7.5.2-45 Comparison of model-predicted earthquake counts for RR using Case $E$ magnitude weights. Error bars as in Figure 7.5.2-4.

Figure 7.5.2-46 Comparison of model-predicted earthquake counts for RR_RCG using Case A magnitude weights. Error bars as in Figure 7.5.2-4.

Figure 7.5.2-47 Comparison of model-predicted earthquake counts for RR_RCG using Case B magnitude weights. Error bars as in Figure 7.5.2-4.

Figure 7.5.2-48 Comparison of model-predicted earthquake counts for RR_RCG using Case $\mathrm{E}$ magnitude weights. Error bars as in Figure 7.5.2-4.

Figure 7.5.2-49 Comparison of model-predicted earthquake counts for SLR using Case A magnitude weights. Error bars as in Figure 7.5.2-4.

Figure 7.5.2-50 Comparison of model-predicted earthquake counts for SLR using Case B magnitude weights. Error bars as in Figure 7.5.2-4.

Figure 7.5.2-51 Comparison of model-predicted earthquake counts for SLR using Case E magnitude weights. Error bars as in Figure 7.5.2-4.

Figure 8.1-1 Map showing the study area and seven test sites for the CEUS SSC Project ....8-28

Figure 8.1-2 Mean VS profile for shallow soil site 8-29

Figure 8.1-3 Mean VS profile for deep soil site.... 
Figure 8.1-4 Mean amplification factors for shallow soil site.

Figure 8.1-5 Mean amplification factors for deep soil site.

Figure 8.2-1a Central Illinois $10 \mathrm{~Hz}$ rock hazard: mean and fractile total hazard.

Figure 8.2-1b Central Illinois $1 \mathrm{~Hz}$ rock hazard: mean and fractile total hazard.

Figure 8.2-1d Central Illinois $10 \mathrm{~Hz}$ rock hazard: total and contribution by RLME and background

Figure 8.2-1e Central Illinois $1 \mathrm{~Hz}$ rock hazard: total and contribution by RLME and background

Figure 8.2-1f Central Illinois PGA rock hazard: total and contribution by RLME and background

Figure 8.2-1g Central Illinois $10 \mathrm{~Hz}$ rock hazard: contribution by background source.........

Figure 8.2-1h Central Illinois $1 \mathrm{~Hz}$ rock hazard: contribution by background source.

Figure 8.2-1i Central Illinois PGA rock hazard: contribution by background source

Figure 8.2-1j Central Illinois $10 \mathrm{~Hz}$ rock hazard: comparison of three source models. 8-42

Figure 8.2-1k Central Illinois $1 \mathrm{~Hz}$ rock hazard: comparison of three source models

Figure 8.2-1I Central Illinois PGA rock hazard: comparison of three source models

Figure 8.2-1m Central Illinois $10 \mathrm{~Hz}$ shallow soil hazard: total and total and contribution by RLME and background.

Figure 8.2-1n Central Illinois $1 \mathrm{~Hz}$ shallow soil hazard: total and contribution by RLME and background

Figure 8.2-10 Central Illinois PGA shallow soil hazard: total and contribution by RLME and background

Figure 8.2-1p Central Illinois $10 \mathrm{~Hz}$ deep soil hazard: total and contribution by RLME and background

Figure 8.2-1q Central Illinois $1 \mathrm{~Hz}$ deep soil hazard: total and contribution by RLME and background

Figure 8.2-1r Central Illinois PGA deep soil hazard: total and contribution by RLME and background

Figure 8.2-1s Central Illinois $10 \mathrm{~Hz}$ hazard: comparison of three site conditions $8-51$

Figure 8.2-1t Central Illinois $1 \mathrm{~Hz}$ hazard: comparison of three site conditions ...................... 8-52

Figure 8.2-1u Central Illinois PGA hazard: comparison of three site conditions. $8-53$

Figure 8.2-1v Central Illinois $10 \mathrm{~Hz}$ rock hazard: sensitivity to seismotectonic vs. Mmax zones

Figure 8.2-1w Central Illinois $1 \mathrm{~Hz}$ rock hazard: sensitivity to seismotectonic vs. Mmax zones......

Figure 8.2-1x Central Illinois $10 \mathrm{~Hz}$ rock hazard: sensitivity to Mmax for source IBEB............ 8-56

Figure 8.2-1y Central Illinois $1 \mathrm{~Hz}$ rock hazard: sensitivity to Mmax for source IBEB............. 8-57

Figure 8.2-1z Central Illinois $10 \mathrm{~Hz}$ rock hazard: sensitivity to smoothing options .................. 8-58

Figure 8.2-1aa Central Illinois $1 \mathrm{~Hz}$ rock hazard: sensitivity to smoothing options .................. 8-59

Figure 8.2-1bb Central Illinois $10 \mathrm{~Hz}$ rock hazard: sensitivity to eight realizations for source IBEB, Case A 
Figure 8.2-1 cc Central Illinois $10 \mathrm{~Hz}$ rock hazard: sensitivity to eight realizations for source IBEB, Case $B$

Figure 8.2-1dd Central Illinois $10 \mathrm{~Hz}$ rock hazard: sensitivity to eight realizations for source IBEB, Case $\mathrm{E}$

Figure 8.2-1ee Central Illinois $1 \mathrm{~Hz}$ rock hazard: sensitivity to eight realizations for source IBEB, Case A

Figure 8.2-1ff Central Illinois $1 \mathrm{~Hz}$ rock hazard: sensitivity to eight realizations for source IBEB, Case B

Figure 8.2-1gg Central Illinois $1 \mathrm{~Hz}$ rock hazard: sensitivity to eight realizations for source IBEB, Case $\mathrm{E}$ $8-65$

Figure 8.2-2a Chattanooga $10 \mathrm{~Hz}$ rock hazard: mean and fractile total hazard $8-66$

Figure 8.2-2b Chattanooga $1 \mathrm{~Hz}$ rock hazard: mean and fractile total hazard. 8-67

Figure 8.2-2c Chattanooga PGA rock hazard: mean and fractile total hazard 8-68

Figure 8.2-2d Chattanooga $10 \mathrm{~Hz}$ rock hazard: total and contribution by RLME and background

Figure 8.2-2e Chattanooga $1 \mathrm{~Hz}$ rock hazard: total and contribution by RLME and background

Figure 8.2-2f Chattanooga PGA rock hazard: total and contribution by RLME and background

Figure 8.2-2g Chattanooga $10 \mathrm{~Hz}$ rock hazard: contribution by background source $8-72$

Figure 8.2-2h Chattanooga $1 \mathrm{~Hz}$ rock hazard: contribution by background source..... $8-73$

Figure 8.2-2i Chattanooga PGA rock hazard: contribution by background source $8-74$

Figure 8.2-2j Chattanooga $10 \mathrm{~Hz}$ rock hazard: comparison of three source models 8-75

Figure 8.2-2k Chattanooga is $1 \mathrm{~Hz}$ rock hazard: comparison of three source models $8-76$

Figure 8.2-2I Chattanooga PGA rock hazard: comparison of three source models. 8-77

Figure 8.2-2m Chattanooga $10 \mathrm{~Hz}$ shallow soil hazard: total and contribution by RLME and background

Figure $8.2-2 \mathrm{n}$ Chattanooga $1 \mathrm{~Hz}$ shallow soil hazard: total and contribution by RLME and background

Figure 8.2-2o Chattanooga PGA shallow soil hazard: total and contribution by RLME and background

Figure $8.2-2 p$ Chattanooga $10 \mathrm{~Hz}$ deep soil hazard: total and contribution by RLME and background

Figure 8.2-2q Chattanooga $1 \mathrm{~Hz}$ deep soil hazard: total and contribution by RLME and background

Figure 8.2-2r Chattanooga PGA deep soil hazard: total and contribution by RLME and background

Figure 8.2-2s Chattanooga $10 \mathrm{~Hz}$ hazard: comparison of three site conditions $8-84$

Figure 8.2-2t Chattanooga $1 \mathrm{~Hz}$ hazard: comparison of three site conditions ..... 8-85

Figure 8.2-2u Chattanooga PGA hazard: comparison of three site conditions 8-86

Figure 8.2-2v Chattanooga $10 \mathrm{~Hz}$ rock hazard: sensitivity to seismotectonic vs. Mmax zones 
Figure 8.2-2w Chattanooga $1 \mathrm{~Hz}$ rock hazard: sensitivity to seismotectonic vs. Mmax zones.

Figure 8.2-2x Chattanooga $10 \mathrm{~Hz}$ rock hazard: sensitivity to Mmax for source PEZ-N ...........8-89

Figure 8.2-2y Chattanooga $1 \mathrm{~Hz}$ rock hazard: sensitivity to Mmax for source PEZ-N ............8-90

Figure 8.2-2z Chattanooga $10 \mathrm{~Hz}$ rock hazard: sensitivity to smoothing options ..................8-91

Figure 8.2-2aa Chattanooga $1 \mathrm{~Hz}$ rock hazard: sensitivity to smoothing options

Figure 8.2-2bb Chattanooga $10 \mathrm{~Hz}$ rock hazard: sensitivity to eight realizations for source PEZ-N, Case A

Figure 8.2-2cc Chattanooga $10 \mathrm{~Hz}$ rock hazard: sensitivity to eight realizations for source PEZ-N, Case B

Figure 8.2-2dd Chattanooga $10 \mathrm{~Hz}$ rock hazard: sensitivity to eight realizations for source PEZ-N, Case E

Figure 8.2-2ee Chattanooga $1 \mathrm{~Hz}$ rock hazard: sensitivity to eight realizations for source PEZ-N, Case A.

Figure 8.2-2ff Chattanooga $1 \mathrm{~Hz}$ rock hazard: sensitivity to eight realizations for source PEZ-N, Case B.

Figure 8.2-2gg Chattanooga $1 \mathrm{~Hz}$ rock hazard: sensitivity to eight realizations for source PEZ-N, Case E

Figure 8.2-3a Houston $10 \mathrm{~Hz}$ rock hazard: mean and fractile total hazard

Figure 8.2-3b Houston $1 \mathrm{~Hz}$ rock hazard: mean and fractile total hazard

Figure 8.2-3c Houston PGA rock hazard: mean and fractile total hazard

Figure 8.2-3d Houston $10 \mathrm{~Hz}$ rock hazard: total and contribution by RLME and background

Figure 8.2-3e Houston $1 \mathrm{~Hz}$ rock hazard: total and contribution by RLME and background

Figure 8.2-3f Houston PGA rock hazard: total and contribution by RLME and background .. 8-104

Figure 8.2-3g Houston $10 \mathrm{~Hz}$ rock hazard: contribution by background source 8-105

Figure 8.2-3h Houston $1 \mathrm{~Hz}$ rock hazard: contribution by background source 8-106

Figure 8.2-3i Houston PGA rock hazard: contribution by background source 8-107

Figure 8.2-3j Houston $10 \mathrm{~Hz}$ rock hazard: comparison of three source models 8-108

Figure 8.2-3k Houston is $1 \mathrm{~Hz}$ rock hazard: comparison of three source models 8-109

Figure 8.2-3I Houston PGA rock hazard: comparison of three source models 8-110

Figure 8.2-3m Houston $10 \mathrm{~Hz}$ shallow soil hazard: total and contribution by RLME and background

Figure 8.2-3n Houston $1 \mathrm{~Hz}$ shallow soil hazard: total and contribution by RLME and background

Figure 8.2-3o Houston PGA shallow soil hazard: total and contribution by RLME and background

Figure 8.2-3p Houston $10 \mathrm{~Hz}$ deep soil hazard: total and contribution by RLME and background

Figure 8.2-3q Houston $1 \mathrm{~Hz}$ deep soil hazard: total and contribution by RLME and background 
Figure 8.2-3r Houston PGA deep soil hazard: total and contribution by RLME and background

Figure 8.2-3s Houston $10 \mathrm{~Hz}$ hazard: comparison of three site conditions 8-117

Figure 8.2-3t Houston $1 \mathrm{~Hz}$ hazard: comparison of three site conditions 8-118

Figure 8.2-3u Houston PGA hazard: comparison of three site conditions

Figure 8.2-3v Houston $10 \mathrm{~Hz}$ rock hazard: sensitivity to seismotectonic vs. Mmax zones .... 8-120

Figure 8.2-3w Houston $1 \mathrm{~Hz}$ rock hazard: sensitivity to seismotectonic vs. Mmax zones ..... 8-121

Figure 8.2-3x Houston $10 \mathrm{~Hz}$ rock hazard: sensitivity to Mmax for source GHEX.

Figure 8.2-3y Houston $1 \mathrm{~Hz}$ rock hazard: sensitivity to Mmax for source GHEX. 8-123

Figure 8.2-3z Houston $10 \mathrm{~Hz}$ rock hazard: sensitivity to smoothing options 8-124

Figure 8.2-3aa Houston $1 \mathrm{~Hz}$ rock hazard: sensitivity to smoothing options 8-125

Figure 8.2-3bb Houston $10 \mathrm{~Hz}$ rock hazard: sensitivity to eight realizations for source GHEX, Case A.

Figure 8.2-3cc Houston $10 \mathrm{~Hz}$ rock hazard: sensitivity to eight realizations for source GHEX, Case B

Figure 8.2-3dd Houston $10 \mathrm{~Hz}$ rock hazard: sensitivity to eight realizations for source GHEX, Case E

Figure 8.2-3ee Houston $1 \mathrm{~Hz}$ rock hazard: sensitivity to eight realizations for source GHEX, Case A .

Figure 8.2-3ff Houston $1 \mathrm{~Hz}$ rock hazard: sensitivity to eight realizations for source GHEX, Case B

Figure 8.2-3gg Houston $1 \mathrm{~Hz}$ rock hazard: sensitivity to eight realizations for source GHEX, Case E .

Figure 8.2-4a Jackson $10 \mathrm{~Hz}$ rock hazard: mean and fractile total hazard

Figure 8.2-4b Jackson $1 \mathrm{~Hz}$ rock hazard: mean and fractile total hazard

Figure 8.2-4c Jackson PGA rock hazard: mean and fractile total hazard

Figure 8.2-4d Jackson $10 \mathrm{~Hz}$ rock hazard: total and contribution by RLME and background

Figure 8.2-4e Jackson $1 \mathrm{~Hz}$ rock hazard: total and contribution by RLME and background

Figure 8.2-4f Jackson PGA rock hazard: total and contribution by RLME and background .. 8-137

Figure $8.2-4 \mathrm{~g}$ Jackson $10 \mathrm{~Hz}$ rock hazard: contribution by background source

Figure 8.2-4h Jackson $1 \mathrm{~Hz}$ rock hazard: contribution by background source 8-139

Figure 8.2-4i Jackson PGA rock hazard: contribution by background source 8-140

Figure 8.2-4j Jackson $10 \mathrm{~Hz}$ rock hazard: comparison of three source models

Figure 8.2-4k Jackson is $1 \mathrm{~Hz}$ rock hazard: comparison of three source models.....

Figure 8.2-4I Jackson PGA rock hazard: comparison of three source models 8-143

Figure 8.2-4m Jackson $10 \mathrm{~Hz}$ shallow soil hazard: total and contribution by RLME and background

Figure 8.2-4n Jackson $1 \mathrm{~Hz}$ shallow soil hazard: total and contribution by RLME and background

xlvi 
Figure 8.2-4o Jackson PGA shallow soil hazard: total and contribution by RLME and background

Figure 8.2-4p Jackson $10 \mathrm{~Hz}$ deep soil hazard: total and contribution by RLME and background

Figure 8.2-4q Jackson $1 \mathrm{~Hz}$ deep soil hazard: total and contribution by RLME and background

Figure 8.2-4r Jackson PGA deep soil hazard: total and contribution by RLME and background

Figure 8.2-4s Jackson $10 \mathrm{~Hz}$ hazard: comparison of three site conditions

Figure 8.2-4t Jackson $1 \mathrm{~Hz}$ hazard: comparison of three site conditions

Figure 8.2-4u Jackson PGA hazard: comparison of three site conditions

Figure 8.2-4v Jackson $10 \mathrm{~Hz}$ rock hazard: sensitivity to seismotectonic vs. Mmax zones .... 8-153

Figure 8.2-4w Jackson $1 \mathrm{~Hz}$ rock hazard: sensitivity to seismotectonic vs. Mmax zones ..... 8-154

Figure 8.2-4x Jackson $10 \mathrm{~Hz}$ rock hazard: sensitivity to Mmax for source ECC-GC ............ 8-155

Figure 8.2-4y Jackson $1 \mathrm{~Hz}$ rock hazard: sensitivity to Mmax for source ECC-GC ..............8-156

Figure 8.2-4z Jackson $10 \mathrm{~Hz}$ rock hazard: sensitivity to smoothing options........................ 8-157

Figure 8.2-4aa Jackson $1 \mathrm{~Hz}$ rock hazard: sensitivity to smoothing options........................8-158

Figure 8.2-4bb Jackson $10 \mathrm{~Hz}$ rock hazard: sensitivity to eight realizations for source ECC-GC, Case A.

Figure 8.2-4cc Jackson $10 \mathrm{~Hz}$ rock hazard: sensitivity to eight realizations for source ECC-GC, Case B

Figure 8.2-4dd Jackson $10 \mathrm{~Hz}$ rock hazard: sensitivity to eight realizations for source ECC-GC, Case E

Figure 8.2-4ee Jackson $1 \mathrm{~Hz}$ rock hazard: sensitivity to eight realizations for source ECC-GC, Case A.

Figure 8.2-4ff Jackson $1 \mathrm{~Hz}$ rock hazard: sensitivity to eight realizations for source ECCGC, Case B

Figure 8.2-4gg Jackson $1 \mathrm{~Hz}$ rock hazard: sensitivity to eight realizations for source ECC-GC, Case E

Figure 8.2-5a Manchester $10 \mathrm{~Hz}$ rock hazard: mean and fractile total hazard

Figure 8.2-5b Manchester $1 \mathrm{~Hz}$ rock hazard: mean and fractile total hazard

Figure 8.2-5c Manchester PGA rock hazard: mean and fractile total hazard

Figure 8.2-5d Manchester $10 \mathrm{~Hz}$ rock hazard: total and contribution by RLME and background

Figure 8.2-5e Manchester $1 \mathrm{~Hz}$ rock hazard: total and contribution by RLME and background

Figure 8.2-5f Manchester PGA rock hazard: total and contribution by RLME and background

Figure 8.2-5g Manchester $10 \mathrm{~Hz}$ rock hazard: contribution by background source.

Figure 8.2-5h Manchester $1 \mathrm{~Hz}$ rock hazard: contribution by background source.

Figure 8.2-5i Manchester PGA rock hazard: contribution by background source. 8-173

Figure 8.2-5j Manchester $10 \mathrm{~Hz}$ rock hazard: comparison of three source models. 
Figure 8.2-5k Manchester is $1 \mathrm{~Hz}$ rock hazard: comparison of three source models

Figure 8.2-5m Manchester $10 \mathrm{~Hz}$ shallow soil hazard: total and contribution by RLME and background

Figure 8.2-5n Manchester $1 \mathrm{~Hz}$ shallow soil hazard: total and contribution by RLME and background

Figure 8.2-5o Manchester PGA shallow soil hazard: total and contribution by RLME and background

Figure 8.2-5p Manchester $10 \mathrm{~Hz}$ deep soil hazard: total and contribution by RLME and background

Figure 8.2-5q Manchester $1 \mathrm{~Hz}$ deep soil hazard: total and contribution by RLME and background

Figure 8.2-5r Manchester PGA deep soil hazard: total and contribution by RLME and background

Figure 8.2-5s Manchester $10 \mathrm{~Hz}$ hazard: comparison of three site conditions

Figure 8.2-5t Manchester $1 \mathrm{~Hz}$ hazard: comparison of three site conditions.

Figure 8.2-5u Manchester PGA hazard: comparison of three site conditions

Figure 8.2-5v Manchester $10 \mathrm{~Hz}$ rock hazard: sensitivity to seismotectonic vs. Mmax zones.

Figure 8.2-5w Manchester $1 \mathrm{~Hz}$ rock hazard: sensitivity to seismotectonic vs. Mmax zones......

Figure 8.2-5x Manchester $10 \mathrm{~Hz}$ rock hazard: sensitivity to Mmax for source NAP

Figure 8.2-5y Manchester $1 \mathrm{~Hz}$ rock hazard: sensitivity to Mmax for source NAP

Figure 8.2-5z Manchester $10 \mathrm{~Hz}$ rock hazard: sensitivity to smoothing options

Figure 8.2-5aa Manchester $1 \mathrm{~Hz}$ rock hazard: sensitivity to smoothing options

Figure 8.2-5bb Manchester $10 \mathrm{~Hz}$ rock hazard: sensitivity to eight realizations for source NAP, Case A

Figure 8.2-5cc Manchester $10 \mathrm{~Hz}$ rock hazard: sensitivity to eight realizations for source NAP, Case B

Figure 8.2-5dd Manchester $10 \mathrm{~Hz}$ rock hazard: sensitivity to eight realizations for source NAP, Case $\mathrm{E}$

Figure 8.2-5ee Manchester $1 \mathrm{~Hz}$ rock hazard: sensitivity to eight realizations for source NAP, Case A.

Figure 8.2-5ff Manchester $1 \mathrm{~Hz}$ rock hazard: sensitivity to eight realizations for source NAP, Case B

Figure 8.2-5gg Manchester $1 \mathrm{~Hz}$ rock hazard: sensitivity to eight realizations for source NAP, Case E

Figure 8.2-6a Savannah $10 \mathrm{~Hz}$ rock hazard: mean and fractile total hazard.....

Figure 8.2-6b Savannah $1 \mathrm{~Hz}$ rock hazard: mean and fractile total hazard.....

Figure 8.2-6c Savannah PGA rock hazard: mean and fractile total hazard........

Figure 8.2-6d Savannah $10 \mathrm{~Hz}$ rock hazard: total and contribution by RLME and background

xlviii 
Figure 8.2-6e Savannah $1 \mathrm{~Hz}$ rock hazard: total and contribution by RLME and background

Figure 8.2-6f Savannah PGA rock hazard: total and contribution by RLME and background

Figure 8.2-6g Savannah $10 \mathrm{~Hz}$ rock hazard: contribution by background source 8-204

Figure 8.2-6h Savannah $1 \mathrm{~Hz}$ rock hazard: contribution by background source .... 8-205

Figure 8.2-6i Savannah PGA rock hazard: contribution by background source 8-206

Figure 8.2-6j Savannah $10 \mathrm{~Hz}$ rock hazard: comparison of three source models 8-207

Figure 8.2-6k Savannah is $1 \mathrm{~Hz}$ rock hazard: comparison of three source models 8-208

Figure 8.2-6I Savannah PGA rock hazard: comparison of three source models 8-209

Figure 8.2-6m Savannah $10 \mathrm{~Hz}$ shallow soil hazard: total and contribution by RLME and background

Figure 8.2-6n Savannah $1 \mathrm{~Hz}$ shallow soil hazard: total and contribution by RLME and background

Figure 8.2-6o Savannah PGA shallow soil hazard: total and contribution by RLME and background

Figure 8.2-6p Savannah $10 \mathrm{~Hz}$ deep soil hazard: total and contribution by RLME and background

Figure 8.2-6q Savannah $1 \mathrm{~Hz}$ deep soil hazard: total and contribution by RLME and background

Figure 8.2-6r Savannah PGA deep soil hazard: total and contribution by RLME and background

Figure 8.2-6s Savannah $10 \mathrm{~Hz}$ hazard: comparison of three site conditions 8-216

Figure 8.2-6t Savannah $1 \mathrm{~Hz}$ hazard: comparison of three site conditions......

Figure 8.2-6u Savannah PGA hazard: comparison of three site conditions

Figure 8.2-6v Savannah $10 \mathrm{~Hz}$ rock hazard: sensitivity to seismotectonic vs. Mmax zones.

Figure 8.2-6w Savannah $1 \mathrm{~Hz}$ rock hazard: sensitivity to seismotectonic vs. Mmax zones .. 8-220

Figure 8.2-6x Savannah $10 \mathrm{~Hz}$ rock hazard: sensitivity to Mmax for source ECC-AM .

Figure 8.2-6y Savannah $1 \mathrm{~Hz}$ rock hazard: sensitivity to Mmax for source ECC-AM

Figure 8.2-6z Savannah $10 \mathrm{~Hz}$ rock hazard: sensitivity to smoothing options.....

Figure 8.2-6aa Savannah $1 \mathrm{~Hz}$ rock hazard: sensitivity to smoothing options

Figure 8.2-6bb Savannah $10 \mathrm{~Hz}$ rock hazard: sensitivity to eight realizations for source ECC-AM, Case A .

Figure 8.2-6cc Savannah $10 \mathrm{~Hz}$ rock hazard: sensitivity to eight realizations for source ECC-AM, Case B

Figure 8.2-6dd Savannah $10 \mathrm{~Hz}$ rock hazard: sensitivity to eight realizations for source ECC-AM, Case E

Figure 8.2-6ee Savannah $1 \mathrm{~Hz}$ rock hazard: sensitivity to eight realizations for source ECC-AM, Case A.

Figure 8.2-6ff Savannah $1 \mathrm{~Hz}$ rock hazard: sensitivity to eight realizations for source ECC-AM, Case B 
Figure 8.2-6gg Savannah $1 \mathrm{~Hz}$ rock hazard: sensitivity to eight realizations for source ECC-AM, Case E .

Figure 8.2-7a Topeka $10 \mathrm{~Hz}$ rock hazard: mean and fractile total hazard .....

Figure 8.2-7b Topeka $1 \mathrm{~Hz}$ rock hazard: mean and fractile total hazard

Figure 8.2-7c Topeka PGA rock hazard: mean and fractile total hazard

Figure 8.2-7d Topeka $10 \mathrm{~Hz}$ rock hazard: total and contribution by RLME and background

Figure 8.2-7e Topeka $1 \mathrm{~Hz}$ rock hazard: total and contribution by RLME and background... 8-235

Figure 8.2-7f Topeka PGA rock hazard: total and contribution by RLME and background ...8-236

Figure 8.2-7g Topeka $10 \mathrm{~Hz}$ rock hazard: contribution by background source.

Figure 8.2-7h Topeka $1 \mathrm{~Hz}$ rock hazard: contribution by background source $8-238$

Figure 8.2-7i Topeka PGA rock hazard: contribution by background source

Figure 8.2-7j Topeka $10 \mathrm{~Hz}$ rock hazard: comparison of three source models

Figure 8.2-7k Topeka is $1 \mathrm{~Hz}$ rock hazard: comparison of three source models.

Figure 8.2-7I Topeka PGA rock hazard: comparison of three source models $8-242$

Figure $8.2-7 \mathrm{~m}$ Topeka $10 \mathrm{~Hz}$ shallow soil hazard: total and contribution by RLME and background

Figure 8.2-7n Topeka $1 \mathrm{~Hz}$ shallow soil hazard: total and contribution by RLME and background

Figure 8.2-7o Topeka PGA shallow soil hazard: total and contribution by RLME and background

Figure 8.2-7p Topeka $10 \mathrm{~Hz}$ deep soil hazard: total and contribution by RLME and background

Figure 8.2-7q Topeka $1 \mathrm{~Hz}$ deep soil hazard: total and contribution by RLME and background

Figure 8.2-7r Topeka PGA deep soil hazard: total and contribution by RLME and background

Figure 8.2-7s Topeka $10 \mathrm{~Hz}$ hazard: comparison of three site conditions

Figure 8.2-7t Topeka $1 \mathrm{~Hz}$ hazard: comparison of three site conditions

Figure 8.2-7u Topeka PGA hazard: comparison of three site conditions

Figure 8.2-7v Topeka $10 \mathrm{~Hz}$ rock hazard: sensitivity to seismotectonic vs. Mmax zones ..... 8-252

Figure 8.2-7w Topeka $1 \mathrm{~Hz}$ rock hazard: sensitivity to seismotectonic vs. Mmax zones....... 8-253

Figure 8.2-7x Topeka $10 \mathrm{~Hz}$ rock hazard: sensitivity to Mmax for source MidC-A ............... 8-254

Figure 8.2-7y Topeka $1 \mathrm{~Hz}$ rock hazard: sensitivity to Mmax for source MidC-A .................. 8-255

Figure 8.2-7z Topeka $10 \mathrm{~Hz}$ rock hazard: sensitivity to smoothing options ......................... 8-256

Figure 8.2-7aa Topeka $1 \mathrm{~Hz}$ rock hazard: sensitivity to smoothing options......................... 8-257

Figure 8.2-7bb Topeka $10 \mathrm{~Hz}$ rock hazard: sensitivity to eight realizations for source MidC-A, Case A

Figure 8.2-7cc Topeka $10 \mathrm{~Hz}$ rock hazard: sensitivity to eight realizations for source MidC-A, Case B 
Figure 8.2-7dd Topeka $10 \mathrm{~Hz}$ rock hazard: sensitivity to eight realizations for source MidC-A, Case E

Figure 8.2-7ee Topeka $1 \mathrm{~Hz}$ rock hazard: sensitivity to eight realizations for source MidC-A, Case A .

Figure 8.2-7ff Topeka $1 \mathrm{~Hz}$ rock hazard: sensitivity to eight realizations for source MidCA, Case B

Figure 8.2-7gg Topeka $1 \mathrm{~Hz}$ rock hazard: sensitivity to eight realizations for source MidC-A, Case E

Figure 9.3-1 $1 \mathrm{~Hz}$ sensitivity to rupture orientation at Savannah for the Charleston regional source.

Figure 9.3-2 $10 \mathrm{~Hz}$ sensitivity to rupture orientation at Savannah for the Charleston regional source.

Figure 9.3-3 $1 \mathrm{~Hz}$ sensitivity to seismogenic thickness at Manchester for the Charlevoix area source

Figure 9.3-4 $10 \mathrm{~Hz}$ sensitivity to seismogenic thickness at Manchester for the Charlevoix area source

Figure 9.3-5 $1 \mathrm{~Hz}$ sensitivity to rupture orientation (dip) at Manchester for the Charlevoix area source

Figure 9.3-6 $10 \mathrm{~Hz}$ sensitivity to rupture orientation (dip) at Manchester for the Charlevoix area source

Figure 9.3-7 $1 \mathrm{~Hz}$ sensitivity to seismogenic thickness at Topeka for the Cheraw fault source

Figure 9.3-8 $10 \mathrm{~Hz}$ sensitivity to seismogenic thickness at Topeka for the Cheraw fault source

Figure 9.3-9 $1 \mathrm{~Hz}$ sensitivity to rupture orientation (dip) at Topeka for the Cheraw fault source

Figure 9.3-10 $10 \mathrm{~Hz}$ sensitivity to rupture orientation at Topeka for the Cheraw fault source

Figure 9.3-11 $1 \mathrm{~Hz}$ sensitivity to seismogenic thickness at Jackson for the Commerce area source

Figure 9.3-12 $10 \mathrm{~Hz}$ sensitivity to seismogenic thickness at Jackson for the Commerce area source

Figure 9.3-13 $1 \mathrm{~Hz}$ sensitivity to seismogenic thickness at Jackson for the ERM-N area source

Figure 9.3-14 $10 \mathrm{~Hz}$ sensitivity to seismogenic thickness at Jackson for the ERM-N area source

Figure 9.3-15 $1 \mathrm{~Hz}$ sensitivity to seismogenic thickness at Jackson for the ERM-S area source

Figure 9.3-16 $10 \mathrm{~Hz}$ sensitivity to seismogenic thickness at Jackson for the ERM-S area source

Figure 9.3-17 $1 \mathrm{~Hz}$ sensitivity to seismogenic thickness at Jackson for the Marianna area source

Figure 9.3-18 $10 \mathrm{~Hz}$ sensitivity to seismogenic thickness at Jackson for the Marianna area source 
Figure 9.3-19 $1 \mathrm{~Hz}$ sensitivity to seismogenic thickness at Topeka for the Meers fault and OKA area sources

Figure 9.3-20 $1 \mathrm{~Hz}$ sensitivity to seismogenic thickness at Houston for the Meers fault and OKA area sources.

Figure 9.3-21 $10 \mathrm{~Hz}$ sensitivity to seismogenic thickness at Topeka for the Meers fault and OKA area sources.

Figure 9.3-22 $10 \mathrm{~Hz}$ sensitivity to seismogenic thickness at Houston for the Meers fault and OKA area sources.

Figure 9.3-23 $1 \mathrm{~Hz}$ sensitivity to rupture orientation at Houston for the OKA area source ......9-46

Figure 9.3-24 $10 \mathrm{~Hz}$ sensitivity to rupture orientation at Houston for the OKA area source ....9-47

Figure 9.3-25 $1 \mathrm{~Hz}$ sensitivity to rupture orientation (dip) at Topeka for the OKA area source

Figure 9.3-26 $1 \mathrm{~Hz}$ sensitivity to rupture orientation (dip) at Houston for the OKA area source

Figure 9.3-27 $10 \mathrm{~Hz}$ sensitivity to rupture orientation (dip) at Topeka for the OKA area source

Figure 9.3-28 $10 \mathrm{~Hz}$ sensitivity to rupture orientation (dip) at Houston for the OKA area source

Figure 9.3-29 $1 \mathrm{~Hz}$ sensitivity to rupture orientation (dip) at Topeka for the Meers fault source

Figure 9.3-30 $1 \mathrm{~Hz}$ sensitivity to rupture orientation (dip) at Houston for the Meers fault source

Figure 9.3-31 $10 \mathrm{~Hz}$ sensitivity to rupture orientation (dip) at Topeka for the Meers fault source

Figure 9.3-32 $10 \mathrm{~Hz}$ sensitivity to rupture orientation (dip) at Houston for the Meers fault source

Figure 9.3-33 $1 \mathrm{~Hz}$ sensitivity to seismogenic thickness at Jackson for the NMFS fault sources.

Figure 9.3-34 $10 \mathrm{~Hz}$ sensitivity to seismogenic thickness at Jackson for the NMFS fault sources.

Figure 9.3-35 $1 \mathrm{~Hz}$ sensitivity to seismogenic thickness at Central Illinois for the Wabash Valley area source

Figure 9.3-36 $10 \mathrm{~Hz}$ sensitivity to seismogenic thickness at Central Illinois for the Wabash Valley area source

Figure 9.3-37 $1 \mathrm{~Hz}$ sensitivity to rupture orientation (dip) at Central Illinois for the Wabash Valley area source

Figure 9.3-38 $10 \mathrm{~Hz}$ sensitivity to rupture orientation (dip) at Central Illinois for the Wabash Valley area source

Figure 9.3-39 $1 \mathrm{~Hz}$ sensitivity to fault ruptures vs. point source for the Central Illinois site from the Mid C-A background source.

Figure 9.3-40 $10 \mathrm{~Hz}$ sensitivity to fault ruptures vs. point source for the Central Illinois site from the Mid C-A background source.

Figure 9.4-1 COV $_{\mathrm{MH}}$ from EPRI (1989) team sources vs. ground motion amplitude for seven test sites: PGA (top), $10 \mathrm{~Hz} \mathrm{SA}$ (middle), and $1 \mathrm{~Hz} \mathrm{SA}$ (bottom).... 
Figure 9.4-2 $\mathrm{COV}_{\mathrm{MH}}$ from EPRI (1989) team sources vs. seismic hazard (i.e., annual frequency of exceedance) for seven test sites: PGA (top), $10 \mathrm{~Hz}$ SA (middle), and 1 9-Hz SA (bottom)

Figure 9.4-3 $\mathrm{COV}_{\mathrm{MH}}$ from seismic source experts (PEGASOS project) vs. amplitude (top) and annual frequency (bottom)

Figure 9.4-4 $\mathrm{COV}_{\mathrm{K}}$ and $\mathrm{COV}_{\mathrm{MH}}$ from Charleston alternatives for PGA, plotted vs. PGA amplitude (top) and hazard (bottom). $\mathrm{COV}_{\mathrm{MH}}$ is the total COV of mean hazard; see Table 9.4-2 for other labels for curves.

Figure 9.4-5 $\mathrm{COV}_{\mathrm{K}}$ and $\mathrm{COV}_{\mathrm{MH}}$ from Charleston alternatives for $10 \mathrm{~Hz}$, plotted vs. $10 \mathrm{~Hz}$ amplitude (top) and hazard (bottom). $\mathrm{COV}_{\mathrm{MH}}$ is the total COV of mean hazard; see Table 9.4-2 for other labels for curves.

Figure 9.4-6 $\mathrm{COV}_{\mathrm{K}}$ and $\mathrm{COV}_{\mathrm{MH}}$ from Charleston alternatives for $1 \mathrm{~Hz}$, plotted vs. $1 \mathrm{~Hz}$ amplitude (top) and hazard (bottom). $\mathrm{COV}_{\mathrm{MH}}$ is the total COV of mean hazard; see Table 9.4-2 for other labels for curves.

Figure 9.4-7 $\mathrm{COV}_{\mathrm{K}}$ and $\mathrm{COV}_{\mathrm{MH}}$ of total hazard from New Madrid for $1 \mathrm{~Hz}$, plotted vs. 1 $\mathrm{Hz}$ amplitude (top) and hazard (bottom). $\mathrm{COV}_{\mathrm{MH}}$ is the total COV; see the text for other labels for curves.

Figure 9.4-8 PGA hazard curves for Manchester test site. 9-71

Figure 9.4-9 $\mathrm{COV}_{\mathrm{MH}}$ of PGA hazard at Manchester site from ground motion equation vs. PGA

Figure 9.4-10 COV of PGA hazard at Manchester site from ground motion equation vs. hazard

Figure 9.4-11 COV of $10 \mathrm{~Hz}$ hazard at Manchester site from ground motion equations vs. hazard.

Figure 9.4-12 COV of $1 \mathrm{~Hz}$ hazard at Manchester site from ground motion equations vs. hazard

Figure 9.4-13 $1 \mathrm{~Hz}$ spectral acceleration hazard curves for Manchester test site $9-76$

Figure 9.4-14 $\mathrm{COV}_{\mathrm{MH}}$ of PGA hazard at Chattanooga from ground motion equation vs. hazard

Figure 9.4-15 $\mathrm{COV}_{\mathrm{MH}}$ of $10 \mathrm{~Hz}$ hazard at Chattanooga from ground motion equation vs. hazard

Figure 9.4-16 $\mathrm{COV}_{\mathrm{MH}}$ of $1 \mathrm{~Hz}$ hazard at Chattanooga site from ground motion equation vs. hazard

Figure 9.4-17 PGA hazard curves for Savannah test site.

Figure 9.4-18 $\mathrm{COV}_{\mathrm{MH}}$ of PGA hazard at Savannah site from ground motion equations vs. hazard

Figure 9.4-19 $\mathrm{COV}_{\mathrm{MH}}$ of $10 \mathrm{~Hz}$ hazard at Savannah site from ground motion equations vs. hazard....

Figure 9.4-20 $\mathrm{COV}_{\mathrm{MH}}$ of $1 \mathrm{~Hz}$ hazard at Savannah site from ground motion equations vs. hazard

Figure 9.4-21 PGA hazard curves for Columbia site

Figure 9.4-22 $\mathrm{COV}_{\mathrm{MH}}$ of PGA hazard at Columbia from ground motion equations vs. hazard 
Figure 9.4-23 $\mathrm{COV}_{\mathrm{MH}}$ of $10 \mathrm{~Hz}$ hazard at Columbia from ground motion equations vs. hazard

Figure 9.4-24 $\mathrm{COV}_{\mathrm{MH}}$ of $1 \mathrm{~Hz}$ hazard at Columbia from ground motion equations vs. hazard

Figure 9.4-25 $\mathrm{COV}_{\mathrm{MH}}$ of PGA hazard at Chattanooga (New Madrid only) vs. hazard ............9-88

Figure 9.4-26 $\mathrm{COV}_{\mathrm{MH}}$ of $10 \mathrm{~Hz}$ hazard at Chattanooga (New Madrid only) vs. hazard............9-89

Figure 9.4-27 $\mathrm{COV}_{\mathrm{MH}}$ of $1 \mathrm{~Hz}$ hazard at Chattanooga (New Madrid only) vs. hazard.

Figure 9.4-28 $\mathrm{COV}_{\mathrm{MH}}$ for PGA and $1 \mathrm{~Hz}$ SA vs. ground motion amplitude resulting from alternative ground motion experts, PEGASOS project.

Figure 9.4-29 $\mathrm{COV}_{\mathrm{MH}}$ for PGA and $1 \mathrm{~Hz}$ SA vs. mean hazard from alternative ground motion experts, PEGASOS project

Figure 9.4-30 $\mathrm{COV}_{\mathrm{HAZ}}$ from ground motion equations vs. mean hazard for Chattanooga .......9-93

Figure 9.4-31 $\mathrm{COV}_{\mathrm{MH}}$ from ground motion equations vs. mean hazard for Central Illinois ......9-94

Figure 9.4-32 $\mathrm{COV}_{\mathrm{MH}}$ from soil experts vs. PGA and $1 \mathrm{~Hz}$ SA, PEGASOS project ................9-95

Figure 9.4-33 $\mathrm{COV}_{\mathrm{MH}}$ from soil experts vs. mean hazard for PGA and $1 \mathrm{~Hz} \mathrm{SA}$, PEGASOS project.

Figure 9.4-34 $\mathrm{COV}_{\mathrm{MH}}$ resulting from site response models vs. mean hazard for four sites, $1 \mathrm{~Hz}$ (top) and $10 \mathrm{~Hz}$ (bottom).

Figure 11-1 Geologic time scale (Walker and Geissman, 2009)

Figure A-1 GEBCO elevation data for the CEUS study area (BODC, 2009).

Figure A-2 CEUS SSC independent earthquake catalog A-24

Figure A-3 Bedrock geology and extended crust after Kanter (1994).....

Figure A-4 Crustal provinces after Rohs and Van Schmus (2007) A-28

Figure A-5 Geologic map of North America A-31

Figure A-6 Locations of geologic cross sections in the CEUS A-33

Figure A-7 Precambrian crustal boundary after Van Schmus et al. (1996) A-35

Figure A-8a Precambrian geology and features after Reed (1993) A-37

Figure A-8b Explanation of Precambrian geology and features after Reed (1993) ..... A-38

Figure A-9 Precambrian provinces after Van Schmus et al. (2007). A-40

Figure A-10 Precambrian units after Whitmeyer and Karlstrom (2007) A-42

Figure A-11 Surficial materials in the conterminous United States after Soller et al. (2009)

Figure A-12 Basement and sediment thickness in the USGS Crustal Database for North America. Symbol size represents overlying sediment thickness $(\mathrm{km})$; symbol color represents basement thickness $(\mathrm{km})$.

Figure A-13 Top of basement P-wave seismic velocity in the USGS Crustal Database for North America

Figure A-14 Sediment thickness for North America and neighboring regions

Figure A-15 Physiographic divisions of the conterminous United States after Fenneman and Johnson (1946)

Figure A-16 CEUS SSC free-air gravity anomaly grid. Shaded relief with 315-degree azimuth and 30-degree inclination applied. 
Figure A-17 CEUS SSC free-air gravity anomaly grid. Shaded relief with 180-degree azimuth and 30-degree inclination applied.

Figure A-18 CEUS SSC complete Bouguer gravity anomaly grid with free-air gravity anomaly in marine areas. Shaded relief with 315-degree azimuth and 30-degree inclination applied.

Figure A-19 CEUS SSC complete Bouguer gravity anomaly grid with free-air gravity anomaly in marine areas. Shaded relief with 180-degree azimuth and 30-degree inclination applied.

Figure A-20 CEUS SSC residual isostatic gravity anomaly grid. Shaded relief with 315degree azimuth and 30-degree inclination applied.

Figure A-21 CEUS SSC residual isostatic gravity anomaly grid Shaded relief with 180degree azimuth and 30-degree inclination applied.

Figure A-22 CEUS SSC regional isostatic gravity anomaly grid.... A-60

Figure A-23 CEUS SSC first vertical derivative of residual isostatic gravity anomaly grid...... A-61

Figure A-24 CEUS SSC first vertical derivative of Bouguer gravity anomaly grid with free-air anomaly in marine areas

Figure A-25 CEUS SSC complete Bouguer (with marine free-air) gravity anomaly grid low pass filtered at $240 \mathrm{~km}$..

Figure A-26 CEUS SSC complete Bouguer (with marine free-air) gravity anomaly grid high pass filtered at $240 \mathrm{~km}$. Shaded relief with 315-degree azimuth and 30-degree inclination applied.

Figure A-27 CEUS SSC complete Bouguer (with marine free-air) gravity anomaly grid high pass filtered at $240 \mathrm{~km}$. Shaded relief with 180-degree azimuth and 30-degree inclination applied.

Figure A-28 CEUS SSC complete Bouguer (with marine free-air) gravity anomaly grid high pass filtered at $120 \mathrm{~km}$. Shaded relief with 315-degree azimuth and 30-degree inclination applied.

Figure A-29 CEUS SSC complete Bouguer (with marine free-air) gravity anomaly grid high pass filtered at $120 \mathrm{~km}$. Shaded relief with 180-degree azimuth and 30-degree inclination applied.

Figure A-30 CEUS SSC complete Bouguer (with marine free-air) gravity anomaly grid upward continued to $40 \mathrm{~km}$

Figure A-31 CEUS SSC complete Bouguer (with marine free-air) gravity anomaly grid minus the complete Bouguer (with marine free-air) gravity anomaly upward continued to $40 \mathrm{~km}$. Shaded relief with 315-degree azimuth and 30-degree inclination applied.

Figure A-32 CEUS SSC complete Bouguer (with marine free-air) gravity anomaly grid minus the complete Bouguer (with marine free-air) gravity anomaly upward continued to $40 \mathrm{~km}$. Shaded relief with 180-degree azimuth and 30-degree inclination applied.

Figure A-33 CEUS SSC complete Bouguer (with marine free-air) gravity anomaly grid upward continued to $100 \mathrm{~km}$

Figure A-34 CEUS SSC complete Bouguer (with marine free-air) gravity anomaly grid minus the complete Bouguer (with marine free-air) gravity anomaly anomaly 
upward continued to $100 \mathrm{~km}$. Shaded relief with 315-degree azimuth and 30-degree inclination applied.

Figure A-35 CEUS SSC complete Bouguer (with marine free-air) gravity anomaly grid minus the complete Bouguer (with marine free-air) gravity anomaly upward continued to $100 \mathrm{~km}$. Shaded relief with 180-degree azimuth and 30-degree inclination applied.

Figure A-36 CEUS SSC horizontal derivative of residual isostatic gravity anomaly grid ....... A-74

Figure A-37 CEUS SSC horizontal derivative of first vertical derivative of residual isostatic gravity anomaly grid

Figure A-38 Corrected heat flow values from the SMU Geothermal Laboratory Regional Heat Flow Database (2008)

Figure A-39 CEUS SSC total intensity magnetic anomaly grid (Ravat et al., 2009). Shaded relief with 315-degree azimuth and 30-degree inclination applied.

Figure A-40 CEUS SSC total intensity magnetic anomaly grid (Ravat et al., 2009). Shaded relief with 180-degree azimuth and 30-degree inclination applied.

Figure A-41 CEUS SSC differentially reduced to pole magnetic anomaly grid (Ravat, 2009). Shaded relief with 315-degree azimuth and 30-degree inclination applied.

Figure A-42 CEUS SSC differentially reduced to pole magnetic anomaly grid (Ravat, 2009). Shaded relief with 180-degree azimuth and 30-degree inclination applied.

Figure A-43 CEUS SSC tilt derivative of differentially reduced to pole magnetic anomaly grid (degrees) (Ravat, 2009)

Figure A-44 CEUS SSC horizontal derivative of tilt derivative of differentially reduced to pole magnetic anomaly grid (radians) (Ravat, 2009)

Figure A-45 CEUS SSC tilt derivative of differentially reduced to pole magnetic anomaly grid (Ravat, 2009)

Figure A-46 CEUS SSC amplitude of analytic signal magnetic anomaly grid (Ravat, 2009)

Figure A-47 CEUS SSC paleoliquefaction database.

Figure A-48 CEUS SSC compilation of seismic reflection and seismic refraction lines.....

Figure A-49 USGS National Seismic Hazard Maps (Petersen et al., 2008)

Figure A-50 USGS NSHM ground motion hazard at spectral acceleration of $1 \mathrm{hz}$ with $2 \%$ probability of exceedance in 50 years (Petersen et al., 2008)

Figure A-51 USGS NSHM ground motion hazard at spectral acceleration of $1 \mathrm{hz}$ with $5 \%$ probability of exceedance in 50 years (Petersen et al., 2008) ....

Figure A-52 USGS NSHM ground motion hazard at spectral acceleration of $1 \mathrm{hz}$ with $10 \%$ probability of exceedance in 50 years (Petersen et al., 2008)

Figure A-53 USGS NSHM ground motion hazard at spectral acceleration of $3 \mathrm{hz}$ with $2 \%$ probability of exceedance in 50 years (Petersen et al., 2008)

Figure A-54 USGS NSHM ground motion hazard at spectral acceleration of $3 \mathrm{hz}$ with $5 \%$ probability of exceedance in 50 years (Petersen et al., 2008)

Figure A-55 USGS NSHM ground motion hazard at spectral acceleration of $3 \mathrm{hz}$ with $10 \%$ probability of exceedance in 50 years (Petersen et al., 2008) ...

Figure A-56 USGS NSHM ground motion hazard at spectral acceleration of $5 \mathrm{hz}$ with $2 \%$ probability of exceedance in 50 years (Petersen et al., 2008) 
Figure A-57 USGS NSHM ground motion hazard at spectral acceleration of $5 \mathrm{hz}$ with $5 \%$ probability of exceedance in 50 years (Petersen et al., 2008)

Figure A-58 USGS NSHM ground motion hazard at spectral acceleration of $5 \mathrm{hz}$ with $10 \%$ probability of exceedance in 50 years (Petersen et al., 2008).

Figure A-59 USGS NSHM peak ground acceleration with $2 \%$ probability of exceedance in 50 years (Petersen et al., 2008)

Figure A-60 USGS NSHM peak ground acceleration with $5 \%$ probability of exceedance in 50 years (Petersen et al., 2008)

Figure A-61 USGS NSHM peak ground acceleration with $10 \%$ probability of exceedance in 50 years (Petersen et al., 2008)

Figure A-62 Deformation of the North American Plate interior using GPS station data (Calais et al., 2006) A-107

Figure A-63 Stress measurement update for the CEUS (Hurd, 2010) ............................ A-110

Figure A-64 CEUS SSC Project study area boundary.

Figure A-65 USGS Quaternary fault and fold database (USGS, 2006) A-114

Figure A-66 Quaternary features compilation for the CEUS (Crone and Wheeler, 2000; Wheeler, 2005; USGS, 2010)

Figure A-67 CEUS Mesozoic rift basins after Benson (1992)....

Figure A-68 CEUS Mesozoic rift basins after Dennis et al. (2004) A-120

Figure A-69 CEUS Mesozoic rift basins after Schlische (1993)..... A-122

Figure A-70 CEUS Mesozoic rift basins after Withjack et al. (1998). A-124

Figure A-71 RLME zones for the CEUS A-126

Figure A-72 Mesozoic and non-Mesozoic zones for the CEUS, wide interpretation A-128

Figure A-73 Mesozoic and non-Mesozoic zones for the CEUS, narrow interpretation A-129

Figure A-74 CEUS seismotectonic zones model A. A-130

Figure A-75 CEUS seismotectonic zones model $B$ A-131

Figure A-76 CEUS seismotectonic zones model C A-132

Figure A-77 CEUS seismotectonic zones model D A-133

Figure E-1 Map of CEUS showing locations of regional data sets included in the CEUS SSC Project paleoliquefaction database, including New Madrid seismic zone and surrounding region; Marianna, Arkansas, area; St. Louis region; Wabash Valley seismic zone and surrounding region; Arkansas-Louisiana-Mississippi region; Charleston seismic zone; Atlantic Coastal region and the Central Virginia seismic zone; Newburyport, Massachusetts, and surrounding region; and Charlevoix seismic zone and surrounding region.

Figure E-2 Diagram illustrating size parameters of liquefaction features, including sand blow thickness, width, and length; dike width; and sill thickness, as well as some of the diagnostic characteristics of these features.

Figure E-3 Diagram illustrating sampling strategy for dating of liquefaction features as well as age data, such as $14 \mathrm{C}$ maximum and $14 \mathrm{C}$ minimum, used to calculate preferred age estimates and related uncertainties of liquefaction features.

Figure E-4 GIS map of New Madrid seismic zone and surrounding region showing portions of rivers searched for earthquake-induced liquefaction features by $M$. 
Tuttle, R. Van Arsdale, and J. Vaughn and collaborators (see explanation); information contributed for this report. Map projection is USA Contiguous Albers Equal Area Conic, North America Datum 1983.

Figure E-5 GIS map of New Madrid seismic zone and surrounding region showing locations of liquefaction features for which there are and are not radiocarbon data. Map projection is USA Contiguous Albers Equal Area Conic, North America Datum 1983.

Figure E-6 GIS map of New Madrid seismic zone and surrounding region showing locations of liquefaction features that are thought to be historical or prehistoric in age or whose ages are poorly constrained. Map projection is USA Contiguous Albers Equal Area Conic, North America Datum 1983.

Figure E-7 GIS map of New Madrid seismic zone and surrounding region showing preferred age estimates of liquefaction features; features whose ages are poorly constrained are excluded. Map projection is USA Contiguous Albers Equal Area Conic, North America Datum 1983.

Figure E-8 GIS map of New Madrid seismic zone and surrounding region showing measured thicknesses of sand blows. Map projection is USA Contiguous Albers Equal Area Conic, North America Datum 1983.

Figure E-9 GIS map of New Madrid seismic zone and surrounding region showing preferred age estimates and measured thicknesses of sand blows. Map projection is USA Contiguous Albers Equal Area Conic, North America Datum 1983.

Figure E-10 GIS map of New Madrid seismic zone and surrounding region showing measured widths of sand dikes. Map projection is USA Contiguous Albers Equal Area Conic, North America Datum 1983.

Figure E-11 GIS map of New Madrid seismic zone and surrounding region showing preferred age estimates and measured widths of sand dikes. Map projection is USA Contiguous Albers Equal Area Conic, North America Datum 1983.

Figure E-12 GIS map of New Madrid seismic zone and surrounding region illustrating preferred age estimates and measured thicknesses of sand blows as well as preferred age estimates and measured widths of sand dikes for sites where sand blows do not occur. Map projection is USA Contiguous Albers Equal Area Conic, North America Datum 1983.

Figure E-13 GIS map of Marianna, Arkansas, area showing seismicity and locations of paleoliquefaction features relative to mapped traces of Eastern Reelfoot rift margin fault, White River fault zone, Big Creek fault zone, Marianna escarpment, and Daytona Beach lineament. Map projection is USA Contiguous Albers Equal Area Conic, North America Datum 1983.

Figure E-14 (A) Trench log and (B) ground-penetrating radar profile, showing vertical sections of sand blows and sand dikes at Daytona Beach SE2 site along the Daytona Beach lineament southwest of Marianna, Arkansas. Vertical scale of GPR profile is exaggerated (modified from Al-Shukri et al., 2009).

Figure E-15 GIS map of Marianna, Arkansas, area showing locations of liquefaction features for which there are and are not radiocarbon data. Map projection is USA Contiguous Albers Equal Area Conic, North America Datum 1983.

Figure E-16 GIS map of Marianna, Arkansas, area showing locations of liquefaction features that are thought to be historical or prehistoric in age or whose ages are poorly constrained. To date, no liquefaction features thought to have formed during 
1811-1812 earthquakes have been found in area. Map projection is USA

Contiguous Albers Equal Area Conic, North America Datum 1983.

Figure E-17 GIS map of Marianna, Arkansas, area showing preferred age estimates of liquefaction features; features whose ages are poorly constrained are excluded. Map projection is USA Contiguous Albers Equal Area Conic, North America Datum 1983.

Figure E-18 GIS map of Marianna, Arkansas, area showing measured thicknesses of sand blows. Map projection is USA Contiguous Albers Equal Area Conic, North America Datum 1983.

Figure E-19 GIS map of Marianna, Arkansas, area showing preferred age estimates and measured thicknesses of sand blows. Map projection is USA Contiguous Albers Equal Area Conic, North America Datum 1983.

Figure E-20 GIS map of Marianna, Arkansas, area showing measured widths of sand dikes. Map projection is USA Contiguous Albers Equal Area Conic, North America Datum 1983.

Figure E-21 GIS map of Marianna, Arkansas, area showing preferred age estimates and measured widths of sand dikes. Map projection is USA Contiguous Albers Equal Area Conic, North America Datum 1983.

Figure E-22 GIS map of St. Louis, Missouri, region showing seismicity and portions of rivers searched for earthquake-induced liquefaction features by Tuttle and collaborators; information contributed for this report. Map projection is USA Contiguous Albers Equal Area Conic, North America Datum 1983.

Figure E-23 GIS map of St. Louis, Missouri, region showing locations of liquefaction features, including several soft-sediment deformation structures, for which there are and are not radiocarbon data. Map projection is USA Contiguous Albers Equal Area Conic, North America Datum 1983.

Figure E-24 GIS map of St. Louis, Missouri, region showing locations of liquefaction features that are thought to be historical or prehistoric in age or whose ages are poorly constrained. Map projection is USA Contiguous Albers Equal Area Conic, North America Datum 1983.

Figure E-25 GIS map of St. Louis, Missouri, region showing preferred age estimates of liquefaction features; features whose ages are poorly constrained, including several that are prehistoric in age, are not shown. Map projection is USA Contiguous Albers Equal Area Conic, North America Datum 1983.

Figure E-26 GIS map of St. Louis, Missouri, region showing measured thicknesses of sand blows at similar scale as used in Figure E-8 of sand blows in New Madrid seismic zone. Note that few sand blows have been found in St. Louis region. Map projection is USA Contiguous Albers Equal Area Conic, North America Datum 1983.

Figure E-27 GIS map of St. Louis, Missouri, region showing preferred age estimates and measured thicknesses of sand blows. Map projection is USA Contiguous Albers Equal Area Conic, North America Datum 1983.

Figure E-28 GIS map of St. Louis, Missouri, region showing measured widths of sand dikes at similar scale as that used in Figure E-10 for sand dikes in New Madrid seismic zone. Map projection is USA Contiguous Albers Equal Area Conic, North America Datum 1983. 
Figure E-29 GIS map of St. Louis, Missouri, region showing measured widths of sand dikes at similar scale as that used in Figures E-42 and E-48 for sand dikes in the Newburyport and Charlevoix regions, respectively. Map projection is USA

Contiguous Albers Equal Area Conic, North America Datum 1983. E-96

Figure E-30 GIS map of St. Louis, Missouri, region showing preferred age estimates and measured widths of sand dikes. Map projection is USA Contiguous Albers Equal Area Conic, North America Datum 1983.

Figure E-31 GIS map of Wabash Valley seismic zone and surrounding region showing portions of rivers searched for earthquake-induced liquefaction features (digitized from McNulty and Obermeier, 1999). Map projection is USA Contiguous Albers Equal Area Conic, North America Datum 1983.

Figure E-32 GIS map of Wabash Valley seismic zone and surrounding region showing measured widths of sand dikes at similar scale as that used in Figures E-10 and E11 for sand dikes in New Madrid seismic zone. Map projection is USA Contiguous Albers Equal Area Conic, North America Datum 1983.

Figure E-33 GIS map of Wabash Valley region of Indiana and Illinois showing preferred age estimates and paleoearthquake interpretation. Map projection is USA Contiguous Albers Equal Area Conic, North America Datum 1983.

Figure E-34 GIS map of Arkansas-Louisiana-Mississippi (ALM) region showing paleoliquefaction study locations. Map projection is USA Contiguous Albers Equal Area Conic, North America Datum 1983.

Figure E-35 GIS map of Charleston, South Carolina, region showing locations of paleoliquefaction features for which there are and are not radiocarbon dates. Map projection is USA Contiguous Albers Equal Area Conic, North America Datum 1983.

Figure E-36 GIS map of Charleston, South Carolina, region showing locations of historical and prehistoric liquefaction features. Map projection is USA Contiguous Albers Equal Area Conic, North America Datum 1983.

Figure E-37 Map of Atlantic coast region showing areas searched for paleoliquefaction features by Gelinas et al. (1998) and Amick, Gelinas, et al. (1990). Rectangles indicate 7.5-minute quadrangles in which sites were investigated for presence of paleoliquefaction features. The number of sites investigated is shown within that quadrangle, if known. Orange and yellow indicate quadrangles in which paleoliquefaction features were recognized.

Figure E-38 Map of Central Virginia seismic zone region showing portions of rivers searched for earthquake-induced liquefaction features by Obermeier and McNulty (1998).

Figure E-39 GIS map of Newburyport, Massachusetts, and surrounding region showing seismicity and portions of rivers searched for earthquake-induced liquefaction features (Gelinas et al., 1998; Tuttle, 2007, 2009). Solid black line crossing map represents Massachusetts-New Hampshire border. Map projection is USA Contiguous Albers Equal Area Conic, North America Datum 1983.

Figure E-40 GIS map of Newburyport, Massachusetts, and surrounding region showing locations of liquefaction features for which there are and are not radiocarbon dates. Map projection is USA Contiguous Albers Equal Area Conic, North America Datum 1983. 
Figure E-41 GIS map of Newburyport, Massachusetts, and surrounding region showing locations of liquefaction features that are thought to be historical or prehistoric in age or whose ages are poorly constrained. Map projection is USA Contiguous Albers Equal Area Conic, North America Datum 1983.

Figure E-42 GIS map of Newburyport, Massachusetts, and surrounding region showing measured widths of sand dikes. Map projection is USA Contiguous Albers Equal Area Conic, North America Datum 1983.

Figure E-43 GIS map of Newburyport, Massachusetts, and surrounding region showing preferred age estimates and measured widths of sand dikes. Map projection is USA Contiguous Albers Equal Area Conic, North America Datum 1983.

Figure E-44 Map of Charlevoix seismic zone and adjacent St. Lawrence Lowlands showing mapped faults and portions of rivers along which reconnaissance and searches for earthquake-induced liquefaction features were performed. Charlevoix seismic zone is defined by concentration of earthquakes and locations of historical earthquakes northeast of Quebec City. Devonian impact structure in vicinity of Charlevoix seismic zone is outlined by black dashed line. Taconic thrust faults are indicated by solid black lines with sawteeth on upper plate; lapetan rift faults are shown by solid black lines with hachure marks on downthrown side (modified from Tuttle and Atkinson, 2010).

Figure E-45 GIS map of Charlevoix seismic zone and surrounding region showing locations of liquefaction features, including several soft-sediment deformation structures, for which there are and are not radiocarbon data. Note the location of 1988 M 5.9 Saguenay earthquake northwest of the Charlevoix seismic zone. Map projection is USA Contiguous Albers Equal Area Conic, North America Datum 1983.

Figure E-46 GIS map of Charlevoix seismic zone and surrounding region showing locations of liquefaction features that are modern, historical, or prehistoric in age, or whose ages are poorly constrained. Map projection is USA Contiguous Albers Equal Area Conic, North America Datum 1983.

Figure E-47 GIS map of Charlevoix seismic zone and surrounding region showing preferred age estimates of liquefaction features; features whose ages are poorly constrained are excluded. Map projection is USA Contiguous Albers Equal Area Conic, North America Datum 1983.

Figure E-48 GIS map of Charlevoix seismic zone and surrounding region showing measured widths of sand dikes. Map projection is USA Contiguous Albers Equal Area Conic, North America Datum 1983.

Figure E-49 GIS map of Charlevoix seismic zone and surrounding region showing preferred age estimates and measured widths of sand dikes. Map projection is USA Contiguous Albers Equal Area Conic, North America Datum 1983.

Figure E-50 Photograph of moderate-sized sand blow (12 m long, $7 \mathrm{~m}$ wide, and $14 \mathrm{~cm}$ thick) that formed about $40 \mathrm{~km}$ from epicenter of 2001 M 7.7 Bhuj, India, earthquake (from Tuttle, Hengesh, et al., 2002), combined with schematic vertical section illustrating structural and stratigraphic relations of sand blow, sand dike, and source layer (modified from Sims and Garvin, 1995).

Figure E-51 Tree trunks buried and killed by sand blows, vented during 1811-1812 New Madrid earthquakes (from Fuller, 1912)...... 
Figure E-52 Large sand-blow crater that formed during 2002 M 7.7 Bhuj, India, earthquake. Backpack for scale. Photograph: M. Tuttle (2001)

Figure E-53 Sand-blow crater that formed during 1886 Charleston, South Carolina, earthquake. Photograph: J.K. Hillers (from USGS Photograph Library).

Figure E-54 Photograph of sand blow and related sand dikes exposed in trench wall and floor in New Madrid seismic zone. Buried soil horizon is displaced downward approximately $1 \mathrm{~m}$ across two dikes. Clasts of soil horizon occur within dikes and overlying sand blow. Degree of soil development above and within sand blow suggests that it is at least several hundred years old and formed prior to 1811-1812 New Madrid earthquakes. Organic sample (location marked by red flag) from crater fill will provide close minimum age constraint for formation of sand blow. For scale, each colored intervals on shovel handle represents $10 \mathrm{~cm}$. Photograph: M. Tuttle...... E-121

Figure E-55 Sand dikes, ranging up to $35 \mathrm{~cm}$ wide, originate in pebbly sand layer and intrude overlying diamicton, These features were exposed in cutbank along Cahokia Creek about 25 km northeast of downtown St. Louis (from Tuttle, 2000).

Figure E-56 Photograph of small diapirs of medium sand intruding base of overlying deposit of interbedded clayey silt and very fine sand, and clasts of clayey silt in underlying medium sand, observed along Ouelle River in Charlevoix seismic zone. Sand diapirs and clasts probably formed during basal erosion and foundering of clayey silt due to liquefaction of the underlying sandy deposit. Red portion of shovel handle represents $10 \mathrm{~cm}$ (modified from Tuttle and Atkinson, 2010).

Figures E-57 (A) Load cast formed in laminated sediments of Van Norman Lake during 1952 Kern County, California, earthquake. Photograph: J. Sims (from Sims, 1975).

(B) Load cast, pseudonodules, and related folds formed in laminated sediment exposed along Malbaie River in Charlevoix seismic zone. Sand dikes crosscutting these same laminated sediments occur at a nearby site. For scale, each painted interval of the shovel handle represents $10 \mathrm{~cm}$ (modified from Tuttle and Atkinson, 2010).

Figure E-58 Log of sand blow and uppermost portions of related sand dikes exposed in trench wall at Dodd site in New Madrid seismic zone. Sand dikes were also observed in opposite wall and trench floor. Sand blow buries pre-event A horizon, and a subsequent $A$ horizon has developed in top of sand blow. Radiocarbon dating of samples collected above and below sand blow brackets its age between 490 and $660 \mathrm{yr}$ BP. Artifact assemblage indicates that sand blow formed during late Mississippian (300-550 yr BP or AD 1400-1670) (modified from Tuttle, Collier, et al., 1999).

Figures E-59 (A) Photograph of earthquake-induced liquefaction features found in association with cultural horizon and pit exposed in trench wall near Blytheville, Arkansas, in New Madrid seismic zone. Photograph: M. Tuttle. (B) Trench log of features shown in (A). Sand dike formed in thick Native American occupation horizon containing artifacts of early Mississippian cultural period (950-1,150 yr BP). Cultural pit dug into top of sand dike contains artifacts and charcoal used to constrain minimum age of liquefaction features (modified from Tuttle and Schweig, 1995).

Figure E-60 In situ tree trunks such as this one buried and killed by sand blow in New Madrid seismic zone offer opportunity to date paleoearthquakes to the year and season of occurrence. Photograph: M. Tuttle. 
Figure E-61 Portion of dendrocalibration curve illustrating conversion of radiocarbon age to calibrated date in calendar years. In example, 2-sigma radiocarbon age of 2,280$2,520 \mathrm{BP}$ is converted to calibrated date of 770-380 BC (from Tuttle, 1999).

Figure E-62 Empirical relation developed between A horizon thickness of sand blows and years of soil development in New Madrid region. Horizontal bars reflect uncertainties in age estimates of liquefaction features; diamonds mark midpoints of possible age ranges (from Tuttle et al., 2000).

Figure E-63 Diagram illustrating earthquake chronology for New Madrid seismic zone for past 5,500 years based on dating and correlation of liquefaction features at sites (listed at top) across region from north to south. Vertical bars represent age estimates of individual sand blows, and horizontal bars represent event times of $138 \mathrm{yr} \mathrm{BP}$ (AD 1811-1812); $500 \mathrm{yr} \mathrm{BP} \pm 150 \mathrm{yr} ; 1,050 \mathrm{yr} \mathrm{BP} \pm 100 \mathrm{yr}$; and 4,300 yr BP \pm 200 yr (modified from Tuttle, Schweig, et al., 2002; Tuttle et al., 2005).

Figure E-64 Diagram illustrating earthquake chronology for New Madrid seismic zone for past 2,000 years, similar to upper portion of diagram shown in Figure E-63. As in Figure E-63, vertical bars represent age estimates of individual sand blows, and horizontal bars represent event times. Analysis performed during CEUS SSC Project derived two possible uncertainty ranges for timing of paleoearthquakes, illustrated by the darker and lighter portions of the colored horizontal bars, respectively: $503 \mathrm{yr} \mathrm{BP} \pm 8 \mathrm{yr}$ or $465 \mathrm{yr} \mathrm{BP} \pm 65 \mathrm{yr}$, and 1,110 yr BP $\pm 40 \mathrm{yr}$ or 1055 $\pm 95 \mathrm{yr}$ (modified from Tuttle, Schweig, et al., 2002).

Figure E-65 Maps showing spatial distributions and sizes of sand blows and sand dikes attributed to 500 and 1,050 yr BP events. Locations and sizes of liquefaction features that formed during AD 1811-1812 (138 yr BP) New Madrid earthquake sequence shown for comparison (modified from Tuttle, Schweig, et al., 2002).

Figure E-66 Liquefaction fields for 138 yr BP (AD 1811-1812); 500 yr BP (AD 1450); and 1,050 yr BP (AD 900) events as interpreted from spatial distribution and stratigraphy of sand blows (modified from Tuttle, Schweig, et al., 2002). Ellipses define areas where similar-age sand blows have been mapped. Overlapping ellipses indicate areas where sand blows are composed of multiple units that formed during sequence of earthquakes. Dashed ellipse outlines area where historical sand blows are composed of four depositional units. Magnitudes of earthquakes in $500 \mathrm{yr}$ BP and 1,050 yr BP are inferred from comparison with 18111812 liquefaction fields. Magnitude estimates of December (D), January (J), and February $(F)$ main shocks and large aftershocks taken from several sources; rupture scenario from Johnston and Schweig (1996; modified from Tuttle, Schweig,

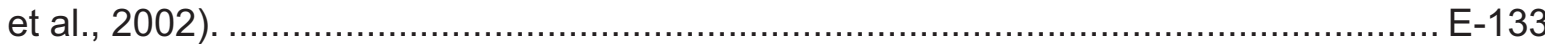

Figure E-67 Empirical relation between earthquake magnitude and epicentral distance to farthest known sand blows induced by instrumentally recorded earthquakes (modified from Castilla and Audemard, 2007).

Figure E-68 Distances to farthest known liquefaction features indicate that 500 and 1,050 yr BP New Madrid events were at least of M 6.7 and 6.9, respectively, when plotted on Ambraseys (1988) relation between earthquake magnitude and epicentral distance to farthest surface expression of liquefaction. Similarity in size distribution of historical and prehistoric sand blows, however, suggests that paleoearthquakes were comparable in magnitude to 1811-1812 events or $\mathrm{M} \sim 7.6$ (modified from Tuttle, 2001).

Figure H-1-1 Region covered by the CEUS SSC model. $\mathrm{H}-44$ 
Figure H-2-1 Master logic tree for the CEUS SSC model ......................................... H-45

Figure H-3-1 Logic tree for the Mmax zones branch of the master logic tree ....................... H-46

Figure H-3-2 Mesozoic extended (MESE-W) and non-extended (NMESE-W) Mmax zones for the "wide" interpretation...

Figure H-3-3 Mesozoic extended (MESE-N) and non-extended (NMESE-N) Mmax zones for the "narrow" interpretation...........................................................................

Figure $\mathrm{H}-4-1$ (a) Logic tree for the seismotectonic zones branch of the master logic tree....... H-49

Figure $\mathrm{H}-4-1$ (b) Logic tree for the seismotectonic zones branch of the master logic tree....... $\mathrm{H}-50$

Figure H-4-2 Seismotectonic zones shown in the case where the Rough Creek Graben is not part of the Reelfoot Rift (RR) and the Paleozoic Extended zone is narrow (PEZ-N)

Figure H-4-3 Seismotectonic zones shown in the case where the Rough Creek Graben is part of the Reelfoot Rift (RR-RCG) and the Paleozoic Extended zone is narrow (PEZ-N)

Figure H-4-4 Seismotectonic zones shown in the case where the Rough Creek Graben is not part of the Reelfoot Rift (RR) and the Paleozoic Extended zone is wide (PEZW).

Figure H-4-5 Seismotectonic zones shown in the case where the Rough Creek Graben is part of the Reelfoot Rift (RR-RCG) and the Paleozoic Extended zone is wide

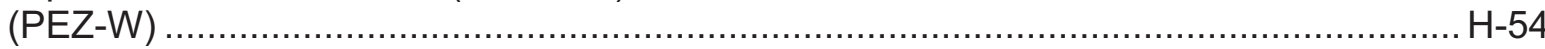

Figure H-5-1 Logic tree for the RLME source branch of the master logic tree..................... H-55

Figure H-5-2 Location of RLME sources in the CEUS SSC model................................ H-56

Figure H-5.1-1 Logic tree for Charlevoix RLME source .............................................. H-57

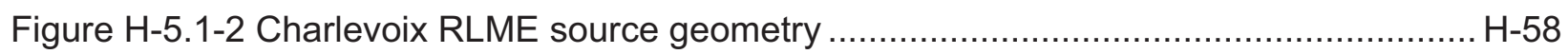

Figure H-5.2-1(a) Logic tree for Charleston RLME source ....................................... H-59

Figure $\mathrm{H}-5.2-1$ (b) Logic tree for Charleston RLME source ....................................... H-60

Figure H-5.2-2 Charleston RLME alternative source geometries .................................... H-61

Figure H-5.3-1 Logic tree for Cheraw RLME source ................................................. H-62

Figure H-5.3-2 Cheraw RLME source geometry................................................... $\mathrm{H}-63$

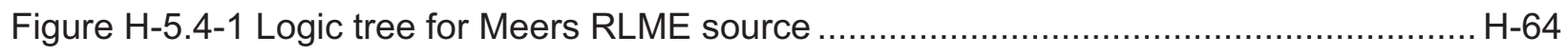

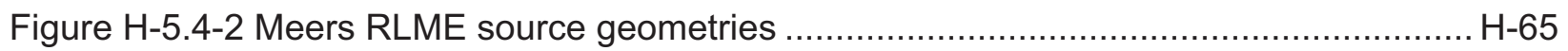

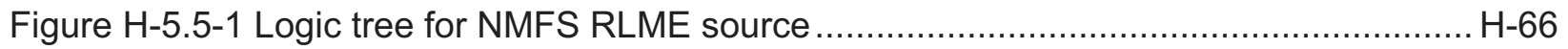

Figure H-5.5-2 New Madrid South (NMS) fault alternative RMLE source geometries:

Blytheville Arch-Bootheel Lineament (BA-BL) and Blytheville Arch-Blytheville fault zone (BA-BFZ) ....

Figure H-5.5-3 New Madrid North (NMN) fault alternative RMLE source geometries: New Madrid North (NMN_S) and New Madrid North plus extension (NMN_L).....

Figure H-5.5-4 Reelfoot Thrust (RFT) fault alternative RMLE source geometries:

Reelfoot thrust (RFT_S) and Reelfoot thrust plus extensions (RFT_L) ........................ H-69

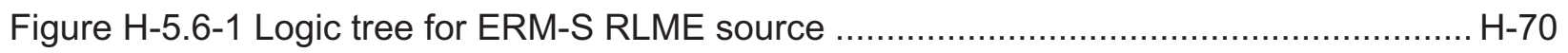

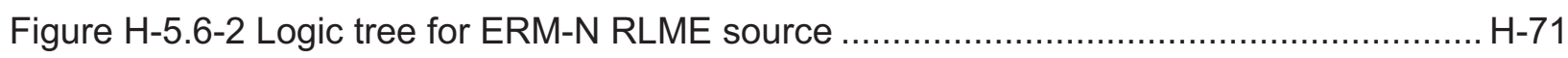

Figure H-5.6-3 ERM-S RLME source geometries............................................... H-72

lxiv 


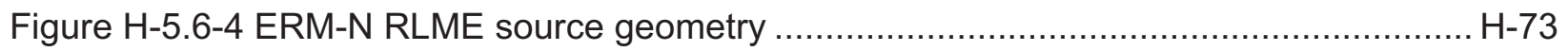

Figure H-5.7-1 Logic tree for Marianna RLME source ............................................. H-74

Figure H-5.7-2 Marianna RLME source geometry ................................................. H-75

Figure H-5.8-1 Logic tree for Commerce Fault Zone RLME source ................................ H-76

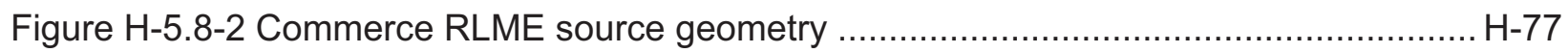

Figure H-5.9-1 Logic tree for Wabash Valley RLME source ....................................... H-78

Figure H-5.9-2 Wabash Valley RLME source geometry ........................................... H-79

Figure $\mathrm{J}-1$ Map of the rate and $b$-value for the study region under the Mmax zonation, with no separation of Mesozoic extended and non-extended; Case A magnitude weights: Realization 1

Figure J-2 Map of the rate and $b$-value for the study region under the Mmax zonation, with no separation of Mesozoic extended and non-extended; Case A magnitude weights: Realization 2

Figure J-3 Map of the rate and $b$-value for the study region under the Mmax zonation, with no separation of Mesozoic extended and non-extended; Case A magnitude weights: Realization 3

Figure J-4 Map of the rate and $b$-value for the study region under the Mmax zonation, with no separation of Mesozoic extended and non-extended; Case A magnitude weights: Realization 4

Figure J-5 Map of the rate and $b$-value for the study region under the Mmax zonation, with no separation of Mesozoic extended and non-extended; Case A magnitude weights: Realization 5

Figure J-6 Map of the rate and $b$-value for the study region under the Mmax zonation, with no separation of Mesozoic extended and non-extended; Case A magnitude weights: Realization 6

Figure J-7 Map of the rate and $b$-value for the study region under the Mmax zonation, with no separation of Mesozoic extended and non-extended; Case A magnitude weights: Realization 7

Figure J-8 Map of the rate and $b$-value for the study region under the Mmax zonation, with no separation of Mesozoic extended and non-extended; Case A magnitude weights: Realization 8

Figure J-9 Map of the coefficient of variation of the rate and the standard deviation of the $b$-value for the study region under the Mmax zonation, with no separation of Mesozoic extended and non-extended; Case A magnitude weights

Figure $\mathrm{J}-10$ Map of the rate and $b$-value for the study region under the Mmax zonation, with no separation of Mesozoic extended and non-extended; Case B magnitude weights: Realization 1

Figure $\mathrm{J}-11$ Map of the rate and $b$-value for the study region under the Mmax zonation, with no separation of Mesozoic extended and non-extended; Case B magnitude weights: Realization 2

Figure J-12 Map of the rate and $b$-value for the study region under the Mmax zonation, with no separation of Mesozoic extended and non-extended; Case B magnitude weights: Realization 3 
Figure $\mathrm{J}$-13 Map of the rate and $b$-value for the study region under the Mmax zonation, with no separation of Mesozoic extended and non-extended; Case B magnitude weights: Realization 4

Figure $\mathrm{J}-14$ Map of the rate and $b$-value for the study region under the Mmax zonation, with no separation of Mesozoic extended and non-extended; Case B magnitude weights: Realization 5

Figure J-15 Map of the rate and $b$-value for the study region under the Mmax zonation, with no separation of Mesozoic extended and non-extended; Case B magnitude weights: Realization 6

Figure $\mathrm{J}-16$ Map of the rate and $b$-value for the study region under the Mmax zonation, with no separation of Mesozoic extended and non-extended; Case B magnitude weights: Realization 7

Figure J-17 Map of the rate and $b$-value for the study region under the Mmax zonation, with no separation of Mesozoic extended and non-extended; Case B magnitude weights: Realization 8

Figure J-18 Map of the coefficient of variation of the rate and the standard deviation of the $b$-value for the study region under the Mmax zonation, with no separation of Mesozoic extended and non-extended; Case B magnitude weights.....

Figure J-19 Map of the rate and $b$-value for the study region under the Mmax zonation, with no separation of Mesozoic extended and non-extended; Case E magnitude weights: Realization 1

Figure J-20 Map of the rate and $b$-value for the study region under the Mmax zonation, with no separation of Mesozoic extended and non-extended; Case E magnitude weights: Realization 2

Figure J-21 Map of the rate and $b$-value for the study region under the Mmax zonation, with no separation of Mesozoic extended and non-extended; Case E magnitude weights: Realization 3

Figure J-22 Map of the rate and $b$-value for the study region under the Mmax zonation, with no separation of Mesozoic extended and non-extended; Case E magnitude weights: Realization 4

Figure J-23 Map of the rate and $b$-value for the study region under the Mmax zonation, with no separation of Mesozoic extended and non-extended; Case E magnitude weights: Realization 5

Figure J-24 Map of the rate and $b$-value for the study region under the Mmax zonation, with no separation of Mesozoic extended and non-extended; Case E magnitude weights: Realization 6

Figure J-25 Map of the rate and $b$-value for the study region under the Mmax zonation, with no separation of Mesozoic extended and non-extended; Case E magnitude weights: Realization 7

Figure J-26 Map of the rate and $b$-value for the study region under the Mmax zonation, with no separation of Mesozoic extended and non-extended; Case E magnitude weights: Realization 8

Figure J-27 Map of the coefficient of variation of the rate and the standard deviation of the $b$-value for the study region under the Mmax zonation, with no separation of Mesozoic extended and non-extended; Case $\mathrm{E}$ magnitude weights..... 
Figure J-28 Map of the rate and $b$-value for the study region under the Mmax zonation, with separation of Mesozoic extended and non-extended; Case A magnitude weights: Realization 1

Figure J-29 Map of the rate and $b$-value for the study region under the Mmax zonation, with separation of Mesozoic extended and non-extended; Case A magnitude weights: Realization 2

Figure J-30 Map of the rate and $b$-value for the study region under the Mmax zonation, with separation of Mesozoic extended and non-extended; Case A magnitude weights: Realization 3

Figure J-31 Map of the rate and $b$-value for the study region under the Mmax zonation, with separation of Mesozoic extended and non-extended; Case A magnitude weights: Realization 4

Figure J-32 Map of the rate and $b$-value for the study region under the Mmax zonation, with separation of Mesozoic extended and non-extended; Case A magnitude weights: Realization 5

Figure J-33 Map of the rate and $b$-value for the study region under the Mmax zonation, with separation of Mesozoic extended and non-extended; Case A magnitude weights: Realization 6

Figure J-34 Map of the rate and b-value for the study region under the Mmax zonation, with separation of Mesozoic extended and non-extended; Case A magnitude weights: Realization 7

Figure J-35 Map of the rate and $b$-value for the study region under the Mmax zonation, with separation of Mesozoic extended and non-extended; Case A magnitude weights: Realization 8

Figure J-36 Map of the coefficient of variation of the rate and the standard deviation of the $b$-value for the study region under the Mmax zonation, with separation of Mesozoic extended and non-extended; Case A magnitude weights.....

Figure J-37 Map of the rate and $b$-value for the study region under the Mmax zonation, with separation of Mesozoic extended and non-extended; Case B magnitude weights: Realization 1

Figure J-38 Map of the rate and $b$-value for the study region under the Mmax zonation, with separation of Mesozoic extended and non-extended; Case B magnitude weights: Realization 2

Figure J-39 Map of the rate and $b$-value for the study region under the Mmax zonation, with separation of Mesozoic extended and non-extended; Case B magnitude weights: Realization 3

Figure J-40 Map of the rate and $b$-value for the study region under the Mmax zonation, with separation of Mesozoic extended and non-extended; Case B magnitude weights: Realization 4

Figure J-41 Map of the rate and $b$-value for the study region under the Mmax zonation, with separation of Mesozoic extended and non-extended; Case B magnitude weights: Realization 5

Figure J-42 Map of the rate and $b$-value for the study region under the Mmax zonation, with separation of Mesozoic extended and non-extended; Case B magnitude weights: Realization 6 
Figure J-43 Map of the rate and $b$-value for the study region under the Mmax zonation, with separation of Mesozoic extended and non-extended; Case B magnitude weights: Realization 7

Figure J-44 Map of the rate and $b$-value for the study region under the Mmax zonation, with separation of Mesozoic extended and non-extended; Case B magnitude weights: Realization 8

Figure J-45 Map of the coefficient of variation of the rate and the standard deviation of the $b$-value for the study region under the Mmax zonation, with separation of Mesozoic extended and non-extended; Case B magnitude weights.

Figure J-46 Map of the rate and $b$-value for the study region under the Mmax zonation, with separation of Mesozoic extended and non-extended; Case E magnitude weights: Realization 1

Figure J-47 Map of the rate and $b$-value for the study region under the Mmax zonation, with separation of Mesozoic extended and non-extended; Case E magnitude weights: Realization 2

Figure J-48 Map of the rate and $b$-value for the study region under the Mmax zonation, with separation of Mesozoic extended and non-extended; Case E magnitude weights: Realization 3

Figure J-49 Map of the rate and $b$-value for the study region under the Mmax zonation, with separation of Mesozoic extended and non-extended; Case E magnitude weights: Realization 4

Figure $\mathrm{J}-50$ Map of the rate and $b$-value for the study region under the Mmax zonation, with separation of Mesozoic extended and non-extended; Case E magnitude weights: Realization 5

Figure J-51 Map of the rate and $b$-value for the study region under the Mmax zonation, with separation of Mesozoic extended and non-extended; Case E magnitude weights: Realization 6

Figure J-52 Map of the rate and $b$-value for the study region under the Mmax zonation, with separation of Mesozoic extended and non-extended; Case E magnitude weights: Realization 7

Figure J-53 Map of the rate and $b$-value for the study region under the Mmax zonation, with separation of Mesozoic extended and non-extended; Case E magnitude weights: Realization 8

Figure J-54 Map of the coefficient of variation of the rate and the standard deviation of the $b$-value for the study region under the Mmax zonation, with separation of Mesozoic extended and non-extended; Case $\mathrm{E}$ magnitude weights.....

Figure J-55 Map of the rate and $b$-value for the study region under the Mmax zonation, with separation of Mesozoic extended and non-extended; Case A magnitude weights: Realization 1

Figure J-56 Map of the rate and $b$-value for the study region under the Mmax zonation, with separation of Mesozoic extended and non-extended; Case A magnitude weights: Realization 2

Figure J-57 Map of the rate and $b$-value for the study region under the Mmax zonation, with separation of Mesozoic extended and non-extended; Case A magnitude weights: Realization 3 
Figure J-58 Map of the rate and $b$-value for the study region under the Mmax zonation, with separation of Mesozoic extended and non-extended; Case A magnitude weights: Realization 4

Figure J-59 Map of the rate and $b$-value for the study region under the Mmax zonation, with separation of Mesozoic extended and non-extended; Case A magnitude weights: Realization 5

Figure J-60 Map of the rate and $b$-value for the study region under the Mmax zonation, with separation of Mesozoic extended and non-extended; Case A magnitude weights: Realization 6

Figure J-61 Map of the rate and $b$-value for the study region under the Mmax zonation, with separation of Mesozoic extended and non-extended; Case A magnitude weights: Realization 7

Figure J-62 Map of the rate and $b$-value for the study region under the Mmax zonation, with separation of Mesozoic extended and non-extended; Case A magnitude weights: Realization 8

Figure J-63 Map of the coefficient of variation of the rate and the standard deviation of the $b$-value for the study region under the Mmax zonation, with separation of Mesozoic extended and non-extended; Case A magnitude weights..... J-64

Figure J-64 Map of the rate and $b$-value for the study region under the Mmax zonation, with separation of Mesozoic extended and non-extended; Case B magnitude weights: Realization 1

Figure J-65 Map of the rate and $b$-value for the study region under the Mmax zonation, with separation of Mesozoic extended and non-extended; Case B magnitude weights: Realization 2

Figure J-66 Map of the rate and $b$-value for the study region under the Mmax zonation, with separation of Mesozoic extended and non-extended; Case B magnitude weights: Realization 3

Figure J-67 Map of the rate and $b$-value for the study region under the Mmax zonation, with separation of Mesozoic extended and non-extended; Case B magnitude weights: Realization 4

Figure J-68 Map of the rate and $b$-value for the study region under the Mmax zonation, with separation of Mesozoic extended and non-extended; Case B magnitude weights: Realization 5

Figure J-69 Map of the rate and $b$-value for the study region under the Mmax zonation, with separation of Mesozoic extended and non-extended; Case B magnitude weights: Realization 6

Figure J-70 Map of the rate and $b$-value for the study region under the Mmax zonation, with separation of Mesozoic extended and non-extended; Case B magnitude weights: Realization 7

Figure J-71 Map of the rate and $b$-value for the study region under the Mmax zonation, with separation of Mesozoic extended and non-extended; Case B magnitude weights: Realization 8

Figure J-72 Map of the coefficient of variation of the rate and the standard deviation of the $b$-value for the study region under the Mmax zonation, with separation of Mesozoic extended and non-extended; Case B magnitude weights. $\mathrm{J}-73$ 
Figure J-73 Map of the rate and $b$-value for the study region under the Mmax zonation, with separation of Mesozoic extended and non-extended; Case E magnitude weights: Realization 1

Figure J-74 Map of the rate and $b$-value for the study region under the Mmax zonation, with separation of Mesozoic extended and non-extended; Case E magnitude weights: Realization 2

Figure J-75 Map of the rate and $b$-value for the study region under the Mmax zonation, with separation of Mesozoic extended and non-extended; Case E magnitude weights: Realization 3

Figure J-76 Map of the rate and $b$-value for the study region under the Mmax zonation, with separation of Mesozoic extended and non-extended; Case E magnitude weights: Realization 4

Figure J-77 Map of the rate and $b$-value for the study region under the Mmax zonation, with separation of Mesozoic extended and non-extended; Case E magnitude weights: Realization 5

Figure J-78 Map of the rate and $b$-value for the study region under the Mmax zonation, with separation of Mesozoic extended and non-extended; Case E magnitude weights: Realization 6

Figure J-79 Map of the rate and b-value for the study region under the Mmax zonation, with separation of Mesozoic extended and non-extended; Case E magnitude weights: Realization 7

Figure $\mathrm{J}-80$ Map of the rate and $b$-value for the study region under the Mmax zonation, with separation of Mesozoic extended and non-extended; Case E magnitude weights: Realization 8

Figure J-81 Map of the coefficient of variation of the rate and the standard deviation of the $b$-value for the study region under the Mmax zonation, with separation of Mesozoic extended and non-extended; Case E magnitude weights.....

Figure J-82 Map of the rate and $b$-value for the study region under the seismotectonic zonation, with narrow interpretation of PEZ; Case A magnitude weights: Realization 1 .

Figure J-83 Map of the rate and $b$-value for the study region under the seismotectonic zonation, with narrow interpretation of PEZ; Case A magnitude weights: Realization 2 .

Figure J-84 Map of the rate and $b$-value for the study region under the seismotectonic zonation, with narrow interpretation of PEZ; Case A magnitude weights: Realization 3.

Figure J-85 Map of the rate and $b$-value for the study region under the seismotectonic zonation, with narrow interpretation of PEZ; Case A magnitude weights: Realization 4.

Figure J-86 Map of the rate and $b$-value for the study region under the seismotectonic zonation, with narrow interpretation of PEZ; Case A magnitude weights: Realization 5 .

Figure J-87 Map of the rate and $b$-value for the study region under the seismotectonic zonation, with narrow interpretation of PEZ; Case A magnitude weights: Realization 6 . 
Figure J-88 Map of the rate and $b$-value for the study region under the seismotectonic zonation, with narrow interpretation of PEZ; Case A magnitude weights: Realization 7

Figure J-89 Map of the rate and $b$-value for the study region under the seismotectonic zonation, with narrow interpretation of PEZ; Case A magnitude weights: Realization 8

Figure J-90 Map of the coefficient of variation of the rate and the standard deviation of the $b$-value for the study region under the seismotectonic zonation, with narrow interpretation of PEZ; Case A magnitude weights

Figure J-91 Map of the rate and $b$-value for the study region under the seismotectonic zonation, with narrow interpretation of PEZ; Case B magnitude weights: Realization 1

Figure J-92 Map of the rate and $b$-value for the study region under the seismotectonic zonation, with narrow interpretation of PEZ; Case B magnitude weights: Realization 2 .

Figure J-93 Map of the rate and $b$-value for the study region under the seismotectonic zonation, with narrow interpretation of PEZ; Case B magnitude weights: Realization 3

Figure J-94 Map of the rate and $b$-value for the study region under the seismotectonic zonation, with narrow interpretation of PEZ; Case B magnitude weights: Realization 4

Figure J-95 Map of the rate and $b$-value for the study region under the seismotectonic zonation, with narrow interpretation of PEZ; Case B magnitude weights: Realization 5

Figure J-96 Map of the rate and $b$-value for the study region under the seismotectonic zonation, with narrow interpretation of PEZ; Case B magnitude weights: Realization 6

Figure J-97 Map of the rate and $b$-value for the study region under the seismotectonic zonation, with narrow interpretation of PEZ; Case B magnitude weights: Realization 7

Figure J-98 Map of the rate and $b$-value for the study region under the seismotectonic zonation, with narrow interpretation of PEZ; Case B magnitude weights: Realization 8

Figure J-99 Map of the coefficient of variation of the rate and the standard deviation of the $b$-value for the study region under the seismotectonic zonation, with narrow interpretation of PEZ; Case B magnitude weights

Figure J-100 Map of the rate and $b$-value for the study region under the seismotectonic zonation, with narrow interpretation of PEZ; Case E magnitude weights: Realization 1

Figure J-101 Map of the rate and $b$-value for the study region under the seismotectonic zonation, with narrow interpretation of PEZ; Case E magnitude weights: Realization 2

Figure J-102 Map of the rate and $b$-value for the study region under the seismotectonic zonation, with narrow interpretation of PEZ; Case E magnitude weights: Realization 3. 
Figure $\mathrm{J}-103$ Map of the rate and $b$-value for the study region under the seismotectonic zonation, with narrow interpretation of PEZ; Case E magnitude weights: Realization 4

Figure $\mathrm{J}$-104 Map of the rate and $b$-value for the study region under the seismotectonic zonation, with narrow interpretation of PEZ; Case E magnitude weights: Realization 5 .

Figure $\mathrm{J}-105$ Map of the rate and $b$-value for the study region under the seismotectonic zonation, with narrow interpretation of PEZ; Case E magnitude weights: Realization 6 ......

Figure J-106 Map of the rate and $b$-value for the study region under the seismotectonic zonation, with narrow interpretation of PEZ; Case E magnitude weights: Realization 7

Figure $\mathrm{J}-107$ Map of the rate and $b$-value for the study region under the seismotectonic zonation, with narrow interpretation of PEZ; Case E magnitude weights: Realization 8.

Figure J-108 Map of the coefficient of variation of the rate and the standard deviation of the $b$-value for the study region under the seismotectonic zonation, with narrow interpretation of PEZ; Case E magnitude weights

Figure $\mathrm{J}-109$ Map of the rate and $b$-value for the study region under the seismotectonic zonation, with narrow interpretation of PEZ; Case A magnitude weights: Realization 1

Figure $\mathrm{J}-110$ Map of the rate and $b$-value for the study region under the seismotectonic zonation, with narrow interpretation of PEZ; Case A magnitude weights: Realization 2 ......

Figure $\mathrm{J}$-111 Map of the rate and $b$-value for the study region under the seismotectonic zonation, with narrow interpretation of PEZ; Case A magnitude weights: Realization 3.

Figure $\mathrm{J}-112$ Map of the rate and $b$-value for the study region under the seismotectonic zonation, with narrow interpretation of PEZ; Case A magnitude weights: Realization 4

Figure $\mathrm{J}-113$ Map of the rate and $b$-value for the study region under the seismotectonic zonation, with narrow interpretation of PEZ; Case A magnitude weights: Realization 5

Figure $\mathrm{J}$-114 Map of the rate and $b$-value for the study region under the seismotectonic zonation, with narrow interpretation of PEZ; Case A magnitude weights: Realization 6

Figure $\mathrm{J}-115$ Map of the rate and $b$-value for the study region under the seismotectonic zonation, with narrow interpretation of PEZ; Case A magnitude weights: Realization 7

Figure J-116 Map of the rate and $b$-value for the study region under the seismotectonic zonation, with narrow interpretation of PEZ; Case A magnitude weights: Realization 8

Figure J-117 Map of the coefficient of variation of the rate and the standard deviation of the $b$-value for the study region under the seismotectonic zonation, with narrow interpretation of PEZ; Case A magnitude weights 
Figure $\mathrm{J}$-118 Map of the rate and $b$-value for the study region under the seismotectonic zonation, with narrow interpretation of PEZ; Case B magnitude weights: Realization 1

Figure J-119 Map of the rate and $b$-value for the study region under the seismotectonic zonation, with narrow interpretation of PEZ; Case B magnitude weights: Realization 2

Figure $\mathrm{J}-120$ Map of the rate and $b$-value for the study region under the seismotectonic zonation, with narrow interpretation of PEZ; Case B magnitude weights: Realization 3

Figure $\mathrm{J}-121$ Map of the rate and $b$-value for the study region under the seismotectonic zonation, with narrow interpretation of PEZ; Case B magnitude weights: Realization 4

Figure J-122 Map of the rate and $b$-value for the study region under the seismotectonic zonation, with narrow interpretation of PEZ; Case B magnitude weights: Realization 5 .

Figure $\mathrm{J}-123$ Map of the rate and $b$-value for the study region under the seismotectonic zonation, with narrow interpretation of PEZ; Case B magnitude weights: Realization 6

Figure $\mathrm{J}$-124 Map of the rate and $b$-value for the study region under the seismotectonic zonation, with narrow interpretation of PEZ; Case B magnitude weights: Realization 7

Figure J-125 Map of the rate and $b$-value for the study region under the seismotectonic zonation, with narrow interpretation of PEZ; Case B magnitude weights: Realization 8

Figure J-126 Map of the coefficient of variation of the rate and the standard deviation of the $b$-value for the study region under the seismotectonic zonation, with narrow interpretation of PEZ; Case B magnitude weights

Figure $\mathrm{J}-127$ Map of the rate and $b$-value for the study region under the seismotectonic zonation, with narrow interpretation of PEZ; Case E magnitude weights: Realization 1

Figure $\mathrm{J}-128$ Map of the rate and $b$-value for the study region under the seismotectonic zonation, with narrow interpretation of PEZ; Case E magnitude weights: Realization 2

Figure J-129 Map of the rate and $b$-value for the study region under the seismotectonic zonation, with narrow interpretation of PEZ; Case E magnitude weights: Realization 3

Figure J-130 Map of the rate and $b$-value for the study region under the seismotectonic zonation, with narrow interpretation of PEZ; Case E magnitude weights: Realization 4

Figure $\mathrm{J}$-131 Map of the rate and $b$-value for the study region under the seismotectonic zonation, with narrow interpretation of PEZ; Case E magnitude weights: Realization 5

Figure $\mathrm{J}-132$ Map of the rate and $b$-value for the study region under the seismotectonic zonation, with narrow interpretation of PEZ; Case E magnitude weights: Realization 6 
Figure $\mathrm{J}-133$ Map of the rate and $b$-value for the study region under the seismotectonic zonation, with narrow interpretation of PEZ; Case E magnitude weights: Realization 7

Figure $\mathrm{J}-134$ Map of the rate and $b$-value for the study region under the seismotectonic zonation, with narrow interpretation of PEZ; Case E magnitude weights: Realization 8

Figure $\mathrm{J}-135$ Map of the coefficient of variation of the rate and the standard deviation of the $b$-value for the study region under the seismotectonic zonation, with narrow interpretation of PEZ; Case E magnitude weights

Figure $\mathrm{J}-136$ Map of the rate and $b$-value for the study region under the seismotectonic zonation, with wide interpretation of PEZ; Case A magnitude weights: Realization 1 ... J-137

Figure J-137 Map of the rate and $b$-value for the study region under the seismotectonic zonation, with wide interpretation of PEZ; Case A magnitude weights: Realization 2 ... J-138

Figure $\mathrm{J}$-138 Map of the rate and $b$-value for the study region under the seismotectonic zonation, with wide interpretation of PEZ; Case A magnitude weights: Realization $3 \ldots \mathrm{J}-139$

Figure J-139 Map of the rate and $b$-value for the study region under the seismotectonic zonation, with wide interpretation of PEZ; Case A magnitude weights: Realization 4 ... J-140

Figure J-140 Map of the rate and $b$-value for the study region under the seismotectonic zonation, with wide interpretation of PEZ; Case A magnitude weights: Realization 5 ... J-141

Figure $\mathrm{J}-141$ Map of the rate and $b$-value for the study region under the seismotectonic zonation, with wide interpretation of PEZ; Case A magnitude weights: Realization 6 ... J-142

Figure J-142 Map of the rate and $b$-value for the study region under the seismotectonic zonation, with wide interpretation of PEZ; Case A magnitude weights: Realization 7 ... J-143

Figure $\mathrm{J}-143$ Map of the rate and $b$-value for the study region under the seismotectonic zonation, with wide interpretation of PEZ; Case A magnitude weights: Realization 8 ... J-144

Figure J-144 Map of the coefficient of variation of the rate and the standard deviation of the $b$-value for the study region under the seismotectonic zonation, with wide interpretation of PEZ; Case A magnitude weights

Figure $\mathrm{J}-145$ Map of the rate and $b$-value for the study region under the seismotectonic zonation, with wide interpretation of PEZ; Case B magnitude weights: Realization $1 \ldots \mathrm{J}-146$

Figure $\mathrm{J}-146$ Map of the rate and $b$-value for the study region under the seismotectonic zonation, with wide interpretation of PEZ; Case B magnitude weights: Realization 2 ... J-147

Figure $\mathrm{J}-147$ Map of the rate and $b$-value for the study region under the seismotectonic zonation, with wide interpretation of PEZ; Case B magnitude weights: Realization $3 \ldots \mathrm{J}-148$

Figure J-148 Map of the rate and $b$-value for the study region under the seismotectonic zonation, with wide interpretation of PEZ; Case B magnitude weights: Realization 4 ... J-149

Figure $\mathrm{J}-149$ Map of the rate and $b$-value for the study region under the seismotectonic zonation, with wide interpretation of PEZ; Case B magnitude weights: Realization 5 ... J-150

Figure J-150 Map of the rate and $b$-value for the study region under the seismotectonic zonation, with wide interpretation of PEZ; Case B magnitude weights: Realization 6 ... J-151

Figure $\mathrm{J}-151$ Map of the rate and $b$-value for the study region under the seismotectonic zonation, with wide interpretation of PEZ; Case B magnitude weights: Realization 7 ... J-152

Figure J-152 Map of the rate and $b$-value for the study region under the seismotectonic zonation, with wide interpretation of PEZ; Case B magnitude weights: Realization 8 ... J-153

lxxiv 
Figure J-153 Map of the coefficient of variation of the rate and the standard deviation of the $b$-value for the study region under the seismotectonic zonation, with wide interpretation of PEZ; Case B magnitude weights

Figure $\mathrm{J}-154$ Map of the rate and $b$-value for the study region under the seismotectonic zonation, with wide interpretation of PEZ; Case E magnitude weights: Realization 1 ... J-155

Figure J-155 Map of the rate and $b$-value for the study region under the seismotectonic zonation, with wide interpretation of PEZ; Case E magnitude weights: Realization 2 ... J-156

Figure $\mathrm{J}-156$ Map of the rate and $b$-value for the study region under the seismotectonic zonation, with wide interpretation of PEZ; Case E magnitude weights: Realization 3 ... J-157

Figure $\mathrm{J}-157$ Map of the rate and $b$-value for the study region under the seismotectonic zonation, with wide interpretation of PEZ; Case $E$ magnitude weights: Realization 4 ... J-158

Figure J-158 Map of the rate and $b$-value for the study region under the seismotectonic zonation, with wide interpretation of PEZ; Case E magnitude weights: Realization 5 ... J-159

Figure $\mathrm{J}$-159 Map of the rate and $b$-value for the study region under the seismotectonic zonation, with wide interpretation of PEZ; Case E magnitude weights: Realization 6 ... J-160

Figure $\mathrm{J}-160$ Map of the rate and $b$-value for the study region under the seismotectonic zonation, with wide interpretation of PEZ; Case E magnitude weights: Realization 7 ... J-161

Figure $\mathrm{J}-161$ Map of the rate and $b$-value for the study region under the seismotectonic zonation, with wide interpretation of PEZ; Case $\mathrm{E}$ magnitude weights: Realization 8 ... J-162

Figure J-162 Map of the coefficient of variation of the rate and the standard deviation of the $b$-value for the study region under the seismotectonic zonation, with wide interpretation of PEZ; Case E magnitude weights

Figure $\mathrm{J}-163$ Map of the rate and $b$-value for the study region under the seismotectonic zonation, with wide interpretation of PEZ; Case A magnitude weights: Realization 1 ... J-164

Figure $\mathrm{J}-164$ Map of the rate and $b$-value for the study region under the seismotectonic zonation, with wide interpretation of PEZ; Case A magnitude weights: Realization 2 ... J-165

Figure J-165 Map of the rate and $b$-value for the study region under the seismotectonic zonation, with wide interpretation of PEZ; Case A magnitude weights: Realization 3 ... J-166

Figure $\mathrm{J}-166$ Map of the rate and $b$-value for the study region under the seismotectonic zonation, with wide interpretation of PEZ; Case A magnitude weights: Realization 4 ... J-167

Figure J-167 Map of the rate and $b$-value for the study region under the seismotectonic zonation, with wide interpretation of PEZ; Case A magnitude weights: Realization 5 ... J-168

Figure J-168 Map of the rate and $b$-value for the study region under the seismotectonic zonation, with wide interpretation of PEZ; Case A magnitude weights: Realization 6 ... J-169

Figure J-169 Map of the rate and $b$-value for the study region under the seismotectonic zonation, with wide interpretation of PEZ; Case A magnitude weights: Realization 7 ... J-170

Figure $\mathrm{J}-170$ Map of the rate and $b$-value for the study region under the seismotectonic zonation, with wide interpretation of PEZ; Case A magnitude weights: Realization 8 ... J-171

Figure J-171 Map of the coefficient of variation of the rate and the standard deviation of the $b$-value for the study region under the seismotectonic zonation, with wide interpretation of PEZ; Case A magnitude weights

Figure J-172 Map of the rate and $b$-value for the study region under the seismotectonic zonation, with wide interpretation of PEZ; Case B magnitude weights: Realization $1 \ldots \mathrm{J}-173$ 
Figure $\mathrm{J}-173$ Map of the rate and $b$-value for the study region under the seismotectonic zonation, with wide interpretation of PEZ; Case B magnitude weights: Realization 2 ... J-174

Figure $\mathrm{J}-174$ Map of the rate and $b$-value for the study region under the seismotectonic zonation, with wide interpretation of PEZ; Case B magnitude weights: Realization 3 ... J-175

Figure J-175 Map of the rate and $b$-value for the study region under the seismotectonic zonation, with wide interpretation of PEZ; Case B magnitude weights: Realization 4 ... J-176

Figure J-176 Map of the rate and $b$-value for the study region under the seismotectonic zonation, with wide interpretation of PEZ; Case B magnitude weights: Realization 5 ... J-177

Figure $\mathrm{J}-177$ Map of the rate and $b$-value for the study region under the seismotectonic zonation, with wide interpretation of PEZ; Case B magnitude weights: Realization 6 ... J-178

Figure $\mathrm{J}-178$ Map of the rate and $b$-value for the study region under the seismotectonic zonation, with wide interpretation of PEZ; Case B magnitude weights: Realization 7 ... J-179

Figure $\mathrm{J}-179$ Map of the rate and $b$-value for the study region under the seismotectonic zonation, with wide interpretation of PEZ; Case B magnitude weights: Realization $8 \ldots \mathrm{J}-180$

Figure J-180 Map of the coefficient of variation of the rate and the standard deviation of the $b$-value for the study region under the seismotectonic zonation, with wide interpretation of PEZ; Case B magnitude weights

Figure $\mathrm{J}-181$ Map of the rate and $b$-value for the study region under the seismotectonic zonation, with wide interpretation of PEZ; Case E magnitude weights: Realization 1 ... J-182

Figure J-182 Map of the rate and $b$-value for the study region under the seismotectonic zonation, with wide interpretation of PEZ; Case E magnitude weights: Realization 2 ... J-183

Figure $\mathrm{J}-183$ Map of the rate and $b$-value for the study region under the seismotectonic zonation, with wide interpretation of PEZ; Case E magnitude weights: Realization 3 ... J-184

Figure $\mathrm{J}-184$ Map of the rate and $b$-value for the study region under the seismotectonic zonation, with wide interpretation of PEZ; Case E magnitude weights: Realization 4 ... J-185

Figure $\mathrm{J}-185$ Map of the rate and $b$-value for the study region under the seismotectonic zonation, with wide interpretation of PEZ; Case E magnitude weights: Realization 5 ... J-186

Figure $\mathrm{J}$-186 Map of the rate and $b$-value for the study region under the seismotectonic zonation, with wide interpretation of PEZ; Case E magnitude weights: Realization 6 ... J-187

Figure $\mathrm{J}-187$ Map of the rate and $b$-value for the study region under the seismotectonic zonation, with wide interpretation of PEZ; Case E magnitude weights: Realization 7 ... J-188

Figure $\mathrm{J}-188$ Map of the rate and $b$-value for the study region under the seismotectonic zonation, with wide interpretation of PEZ; Case E magnitude weights: Realization 8 ... J-189

Figure J-189 Map of the coefficient of variation of the rate and the standard deviation of the $b$-value for the study region under the seismotectonic zonation, with wide interpretation of PEZ; Case E magnitude weights

Figure K-1 Comparison of relationships between number of reporting stations and moment magnitude presented in Johnston et al. (1994) and Johnston (1996b).

Figure K-2 Comparison of relationships between isoseismal areas and moment magnitude presented in Johnston et al. (1994) and Johnston (1996b). 


\section{LIST OF TABLES}

Table 2.2-1 Technical Meetings Conducted as Part of the CEUS SSC Project.....................2-29

Table 2.2-2 Contributors to the CEUS SSC Project....................................................... 2-30

Table 3.2-1 Summary of Earthquakes Added-USGS Earthquake Catalog by Time

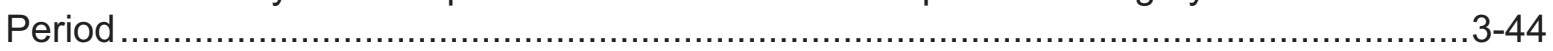

Table 3.2-2 Summary of Earthquakes Added-USGS Earthquake Catalog by Source ............3-45

Table 3.3-1 Conversion Relationships Used-Develop Uniform Moment Magnitudes E[M] ..... 3-46

Table 3.4-1 Comparison of CEUS SSC Catalog Declustering Results Obtained Using the EPRI (1988) Approach with the Gardner Knopoff (1974) Approach ..............................3-47

Table 3.5-1 Probability of Detection and Equivalent Periods of Completeness for the CEUS for Magnitude Weighting Case A

Table 3.5-2 Probability of Detection and Equivalent Periods of Completeness for the CEUS for Magnitude Weighting Case B

Table 3.5-3 Probability of Detection and Equivalent Periods of Completeness for the CEUS for Magnitude Weighting Case $\mathrm{E}$

Table 4.1.2-1 Sample table indicating particular types of data that can be considered in the identification and characterization of seismic sources (Table 2, ANSI/ANS-2.272008)

Table 4.1.2-2 Sample table identifying the types of data that can be considered for characterizing different types of seismic sources, and an evaluation of the relative usefulness or credibility of the various data types (Budnitz et al., 1997)...

Table 4.1.2-3 Table showing the "generic" (not source-specific) evaluation of data to address indicators of a unique seismic source. The table indicates the TI Team's assessment of the types of data that can be used to address the indicators and their relative usefulness.

Table 4.1.2-4 Example of Data Evaluation Table for the Illinois Basin-Extended Basement Zone (IBEB)

Table 4.1.2-5 Example of Data Summary Table for the Extended Continental CrustAtlantic Margin (ECC-AM) and Atlantic Highly Extended Crust (AHEX) Zones

Table 4.1.3-1 Criteria Used to Define the Seismotectonic Zones and Mmax Zones

Table 4.2.2-1 RLME Sources

Table 4.2.4-1 Seismotectonic Zones 4-39

Table 5.2.1-1 Mesozoic-and-Younger Extended Superdomains (MESE)..........................5-60

Table 5.2.1-2 Older Extended and Non-Extended Superdomains (NMESE) ........................5-61

Table 5.2.1-3 Composite SCR Superdomains (COMP)................................................ 5-62

Table 5.2.1-4 Results of Analyses of Updated SCR Superdomains ..................................5-63 
Table 5.2.1-5 Source Zones, $\mathrm{P}\left(\mathrm{m}^{\mathrm{u}}>\right.$ 81/4) Values, and Weights on Kijko (2004) K-S-B

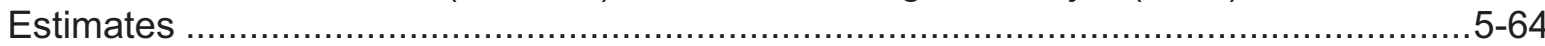

Table 5.2.1-6 Mmax Distributions for the Two Example Seismic Sources............................. 5-65

Table 5.3.2-1 Alternative Cases Considered for the Magnitude-Dependent Weights.............5-65

Table 5.3.3-1 Miller and Rice (1983) Discrete 5-Point Approximation to a Continuous

Probability Distribution and the Modified Form Used in This Study ...........................5-65

Table 5.4-1 Assessment of Default Characteristics of Future Earthquakes in the CEUS.......5-66

Table 5.4-2 Characteristics of Future Earthquakes for Individual Seismic Sources ............... 5-68

Table 5.4-3 Estimates of $D_{90}$ for Individual Seismic Source Zones.................................... 5-71

Table 6.1-1 Summary of Data Used to Assess RLME Recurrence Frequencies....................6-80

Table 6.1.1-1 Charlevoix RLME Recurrence Frequency ...............................................6-83

Table 6.1.2-1 Summary of Interpreted Charleston Earthquake Ages and Sizes from "Contemporary Ages Only" Scenario .................................................................. 6-84

Table 6.1.2-2 Summary of Interpreted Charleston Earthquake Ages and Sizes from "All Ages" Scenario.

Table 6.1.2-3 Charleston Liquefaction Feature Ages Used to Assess Ages of Prehistoric Earthquakes

Table 6.1.2-4 Charleston RLME Recurrence Frequency for Poisson Model .........................6-86

Table 6.1.2-5 Charleston RLME Recurrence Frequency for Renewal Model ........................6-87

Table 6.1.3-1 Range of Cheraw Fault Estimated Magnitudes (M) ....................................6-88

Table 6.1.3-2 Cheraw RLME In-Cluster Recurrence Frequency .......................................6-89

Table 6.1.3-3 Cheraw RLME In-Cluster Slip Rates ....................................................6-89

Table 6.1.3-4 Cheraw RLME Out-of-Cluster Recurrence Frequency .................................6-90

Table 6.1.3-5 Cheraw RLME Out-of-Cluster Slip Rates ................................................6-90

Table 6.1.4-1 Range of Estimated Meers Fault Earthquake Magnitudes (M) .......................6-91

Table 6.1.4-2 Meers RLME In-Cluster Recurrence Frequency......................................6-91

Table 6.1.4-3 Meers RLME Out-of-Cluster Recurrence Frequency................................6-91

Table 6.1.5-1 Preferred Ages for Paleoearthquakes in the New Madrid Region ${ }^{1}$..................6-92

Table 6.1.5-2 Magnitude Comparisons for New Madrid 1811-1812 Earthquake Sequence.

Table 6.1.5-3 Liquefaction Constraints on Age of AD 1450 NMFS RLME...........................6-94

Table 6.1.5-4 Liquefaction Constraints on Age of AD 900 NMFS RLME .............................6-95

Table 6.1.5-5 NMFS In-Cluster RLME Recurrence Frequency_Poisson Model ..................6-96

Table 6.1.5-6 NMFS In-Cluster RLME Recurrence Frequency_Renewal Model .................6-96

Table 6.1.5-7 NMFS Out-of-Cluster RLME Recurrence Frequency_Poisson Model ............6-96

Table 6.1.6-1 Range of ERM-S Estimated Magnitudes (M) ...........................................6-97

Table 6.1.6-2 Range of ERM-N Estimated Magnitudes (M) ......................................... 6-98

Table 6.1.6-3 ERM-S RLME Recurrence Frequency................................................... 6-98

Table 6.1.6-4 ERM-N RLME Recurrence Frequency .................................................6-99

Table 6.1.7-1 Marianna RLME Recurrence Frequency ................................................6-99

lxxviii 
Table 6.1.8-1 Range of Commerce Fault Zone RLME Estimated Magnitudes (M).

Table 6.1.8-2 Commerce Fault Zone RLME Recurrence Frequency.

6-101

Table 6.1.9-1 Liquefaction Evidence for Prehistoric Earthquakes in the Southern Illinois Basin

Table 6.1.9-2 Wabash RLME Recurrence Frequency

Table 6.2-1 Alternative Mmax Zonation Models

Table 6.3.2-1 Maximum Magnitude Distributions for Mmax Distributed Seismicity Sources

Table 7.1-1 Data Summary and Data Evaluation Tables for Seismotectonic Zones in Appendices C and D

Table 7.4.2-1 Maximum Magnitude Distributions for Seismotectonic Distributed Seismicity Sources

Table 8.1-1 Description of Seven Test Sites....

Table 8.2.1-1 Mean and Select Fractiles for Rock Hazard at Central Illinois: Digital Data for Figures 8.2-1a through 8.2-1c.....

Table 8.2.2-1 Mean and Select Fractiles for Rock Hazard at Chattanooga: Digital Data for Figures 8.2-2a through 8.2-2c......

Table 8.2.3-1 Mean and Select Fractiles for Rock Hazard at Houston: Digital Data for Figures 8.2-3a through 8.2-3c

Table 8.2.4-1 Mean and Select Fractiles for Rock Hazard at Jackson: Digital Data for Figures 8.2-4a through 8.2-4c

Table 8.2.5-1 Mean and Select Fractiles for Rock Hazard at Manchester: Digital Data for Figures 8.2-5a through 8.2-5c....

Table 8.2.6-1 Mean and Select Fractiles for Rock Hazard at Savannah: Digital Data for Figures 8.2-6a through 8.2-6c

Table 8.2.7-1 Mean and Select Fractiles for Rock Hazard at Topeka: Digital Data for Figures 8.2-7a through 8.2-7c

Table 9.4-1 Available Information for Determining the Precision of Mean Hazard

Table 9.4-2 Summary of an Example Logic Tree Representing Uncertainties for the Charleston Seismic Zone

Table 9.4-3 Basic Weights Given in EPRI (2004) for Ground Motion Equations

Table 9.4-4 Ground Motion Equations and Weights Used in USGS 2008 National Hazard Map for CEUS

Table 9.4-5 Minimum COV ${ }_{\mathrm{MH}}$ Values Observed in Seismic Hazard 9-23

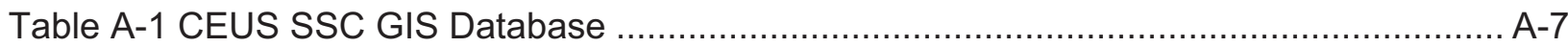

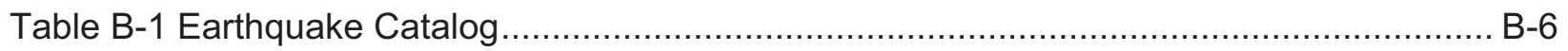

Table B-2 Moment Magnitude Data …....................................................................... B-312

Table B-3 Approximate Moment Magnitude Data ......................................................... B-324

Table C-5.4 Data Evaluation Future Earthquake Characteristics .................................... C-3

Table C-6.1.1 Data Evaluation Charlevoix RLME ....................................................... C-9

Table C-6.1.2 Data Evaluation Charleston RLME …...................................................... C-14

Table C-6.1.3 Data Evaluation Cheraw Fault RLME ................................................ C-30 
Table C-6.1.4 Data Evaluation Oklahoma Aulacogen RLME ........................................ C-36

Table C-6.1.5 Data Evaluation Reelfoot Rift-New Madrid Fault System RLMEs .................. C-42

Table C-6.1.6 Data Evaluation Reelfoot Rift-Eastern Margin Fault(s) RLMEs..................... C-51

Table C-6.1.7 Data Evaluation Reelfoot Rift-Marianna RLME ....................................... C-62

Table C-6.1.8 Data Evaluation Reelfoot Rift-Commerce Fault Zone RLME ....................... C-67

Table C-6.1.9 Data Evaluation Wabash Valley RLME ................................................. C-75

Table C-7.3.1 Data Evaluation St. Lawrence Rift Zone ................................................ C-83

Table C-7.3.2 Data Evaluation Great Meteor Hotspot Zone .............................................. C-92

Table C-7.3.3 Data Evaluation Northern Appalachian Zone ............................................... C-99

Table C-7.3.4 Data Evaluation Paleozoic Extended Crust Zone ....................................... C-105

Table C-7.3.5 Data Evaluation Illinois Basin-Extended Basement Zone ........................... C-112

Table C-7.3.6 Data Evaluation Reelfoot Rift Zone .......................................................... C-124

Tables C-7.3.7/7.3.8 Data Evaluation Extended Continental Crust-Atlantic...................... C-131

Tables C-7.3.9/7.3.10 Data Evaluation Extended Continental Crust-Gulf Coast ................ C-138

Table C-7.3.12 Data Evaluation Midcontinent-Craton Zone ........................................ C-146

Table D-5.4 Data Summary Future Earthquake Characteristics ..................................... D-3

Table D-6.1.1 Data Summary Charlevoix RLME ...................................................... D-10

Table D-6.1.2 Data Summary Charleston RLME ........................................................ D-17

Table D-6.1.3 Data Summary Cheraw Fault RLME ................................................. D-35

Table D-6.1.4 Data Summary Oklahoma Aulacogen RLME ........................................ D-38

Table D-6.1.5 Data Summary Reelfoot Rift-New Madrid Seismic Zone (NMSZ) Region....... D-44

Table D-6.1.9 Data Summary Wabash Valley RLME ................................................. D-92

Table D-7.3.1 Data Summary St. Lawrence Rift Zone (SLR) ...................................... D-121

Table D-7.3.2 Data Summary Great Meteor Hotspot Zone (GMH) .............................. D-141

Table D-7.3.3 Data Summary Northern Appalachian Zone (NAP) ................................. D-151

Table D-7.3.4 Data Summary Paleozoic Extended Crust Zone....................................... D-163

Table D-7.3.7 Data Summary Extended Continental Crust Zone-Atlantic Margin (ECC-

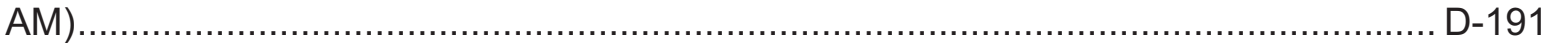

Table D-7.3.9 Data Summary Extended Continental Crust Zone-Gulf Coast (ECC-GC)..... D-225

Table D-7.3.12 Data Summary Midcontinent-Craton Zone (MidC) ................................ D-240

Table E-1.2-1. Summary of Information on Liquefaction Features in Regional Data Sets........ E-5

Table E-1.2-2 Summary of Type and Prevalence of Paleoliquefaction Features ................... E-7

Table E-2.1.3. Summary of Dating Techniques Used in Paleoliquefaction Studies............... E-30

Table E-2.2. Uncertainties Related to Interpretation of Paleoearthquake Parameters ........... E-36

Table 1: Key Questions and Topics That Workshop 2 Presenters Were Asked to Address

Table H-3-1 Weighted Alternative Seismogenic Crustal Thickness Values for Mmax Zones

Table H-3-2 Aleatory Distributions for Characterization of Future Earthquake Ruptures for Mmax Zones

$\operatorname{lxxx}$ 
Table H-3-3 Maximum Magnitude Distributions for Mmax Distributed Seismicity Sources .... H-20 Table H-4-1 Seismotectonic Source Zones

Table H-4-2 Weighted Alternative Seismogenic Crustal Thickness Values for Seismotectonic Zones

Table H-4-3 Aleatory Distributions for Characterization of Future Earthquake Ruptures for Seismotectonic Zones.

Table H-4-4 Maximum Magnitude Distributions for Seismotectonic Distributed Seismicity Sources

Table H-5.1-1 Charlevoix RLME Magnitude Distribution

Table H-5.1-2 Annual Frequencies for Charlevoix RLME Events Data Set 1: 1870 and 1663

Table H-5.1-3 Annual Frequencies for Charlevoix RLME Events Data Set 2: 3 Earthquakes in 6-7 kyr BP.....

Table H-5.1-4 Annual Frequencies for Charlevoix RLME Events Data Set 3: 4 Earthquakes in 9.5-10.2 kyr BP

Table H-5.2-1 Charleston RLME Magnitude Distribution

Table H-5.2-2 Annual Frequencies for Charleston RLME Events Poisson Model, 2,000Year Time Period Earthquakes 1886, A, B, and C....

Table H-5.2-3 Annual Frequencies for Charleston RLME Events Poisson Model, 5,500Year Time Period Earthquakes 1886, A, B, and C

Table H-5.2-4 Annual Frequencies for Charleston RLME Events Poisson Model, 5,500Year Time Period Earthquakes 1886, A, B, C, and D

Table H-5.2-5 Annual Frequencies for Charleston RLME Events Poisson Model, 5,500Year Time Period Earthquakes 1886, A, B, C, and E

Table H-5.2-6 Annual Frequencies for Charleston RLME Events Poisson Model, 5,500Year Time Period Earthquakes 1886, A, B, C, D, and E.

Table H-5.2-7 Annual Frequencies for Charleston RLME Events BPT Renewal Model, $\alpha$ $=0.3,2,000-$ Year Time Period Earthquakes 1886, A, B, and C

Table H-5.2-8 Annual Frequencies for Charleston RLME Events BPT Renewal Model, $\alpha$ $=0.5,2,000-$ Year Time Period Earthquakes 1886, A, B, and C

Table H-5.2-9 Annual Frequencies for Charleston RLME Events BPT Renewal Model, $\alpha$ $=0.7,2,000$-Year Time Period Earthquakes 1886, A, B, and C

Table H-5.2-10 Annual Frequencies for Charleston RLME Events BPT Renewal Model, $\alpha$ $=0.3,5,500-$ Year Time Period Earthquakes 1886, A, B, and C

Table H-5.2-11 Annual Frequencies for Charleston RLME Events BPT Renewal Model, $\alpha$ $=0.5,5,500-$ Year Time Period Earthquakes 1886, A, B, and C

Table H-5.2-12 Annual Frequencies for Charleston RLME Events BPT Renewal Model, $\alpha$ $=0.7,5,500-$ Year Time Period Earthquakes 1886, A, B, and C

Table H-5.2-13 Annual Frequencies for Charleston RLME Events BPT Renewal Model, $\alpha$ $=0.3,5,500-$ Year Time Period Earthquakes 1886, A, B, C, and D

Table H-5.2-14 Annual Frequencies for Charleston RLME Events BPT Renewal Model, $\alpha$ $=0.5,5,500-$ Year Time Period Earthquakes 1886, A, B, C, and D 
Table H-5.2-15 Annual Frequencies for Charleston RLME Events BPT Renewal Model, $\alpha$ $=0.7,5,500-$ Year Time Period Earthquakes 1886, A, B, C, and D.....

Table H-5.2-16 Annual Frequencies for Charleston RLME Events BPT Renewal Model, $\alpha$ $=0.3,5,500-$ Year Time Period Earthquakes 1886, A, B, C, and E

Table H-5.2-17 Annual Frequencies for Charleston RLME Events BPT Renewal Model, $\alpha$ $=0.5,5,500-$ Year Time Period Earthquakes 1886, A, B, C, and E

Table H-5.2-18 Annual Frequencies for Charleston RLME Events BPT Renewal Model, $\alpha$ $=0.7,5,500-$ Year Time Period Earthquakes 1886, A, B, C, and E

Table H-5.2-19 Annual Frequencies for Charleston RLME Events BPT Renewal Model, $\alpha$ $=0.3,5,500-$ Year Time Period Earthquakes 1886, A, B, C, D, and E

Table H-5.2-20 Annual Frequencies for Charleston RLME Events BPT Renewal Model, $\alpha$ $=0.5,5,500$-Year Time Period Earthquakes 1886, A, B, C, D, and E

Table H-5.2-21 Annual Frequencies for Charleston RLME Events BPT Renewal Model, $\alpha$ $=0.7,5,500-$ Year Time Period Earthquakes 1886, A, B, C, D, and E ....................... H-33

Table H-5.3-1 Cheraw RLME Magnitude Distribution....

Table H-5.3-2 Annual Frequencies for Cheraw RLME Events In-Cluster Case, Data Set: 2 Earthquakes in 20-25 kyr

Table H-5.3-3 Annual Frequencies for Cheraw RLME Events In-Cluster Case, Data Set: 3 Earthquakes in 20-25 kyr

Table H-5.3-4 Slip Rates for Cheraw Fault In-Cluster Case, Data Set: 3.2-4.1 m in 20$25 \mathrm{kyr}$

Table H-5.3-5 Annual Frequencies for Cheraw RLME Events Out-of-Cluster Case, Time Between Clusters

Table H-5.3-6 Slip Rates for Cheraw Fault Out-of-Cluster Case, Data Set: 7-8 m in 0.42.0 myr .....

Table H-5.4-1 Meers RLME Magnitude Distribution

Table H-5.4-2 Annual Frequencies for Meers RLME Events In-Cluster Case. $\mathrm{H}-35$

Table H-5.4-3 Annual Frequencies for Meers RLME Events Out-of-Cluster Case H-36

Table H-5.5-1 NMFS RLME Magnitude Distribution ................................................. H-36

Table H-5.5-2 Annual Frequencies for NMFS RLME Events In-Cluster Case, Poisson Model

Table H-5.5-3 Annual Frequencies for NMFS RLME Events In-Cluster Case, BPT Model, $\alpha=0.3$

Table H-5.5-4 Annual Frequencies for NMFS RLME Events In-Cluster Case, BPT Model, $\alpha=0.5$

Table H-5.5-5 Annual Frequencies for NMFS RLME Events In-Cluster Case, BPT Model, $\alpha=0.7$

Table H-5.5-6 Annual Frequencies for NMFS RLME Events Out-of-Cluster Case, Poisson Model.

Table H-5.6-1 ERM-S RLME Magnitude Distribution................................................ H-38

Table H-5.6-2 ERM-N RLME Magnitude Distribution $\mathrm{H}-38$

Table H-5.6-3 Annual Frequencies for ERM-S RLME Events Data Set: 2 Earthquakes in 17.7-21.7 kyr

lxxxii 
Table H-5.6-4 Annual Frequencies for ERM-S RLME Events Data Set: 3 Earthquakes in 17.7-21.7 kyr

Table H-5.6-5 Annual Frequencies for ERM-S RLME Events Data Set: 4 Earthquakes in $17.7-21.7 \mathrm{kyr}$

Table H-5.6-6 Annual Frequencies for ERM-N RLME Events Data Set: 1 Earthquake in $12-35 \mathrm{kyr}$

Table H-5.6-7 Annual Frequencies for ERM-N RLME Events Data Set: 2 Earthquakes in $12-35 \mathrm{kyr}$

Table H-5.7-1 Marianna RLME Magnitude Distribution

Table H-5.7-2 Annual Frequencies for Marianna RLME Events Data Set: 3 Earthquakes in 9.6-10.2 kyr.

Table H-5.7-3 Annual Frequencies for Marianna RLME Events Data Set: 4 Earthquakes in $9.6-10.2 \mathrm{kyr}$

Table H-5.8-1 Commerce RLME Magnitude Distribution

Table H-5.8-2 Annual Frequencies for Commerce RLME Events Data Set: 2 Earthquakes in 18.9-23.6 kyr

Table H-5.8-3 Annual Frequencies for Commerce RLME Events Data Set: 3 Earthquakes in 18.9-23.6 kyr

Table H-5.9-1 Wabash RLME Magnitude Distribution

Table H-5.9-2 Annual Frequencies for Wabash RLME Events Data Set: 2 Earthquakes in 11-13 kyr.

PPRP Comment Response Table (Appendix I)

Table K-1 SCR Earthquake Catalog $\mathrm{K}-5$

Table K-2 SCR Domains Updated from Johnston et al. (1994) $\mathrm{K}-34$ 



\section{EXECUTIVE SUMMARY}

The Central and Eastern United States Seismic Source Characterization for Nuclear Facilities (CEUS SSC) Project was conducted over the period from April 2008 to December 2011 to provide a regional seismic source model for use in probabilistic seismic hazard analyses (PSHAs) for nuclear facilities. The study replaces previous regional seismic source models conducted for this purpose, including the Electric Power Research Institute-Seismicity Owners Group (EPRI-SOG) model (EPRI, 1988, 1989) and the Lawrence Livermore National Laboratory model (Bernreuter et al., 1989). Unlike the previous studies, the CEUS SSC Project was sponsored by multiple stakeholders - namely, the EPRI Advanced Nuclear Technology Program, the Office of Nuclear Energy and the Office of the Chief of Nuclear Safety of the U.S. Department of Energy (DOE), and the Office of Nuclear Regulatory Research of the Nuclear Regulatory Commission (NRC). The study was conducted using Senior Seismic Hazard Analysis Committee (SSHAC) Study Level 3 methodology to provide high levels of confidence that the data, models, and methods of the larger technical community have been considered and the center, body, and range of technically defensible interpretations have been included.

The regional seismic source characterization (SSC) model defined by this study can be used for site-specific PSHAs, provided that appropriate site-specific assessments are conducted as required by current regulations and regulatory guidance for the nuclear facility of interest. This model has been designed to be compatible with current and anticipated ground-motion characterization (GMC) models. The current recommended ground-motion models for use at nuclear facilities are those developed by EPRI (2004, 2006a, 2006b). The ongoing Next Generation Attenuation-East (NGA-East) project being supported by the NRC, DOE, and EPRI will provide ground-motion models that are appropriate for use with the CEUS SSC model. The methodology for a SSHAC Level 3 project as applied to the CEUS SSC Project is explained in the SSHAC report (Budnitz et al., 1997), which was written to discuss the evolution of expert assessment methodologies conducted during the previous three decades for purposes of probabilistic risk analyses. The methodological guidance provided in the SSHAC report was intended to build on the lessons learned from those previous studies and, specifically, to arrive at processes that would make it possible to avoid the issues encountered by the previous studies (NRC, 2011).

The SSHAC assessment process, which differs only slightly for Level 3 and 4 studies, is a technical process accepted in the NRC's seismic regulatory guidance (Regulatory Guide 1.208)

for ensuring that uncertainties in data and scientific knowledge have been properly represented in seismic design ground motions consistent with the requirements of the seismic regulation 10 CFR Part 100.23 (“Geologic and Seismic Siting Criteria”). Therefore, the goal of the SSHAC assessment process is the proper and complete representation of knowledge and uncertainties in the SSC and GMC inputs to the PSHA (or similar hazard analysis). As discussed extensively in 
the SSHAC report (Budnitz et al., 1997) and affirmed in NRC (2011), a SSHAC assessment process consists of two important sequential activities, evaluation and integration. For a Level 3 assessment, these activities are conducted by the Technical Integration (TI) Team under the leadership of the TI Lead. As described in NRC (2011),

The fundamental goal of a SSHAC process is to carry out properly and document completely the activities of evaluation and integration, defined as:

Evaluation: The consideration of the complete set of data, models, and methods proposed by the larger technical community that are relevant to the hazard analysis.

Integration: Representing the center, body, and range of technically defensible interpretations in light of the evaluation process (i.e., informed by the assessment of existing data, models, and methods).

Each of the assessment and model-building activities of the CEUS SSC Project is associated with the evaluation and integration steps in a SSHAC Level 3 process. Consistent with the requirements of a SSHAC process, the specific roles and responsibilities of all project participants were defined in the Project Plan, and adherence to those roles was the responsibility of the TI Lead and the Project Manager. The technical assessments are made by the TI Team, who carry the principal responsibility of evaluation and integration, under the technical leadership of the TI Lead. The Database Manager and other technical support individuals assist in the development of work products. Resource and proponent experts participate by presenting their data, models, and interpretations at workshops and through technical interchange with the TI Team throughout the project. The Participatory Peer Review Panel (PPRP) is responsible for a continuous review of both the SSHAC process being followed and the technical assessments being made. The project management structure is headed by the Project Manager, who serves as the liason with the sponsors and the PPRP and manages the activities of all participants. The SSHAC Level 3 assessment process and implementation is discussed in depth in Chapter 2 of this report.

Each of the methodology steps in the SSHAC guidelines (Budnitz, 1997) was addressed adequately during the CEUS SSC Project. Furthermore, the project developed a number of enhancements to the process steps for conducting a SSHAC Study Level 3 project. For example, the SSHAC guidelines call for process steps that include developing a preliminary assessment model, calculating hazard using that model in order to identify the key issues, and finalizing the model in light of the feedback provided from the hazard calculations and sensitivity analyses. Because of the regional nature of the project and the multitude of assessments required, four rounds of model-building and three rounds of feedback were conducted. These activities ensured that all significant issues and uncertainties were identified and that the appropriate effort was devoted to the issues of most significance to the hazard results. A comparison of the activities conducted during the CEUS SSC Project with those recommended in the SSHAC guidelines themselves (Section 2.6) led to the conclusion that the current standards of practice have been met for a SSHAC Study Level 3 process - both those that are documented in the SSHAC report and those that resulted from precedents set by projects conducted since the SSHAC report was issued.

lxxxvi 
The catalog of past earthquakes that have occurred in a region is an important source of information for the quantification of future seismic hazards. This is particularly true in stable continental regions (SCRs) such as the CEUS where the causative mechanisms and structures for the occurrence of damaging earthquakes are generally poorly understood, and the rates of crustal deformation are low such that surface and near-surface indications of stresses in the crust and the buildup and release of crustal strains are difficult to quantify. Because the earthquake catalog is used in the characterization of the occurrence of future earthquakes in the CEUS, developing an updated earthquake catalog for the study region was an important focus of the CEUS SSC Project. The specific goals for earthquake catalog development and methods used to attain those goals are given in Chapter 3.

The earthquake catalog development consists of four main steps: catalog compilation, assessment of a uniform size measure to apply to each earthquake, identification of dependent earthquakes (catalog declustering), and assessment of the completeness of the catalog as a function of location, time, and earthquake size. An important part of the catalog development process was review by seismologists with extensive knowledge and experience in catalog compilation. The result is an earthquake catalog covering the entire study region for the period from 1568 through the end of 2008. Earthquake size is defined in terms of the moment magnitude scale (Hanks and Kanamori, 1979), consistent with the magnitude scale used in modern ground-motion prediction equations (GMPEs) for CEUS earthquakes. A significant contribution of the CEUS SSC Project is the work conducted to develop an updated and consistent set of conversion relationships between various earthquake size measures (instrumental magnitudes and intensity) and moment magnitude.

The conceptual SSC framework described in Chapter 4 was developed early in the CEUS SSC Project in order to provide a consistent approach and philosophy to SSC by the TI Team. This framework provides the basic underpinnings of the SSC model developed for the project, and it led to the basic structure and elements of the master logic tree developed for the SSC model. In considering the purpose of the CEUS SSC Project, the TI Team identified three attributes that are needed for a conceptual SSC framework:

1. A systematic, documented approach to treating alternatives using logic trees, including alternative conceptual models for future spatial distributions of seismicity (e.g., stationarity); alternative methods for expressing the future temporal distribution of seismicity (e.g., renewal models, Poisson models); and alternative data sets for characterizing seismic sources (e.g., paleoseismic data, historical seismicity data).

2. A systematic approach to identifying applicable data for the source characterization, evaluating the usefulness of the data, and documenting the consideration given to the data by the TI Team.

3. A methodology for identifying seismic sources based on defensible criteria for defining a seismic source, incorporating the lessons learned in SSC over the past two decades, and identifying the range of approaches and models that can be shown to be significant to hazard.

Each of these needs was addressed by the methodology used in the project. For example, the need for a systematic approach to identifying and evaluating the data and information that underlie the source characterization assessments was met by the development of Data Summary 
and Data Evaluation tables. These tables were developed for each seismic source to document the information available at the time of the CEUS SSC assessments (the Data Summary tables) and the way those data were used in the characterization process (the Data Evaluation tables). Given the evolution of approaches to identifying seismic sources, it is appropriate to provide a set of criteria and the logic for their application in the CEUS SSC Project. In the project, unique seismic sources are defined to account for distinct differences in the following criteria:

- Earthquake recurrence rate

- Maximum earthquake magnitude (Mmax)

- Expected future earthquake characteristics (e.g., style of faulting, rupture orientation, depth distribution)

- Probability of activity of tectonic feature(s)

Rather than treat these criteria as operating simultaneously or without priority, the CEUS SSC methodology works through them sequentially. Further, because each criterion adds complexity to the seismic source model, it is applied only if its application would lead to hazard-significant changes in the model. In this way, the model becomes only as complex as required by the available data and information.

The CEUS SSC master logic tree is tied to the conceptual SSC framework that establishes the context for the entire seismic source model. The master logic tree depicts the alternative interpretations and conceptual models that represent the range of defensible interpretations, and the relative weights assessed for the alternatives. By laying out the alternatives initially, the subsequent detailed source evaluations were conducted within a framework that ensures consistency across the sources. Important elements of the master logic tree are as follows:

- Representation of the sources defined based on paleoseismic evidence for the occurrence of repeated large-magnitude earthquakes (RLMEs, defined as two or more earthquakes with $\mathbf{M} \geq 6.5)$.

- Alternatives to the spatial distribution of earthquakes based on differences in maximum magnitudes (Mmax zones approach).

- Representation of uncertainty in spatial stationarity of observed seismicity based on smoothing of recurrence parameters.

- Representation of possible differences in future earthquake characteristics (e.g., style, seismogenic thickness, and orientation of ruptures), which lead to definition of seismotectonic zones in the logic tree (seismotectonic zones approach).

The methodologies used by the project to make the SSC assessments are discussed in Chapter 5. The heart of any SSC model for PSHA is a description of the future spatial and temporal distribution of earthquakes. Continued analysis of the historical seismicity record and network monitoring by regional and local seismic networks has led to acceptance within the community that the general spatial patterns of observed small- to moderate-magnitude earthquakes provide predictive information about the spatial distribution of future large-magnitude earthquakes. The analyses leading to this conclusion have focused on whether the observed patterns of earthquakes 
have varied through time; therefore, in effect, this is an assessment of uncertainty in whether small- to moderate-magnitude earthquakes have been relatively stationary through time. However, the available data on larger-magnitude earthquakes and their relationship to the spatial distribution of smaller earthquakes based on the observed record are quite limited. These data are not sufficient to allow confidence in the predictions generated by empirical spatial models. For this reason, geologic and geophysical data are needed to specify the locations of future earthquakes in addition to the observed patterns of seismicity.

Detailed studies in the vicinity of large historical and instrumental earthquakes, and liquefaction phenomena associated with them, coupled with field and laboratory studies of geotechnical properties, are leading to a stronger technical basis for (1) placing limits on the locations of paleoearthquakes interpreted by the distribution of liquefaction phenomena and (2) defining their magnitudes. In some cases, the paleoseismic evidence for RLMEs is compelling, and the TI Team has included the RLME source in the SSC model. The locations of RLME sources notwithstanding, the spatial distribution of distributed seismicity sources has advanced in PSHA largely because of the assumption of spatial stationarity, and the SSC and hazard community uses approaches to "smooth" observed seismicity to provide a map that expresses the future spatial pattern of recurrence rates. The CEUS SSC model is based largely on the assumption, typical in PSHA studies, that spatial stationarity of seismicity is expected to persist for a period of approximately 50 years.

Estimating Mmax in SCRs such as the CEUS is highly uncertain despite considerable interest and effort by the scientific community over the past few decades. Mmax is defined as the upper truncation point of the earthquake recurrence curve for individual seismic sources, and the typically broad distribution of Mmax for any given source reflects considerable epistemic uncertainty. Because the maximum magnitude for any given seismic source in the CEUS occurs rarely relative to the period of observation, the use of the historical seismicity record provides important but limited constraints on the magnitude of the maximum event. Because of the independent constraints on earthquake size, those limited constraints are used to estimate the magnitudes of RLME. For distributed seismicity source zones, two approaches are used to assess Mmax: the Bayesian approach and the Kijko approach. In the Bayesian procedure (Johnston et al., 1994), the prior distribution is based on the magnitudes of earthquakes that occurred worldwide within tectonically analogous regions. As part of the CEUS SSC Project, the TI Team pursued the refinement and application of the Bayesian Mmax approach becauses it provides a quantitative and repeatable process for assessing Mmax.

The TI Team also explored alternative approaches for the assessment of Mmax that provide quantitative and repeatable results, and the team identified the approach developed by Kijko (2004) as a viable alternative. While the Kijko approach requires fewer assumptions than the Bayesian approach in that it uses only the observed earthquake statistics for the source, this is offset by the need for a relatively larger data sample in order to get meaningful results. Both approaches have the positive attribute that they are repeatable given the same data and they can be readily updated given new information. The relative weighting of the two approaches for inclusion in the logic tree is source-specific, a function of the numbers of earthquakes that are present within the source upon which to base the Mmax assessment: sources with fewer earthquakes are assessed to have little or no weight for the Kijko approach, while those with 
larger numbers of events are assessed higher weight for the Kijko approach. In all cases, because of the stability of the Bayesian approach and the preference for "analogue" approaches within the larger technical community, the Bayesian approach is assessed higher weight than the Kijko approach for all sources.

A major effort was devoted to updating the global set of SCR earthquakes and to assessing statistically significant attributes of those earthquakes following the approach given in Johnston et al. (1994). In doing so, it was found that the only significant attribute defining the prior distribution is the presence or absence of Mesozoic-or-younger extension. The uncertainty in this assessment is reflected in the use of two alternative priors: one that takes into account the presence or absence of crustal domains having this attribute, and another that combines the entire CEUS region as a single SCR crustal domain with a single prior distribution. The use of the Bayesian - and Kijko - approach requires a definition of the largest observed magnitude within each source, and this assessment, along with the associated uncertainty, was incorporated into the Mmax distributions for each seismic source. Consideration of global analogues led to the assessment of an upper truncation to all Mmax distributions at 81/4 and a lower truncation at 51/2. The broad distributions of Mmax for the various seismic source zones reflect the current epistemic uncertainty in the largest earthquake magnitude within each seismic source.

The CEUS SSC model is based to a large extent on an assessment that spatial stationarity of seismicity will persist for time periods of interest for PSHA (approximately the next 50 years). Stationarity in this sense does not mean that future locations and magnitudes of earthquakes will occur exactly where they have occurred in the historical and instrumental record. Rather, the degree of spatial stationarity varies as a function of the type of data available to define the seismic source. RLME sources are based largely on paleoseismic evidence for repeated largemagnitude $(M \geq 6.5)$ earthquakes that occur in approximately the same location over periods of a few thousand years. On the other hand, patterns of seismicity away from the RLME sources within the Mmax and seismotectonic zones are defined from generally small- to moderatemagnitude earthquakes that have occurred during a relatively short (i.e., relative to the repeat times of large events) historical and instrumental record. Thus, the locations of future events are not as tightly constrained by the locations of past events as for RLME sources. The spatial smoothing operation is based on calculations of earthquake recurrence within one-quarter-degree or half-degree cells, with allowance for "communication" between the cells. Both $a$ - and $b$ values are allowed to vary, but the degree of variation has been optimized such that $b$-values vary little across the study region.

The approach used to smooth recurrence parameters is a refinement of the penalized-likelihood approach used in EPRI-SOG (EPRI, 1988), but it is designed to include a number of elements that make the formulation more robust, realistic, and flexible. These elements include the reformulation in terms of magnitude bins, the introduction of magnitude-dependent weights, catalog incompleteness, the effect of Mmax, spatial variation of parameters within the source zone, and the prior distributions of $b$. A key assessment made by the TI Team was the weight assigned to various magnitude bins in the assessment of smoothing parameters (Cases A, B, and E). This assessment represents the uncertainty in the interpretation that smaller magnitudes define the future locations and variation in recurrence parameters. Appropriately, the penalizedlikelihood approach results in higher spatial variation (less smoothing) when the low-magnitude 
bins are included with high weight, and much less variation (higher smoothing) in the case where the lower-magnitude bins are given low or zero weight. The variation resulting from the final set of weights reflects the TI Team's assessment of the epistemic uncertainty in the spatial variation of recurrence parameters throughout the SSC model.

The earthquake recurrence models for the RLME sources are somewhat simpler than those for distributed seismicity sources because the magnitude range for individual RLMEs is relatively narrow and their spatial distribution is limited geographically such that spatial variability is not a concern. This limits the problem to one of estimating the occurrence rate in time of a point process. The data that are used to assess the occurrence rates are derived primarily from paleoseismic studies and consist of two types: data that provide estimated ages of the paleoearthquakes such that the times between earthquakes can be estimated, and data that provide an estimate of the number of earthquakes that have occurred after the age of a particular stratigraphic horizon. These data are used to derive estimates of the RLME occurrence rates and their uncertainty.

The estimation of the RLME occurrence rates is dependent on the probability model assumed for the temporal occurrence of these earthquakes. The standard model applied for most RLME sources in this study is the Poisson model, in which the probability of occurrence of an RLME in a specified time period is completely characterized by a single parameter, $\lambda$, the rate of RLME occurrence. The Poisson process is "memoryless"-that is, the probability of occurrence in the next time interval is independent of when the most recent earthquake occurred, and the time between earthquakes is exponentially distributed with a standard deviation equal to the mean time between earthquakes. For two RLME sources (Reelfoot Rift-New Madrid fault system and the Charleston source), the data are sufficient to suggest that the occurrence of RLMEs is more periodic in nature (the standard deviation is less than the mean time between earthquakes). For these RLME sources a simple renewal model can also be used to assess the probability of earthquake occurrence. In making an estimate of the probability of occurrence in the future, this model takes into account the time that has elapsed since the most recent RLME occurrence.

The CEUS SSC model has been developed for use in future PSHAs. To make this future use possible, the SSC model must be combined with a GMC model. At present, the GMPEs in use for SCRs such as the CEUS include limited information regarding the characteristics of future earthquakes. In anticipation of the possible future development of GMPEs for the CEUS that will make it possible to incorporate similar types of information, a number of characteristics of future earthquakes in the CEUS are assessed. In addition to characteristics that might be important for ground motion assessments, there are also assessed characteristics that are potentially important to the modeling conducted for hazard analysis. Future earthquake characteristics assessed include the tectonic stress regime, sense of slip/style of faulting, strike and dip of ruptures, seismogenic crustal thickness, fault rupture area versus magnitude relationship, rupture length-to-width aspect ratio, and relationship of ruptures to source boundaries.

Chapters 6 and 7 include discussions of the seismic sources that are defined by the Mmax zones and the seismotectonic zones branches of the master logic tree. Because of convincing evidence for their existence, both approaches include RLME sources. The rarity of repeated earthquakes relative to the period of historical observation means that evidence for repeated events comes 
largely from the paleoseismic record. By identifying the RLMEs and including them in the SSC model, there is no implication that the set of RLMEs included is in fact the total set of RLMEs that might exist throughout the study region. This is because the presently available studies that locate and characterize the RLMEs have been concentrated in certain locations and are not systematic across the entire study region. Therefore, the evidence for the existence of the RLMEs is included in the model where it exists, but the remaining parts of the study region are also assessed to have significant earthquake potential, which is evidenced by the inclusion of moderate-to-large magnitudes in the Mmax distributions for every Mmax zone or seismotectonic zone.

In Chapter 6, each RLME source is described in detail by the following factors: (1) evidence for temporal clustering, (2) geometry and style of faulting, (3) RLME magnitude, and (4) RLME recurrence. The descriptions document how the data have been evaluated and assessed to arrive at the various elements of the final SSC model, including all expressions of uncertainty. The Data Summary and Data Evaluation tables (Appendices C and D) complement the discussions in the text, documenting all the data that were considered in the course of data evaluation and integration process for each particular seismic source.

Alternative models for the distributed seismicity zones that serve as background zones to the RLME sources are either Mmax zones or seismotectonic zones. The Mmax zones are described in Chapter 6 and are defined according to constraints on the prior distributions for the Bayesian approach to estimating Mmax. The seismotectonic zones are described in Chapter 7 and are identified based on potential differences in Mmax as well as future earthquake characteristics. Each seismotectonic zone in the CEUS SSC model is described according to the following attributes: (1) background information from various data sets; (2) bases for defining the seismotectonic zone; (3) basis for the source geometry; (4) basis for the zone Mmax (e.g., largest observed earthquake); and (5) future earthquake characteristics. Uncertainties in the seismotectonic zone characteristics are described and are represented in the logic trees developed for each source.

For purposes of demonstrating the CEUS SSC model, seismic hazard calculations were conducted at seven demonstration sites throughout the study region, as described in Chapter 8 . The site locations were selected to span a range of seismic source types and levels of seismicity. The results from the seismic hazard calculations are intended for scientific use to demonstrate the model, and they should not be used for engineering design. Mean hazard results are given for a range of spectral frequencies (PGA, $10 \mathrm{~Hz}$, and $1 \mathrm{~Hz}$ ) and for a range of site conditions. All calculations were made using the EPRI $(2004,2006)$ ground-motion models such that results could be compared to understand the SSC effects alone. Sensitivity analyses were conducted to provide insight into the dominant seismic sources and the important characteristics of the dominant seismic source at each site. The calculated mean hazard results are compared with the results using the SSC model from the 2008 U.S. Geological Survey national seismic hazard maps and the SSC model from the Combined Operating License applications for new nuclear power reactors. The hazard results using the CEUS SSC model given in Chapter 8 are reasonable and readily understood relative to the results from other studies, and sensitivities of the calculated hazard results can be readily explained by different aspects of the new model. The TI Team concludes that the SSC model provides reasonable and explainable calculated seismic hazard 
results, and the most important aspects of the SSC model to the calculated hazard (e.g., recurrence rates of RLME sources, recurrence parameters for distributed seismicity sources, Mmax) and their uncertainties have all been appropriately addressed.

Presumably, the GMC model input to the PSHA calculations will be replaced in the future by the results of the ongoing NGA-East project. The calculated hazard at the demonstration sites in Chapter 8 comes from the regional CEUS SSC model and does not include any local refinements that might be necessary to account for local seismic sources. Depending on the regulatory guidance that is applicable for the facility of interest, additional site-specific studies may be required to provide local refinements to the model.

To assist future users of the CEUS SSC model, Chapter 9 presents a discussion on the use of the model for PSHA. The basic elements of the model necessary for hazard calculations are given in the Hazard Input Document (HID). This document provides all necessary parameter values and probability distributions for use in a modern PSHA computer code. The HID does not, however, provide any justification for the values, since that information is given in the text of this report.

Chapter 9 also describes several simplifications to seismic sources that can be made to increase efficiency in seismic hazard calculations. These simplifications are recommended on the basis of sensitivity studies of alternative hazard curves that represent a range of assumptions on a parameter's value. Sensitivities are presented using the test sites in this study. For applications of the seismic sources from this study, similar sensitivity studies should be conducted for the particular site of interest to confirm these results and to identify additional simplifications that might be appropriate. For the seismic sources presented, only those parameters that can be simplified are discussed and presented graphically. The sensitivity studies consisted of determining the sensitivity of hazard to logic tree branches for each node of the logic tree describing that source. The purpose was to determine which nodes of the logic tree could be collapsed to a single branch in order to achieve more efficient hazard calculations without compromising the accuracy of overall hazard results.

Finally, this report provides a discussion of the level of precision that is associated with seismic hazard estimates in the CEUS. This discussion addresses how seismic hazard estimates might change if the analysis were repeated by independent experts having access to the same basic information (geology, tectonics, seismicity, ground-motion equations, site characterization). It also addresses how to determine whether the difference in hazard would be significant if this basic information were to change and that change resulted in a difference in the assessed seismic hazard. This analysis was performed knowing that future data and models will continue to be developed and that a mechanism for evaluating the significance of that information is needed. Based on the precision model evaluated, if an alternative assumption or parameter is used in a seismic hazard study, and it potentially changes the calculated hazard (annual frequency of exceedence) by less than 25 percent for ground motions with hazards in the range $10^{-4}$ to $10^{-6}$, that potential change is within the level of precision at which one can calculate seismic hazard. It should be noted, however, that a certain level of precision does not relieve users from performing site-specific studies to identify potential capable seismic sources within the site region and vicinity as well as to identify newer models and data. Also, this level of precision does not relieve users from fixing any errors that are discovered in the CEUS SSC model as it is 
implemented for siting critical facilities. In addition, NRC has not defined a set value for requiring or not requiring siting applicants to revise or update PSHAs.

Included in the report are appendices that summarize key data sets and analyses: the earthquake catalog, the Data Summary and Data Evaluation tables, the paleoliquefaction database, the HID, and documentation important to the SSHAC process. These data and analyses will assist future users of the CEUS SSC model in the implementation of the model for purposes of PSHA. The entire report and database will be provided on a website after the Final Project Report is issued.

The TI Team, Project Manager, and Sponsors determined the approach for quality assurance on the CEUS SSC Project in 2008, taking into account the SSHAC assessment process and national standards. The approach was documented in the CEUS SSC Project Plan dated June 2008 and discussed in more detail in the CEUS SSC Report (Appendix L). Beyond the assurance of quality arising from the external scientific review process, it is the collective, informed judgment of the TI Team (via the process of evaluation and integration) and the concurrence of the PPRP (via the participatory peer review process), as well as adherence to the national standard referred to in Appendix L, that ultimately lead to the assurance of quality in the process followed and in the products that resulted from the SSHAC hazard assessment framework. 
October 24, 2011

Cliff Munson

Senior Technical Advisor

Office of New Reactors

U.S. Nuclear Regulatory Commission

Washington, DC 20555

Richard H. Lagdon, Jr.

Chief of Nuclear Safety

Office of the Under Secretary for Nuclear

Security, S-5

U.S. Department of Energy

1000 Independence Avenue SW

Washington, DC 20585

Jeffrey F. Hamel

Advanced Nuclear Technology Program

Manager

Electric Power Research Institute

3420 Hillview Avenue

Palo Alto, CA 94304
Robert Roche

Project Manager

Office of Nuclear Regulatory Research

U.S. Nuclear Regulatory Commission

Washington, DC 20555

Thomas P. Miller

Senior Technical Advisor

Office of Nuclear Energy, NE-72/GTN

U.S. Department of Energy

1000 Independence Avenue SW

Washington, DC 20585

Gentlemen:

Reference: Central and Eastern United States Seismic Source Characterization for Nuclear Facilities Project: Participatory Peer Review Panel Final Report

\section{Introduction}

This letter constitutes the final report of the PPRP ("the Panel") for the Central and Eastern United States Seismic Source Characterization for Nuclear Facilities Project (the "CEUS SSC Project" or "the Project"). The eight Panel members (Jon P. Ake, Walter J. Arabasz, William J. Hinze, Annie M. Kammerer, Jeffrey K. Kimball, Donald P. Moore, Mark D. Petersen, J. Carl Stepp) participated in the Project in a manner fully consistent with the SSHAC Guidance. ${ }^{2}$ The Panel was actively engaged in all phases and activities of the Project's implementation, including final development of the Project Plan and planning of the evaluation and integration activities, which are the core of the SSHAC assessment process.

\footnotetext{
${ }^{1}$ Participatory Peer Review Panel

${ }^{2}$ Budnitz, R. J., G. Apostolakis, D. M. Boore, L. S. Cluff, K. L. Coppersmith, C. A. Cornell, and P. A. Morris, 1997. Recommendations for Probabilistic Seismic Hazard Analysis: Guidance on Uncertainty and the Use of Experts (known as the "Senior Seismic Hazard Analysis Committee Report," or the "SSHAC Guidance"). NUREG/CR-6372, U. S. Nuclear Regulatory Commission. TIC; 235076. Washington, DC.
} 
The Panel's involvement, described more fully later in this letter, also included review of analyses performed by the Project to support the evaluation and integration processes, review of interim evaluation and integration products, and review of the interim draft project report and the final project report. Additionally, panel members participated in specific analyses as resource experts, and panel members were observers in or participated as resource experts in eight of the eleven Technical Integrator Team (TI Team) working meetings held to implement the integration phase of the assessment process. We want to express our appreciation for the opportunity to participate in the CEUS SSC Project in this way.

In the remainder of this letter we provide our observations and conclusions on key elements of the project implementation process, and we summarize our reviews of the draft and final project reports. As we explain in our comments, assurance that the center, body, and range of the technically-defensible interpretations ("CBR of the TDI") ${ }^{3}$ have been properly represented in the CEUS SSC Model fundamentally comes from implementing the structure and rigor of the SSHAC Guidance itself. We are aware that the SSHAC Guidance is accepted by the Nuclear Regulatory Commission and the Department of Energy for developing seismic hazard models that provide reasonable assurance, consistent with the seismic safety decision-making practices of these agencies, of compliance with their seismic safety policies and regulatory requirements. For these reasons, we describe aspects of the SSHAC Guidance to provide context for our observations and conclusions.

\section{Project Plan: Conformity to the SSHAC Assessment Process}

The SSHAC Guidance recognizes that observed data, available methods, models, and interpretations all contain uncertainties. These uncertainties lead to alternative scientific analyses and interpretations. In other words, experts in the broad technical community do not hold a single interpretation. Accepting this scientific situation, the SSHAC assessment process is designed to engage the scientific community in an orderly assessment of relevant data, methods, models, and interpretations that constitute current scientific knowledge as the basis for development of a seismic hazard model that represents the CBR of the TDI.

The assessment process is carried out by means of two main activities: evaluation and integration. ${ }^{4}$ In implementation, the evaluation activities are structured to inform the integration activities. The evaluations are carried out by means of workshops in which the TI Team engages proponents of alternative interpretations that represent the range of relevant current community knowledge. Resource experts in the various relevant data sets are also engaged. The workshops have the dual purposes of, first, evaluating the degree to which alternative interpretations are supported by observed data and, second, defining uncertainties in the degree to which the interpretations are defensible, given the observed data. Integration is carried out by individual evaluator experts or evaluator expert teams (Level 4 process) or by a Technical Integrator (TI) Team (Level 3 process) who, informed by the evaluation activities, characterize the range of

\footnotetext{
${ }^{3}$ See Section 2.1 in the CEUS SSC Final Report for discussion of concepts relating to the center, body, and range of the "technically-defensible interpretations" vs. the center, body, and range of the "informed technical community."

${ }^{4}$ For an excellent discussion of this two-stage process, see Practical Implementation Guidelines for SSHAC Level 3 and 4 Hazard Studies, USNRC NUREG-XXXX, Draft for Review, Office of Nuclear Regulatory Research, May 2011.
} 
defensible alternative interpretations in an integrated hazard model and assess the scientific uncertainty distribution. Based on our review of the Project Plan and our subsequent discussions with the Project Team, we concurred that the Plan conformed with the SSHAC Guidance, incorporating lessons learned from fourteen years experience using the Guidance, and that the planned implementation was structured to properly carry out the SSHAC assessment process for development of the CEUS SSC Model.

\section{SSHAC Level 3 Assessment Process}

The SSHAC Guidance describes implementation processes for four levels of assessment depending on the scientific complexity of the assessment and the intended use of the assessed hazard model. For an assessment such as the regional SSC model for the Central and Eastern United States, which will be used at many sites for making safety and licensing decisions for nuclear facilities, the SSHAC Guidance recommends using an assessment Level 3 or Level 4.

There are process differences between a Level 3 and Level 4 implementation, but the objective is the same: to obtain from multiple proponent experts information that supports an informed assessment of the range of existent relevant interpretations and associated uncertainties that together represent current community knowledge and to perform an informed assessment of the CBR of the TDI. We understand that within the SSHAC assessment process "technically defensible" means that observed data are sufficient to support evaluation of the interpretation and the corresponding uncertainty.

In a Level 4 assessment process a TI Team facilitates the assessment, identifying and engaging proponent and resource experts, performing supporting analyses, and conducting knowledge evaluation workshops and assessment integration working meetings. Multiple experts or teams of experts perform as evaluators of the range of existent interpretations and as integrators of the hazard model. The individual evaluator experts or evaluator expert teams take ownership of their individual or team assessments. In a Level 3 assessment all of these activities are consolidated under a single TI Team consisting of a TI Lead, multiple evaluator experts representing the scope of required scientific expertise, and experienced data and hazard analysts.

As we noted earlier in this report, assurance that the CBR of the TDI is properly represented in a hazard model comes from rigorously implementing the SSHAC assessment process itself. We note that an important lesson learned from multiple implementations of the SSHAC Guidance over the past fourteen years is that the Level 3 and Level 4 assessment processes provide comparably high assurance that the relevant scientific knowledge and the community uncertainty distribution are properly assessed and represented in the hazard model. The Level 3 assessment is significantly more integrated and cohesive and is more efficient to implement. These considerations led us to endorse use of the Level 3 assessment for implementation of the CEUS SSC Project in our Workshop No. 1 review letter. During the course of the Project we observed that the higher level of cohesiveness inherent in the Level 3 assessment process leads to significantly improved communication, facilitating the experts' performance of their technical work. 


\section{Overall Project Organization}

A complex project with multiple sponsors such as the CEUS SSC Project cannot be successful unless it is well organized and energetically managed so that the various participants understand the interconnectedness of their activities and perform their technical work as a cohesive group. In this regard the adopted project management structure allowed the Project Manager to provide integrated overall project leadership, manage the database development activities, and effectively maintain communication with the PPRP and project sponsors while allowing TI Team lead to concentrate on the structural and technical activities of the assessment as the Project unfolded. We conclude that the project organization was effective overall and particularly so with regard to facilitating the TI Team's implementation of the assessment process.

\section{Implementing the SSHAC Level 3 Assessment Process}

Irrespective of the level of implementation, evaluation and integration are the main activities of a SSHAC assessment. The evaluation activities aim to identify and evaluate all relevant available data, models, methods, and scientific interpretations as well as uncertainties associated with each of them. The integration activities, informed by the evaluations, aim to represent the CBR of the TDI in a fully integrated SSC model.

\section{Evaluation}

Consistent with the SSHAC Guidance the evaluation phase of the CEUS SSC project accomplished a comprehensive evaluation of the data, models, methods, and scientific interpretations existent in the larger technical community that are relevant to the SSC model. In significant part the process was carried out in three structured workshops, each focusing on accomplishing a specific step in the evaluation process.

The first workshop (WS-1) focused on evaluations of relevant geological, geophysical, and seismological datasets (including data quality and uncertainties) and on identification of hazardsignificant data and hazard-significant SSC assessment issues. It became clear that a number of issues relating to the earthquake catalog, the paleoliquefaction data set, the potential-field geophysical data, updating procedures for assessing maximum earthquake magnitude, and development of procedures for assessing earthquake recurrence would require focused analyses. These analyses were appropriately carried out within the TI Team working interactively with appropriate resource experts recognized by the larger scientific and technical community.

WS-2 focused on evaluations of the range of alternative scientific interpretations, methods, and models within the larger scientific community and on corresponding uncertainties. WS-3 focused on evaluations of hazard feedback derived at seven representative test locations using a preliminary CEUS SSC model. Specifically, the workshop focused on the identification of the key issues of most significance to completing the SSC model assessment.

Experience has shown that evaluations to gain understanding of the quality of various data sets and uncertainties associated with them are essential for fully informing an SSC assessment. We observed that in WS-1 resource experts for the various data sets did a high-quality job of describing the data sets and giving their perspective about the data quality and associated uncertainties. We conclude that the understanding of data quality and uncertainties gained in WS-1 together with continued interactions between the TI Team and data resource experts 
significantly informed the TI Team's evaluations. The TI Team's evaluations of the data quality and uncertainties are well documented in the innovative "Data Summary Tables" and "Data Evaluation Tables" included in the Project Report. Importantly, the TI Team continued to effectively engage data resource experts in productive analyses of potential-field geophysical data, the earthquake catalog, development of the paleoearthquake data set (including an integrated assessment of the paleoliquefaction data in order to extend the earthquake catalog), the development of methods for assessing maximum earthquakes, and the development of earthquake recurrence analyses. All of these focused analyses strongly informed the assessment process. Moreover, documentation of the analyses resulted in stand-alone products of the Project that will serve future users of the CEUS SSC Model.

The compilation and evaluation of potentially relevant methods, models, and alternative scientific interpretations representing the community knowledge and corresponding uncertainties must be considered the core process activity of any SSHAC assessment. This step was largely carried out in WS-2. Success in defining the community knowledge depends on fully engaging proponent experts representing the range of methods, models, and interpretations existent at the time. Full engagement means that the proponent experts completely and clearly describe their interpretations and the data that support them and provide their individual evaluations of corresponding uncertainties. We observed that the actions taken by the Project and TI Team to explain the workshop goals and to guide participants toward meeting those goals was very productive. We conclude that the workshop was highly successful in meeting the stated goals and that it fully met the expectation of the SSHAC Guidance with respect to evaluating the range of alternative scientific interpretations. The discussions during the workshop and between the TI Team and Panel following the workshop evolved the "SSC Framework" concept, which provided transparent criteria that framed the TI Team's systematic identification and assessment of seismic sources throughout the CEUS.

Feedback from hazard calculations and sensitivity analyses is an important step in a SSHAC assessment to understand the importance of elements of the model and inform the final assessments. For development of a regional SSC model to be used for site-specific probabilistic seismic hazard analyses (PSHAs) at many geographically distributed sites, feedback based on the preliminary model is particularly important. Following WS-2 a preliminary SSC model termed "the SSC sensitivity model," was developed and used for hazard sensitivity calculations that were evaluated in WS-3. While the SSC sensitivity model was clearly preliminary, the evaluation of sensitivity results that took place in WS-3 provided important feedback for completing analyses and for supporting the TI Team's development of the preliminary CEUS SSC model. The Panel was able to review the preliminary model and provide feedback in a subsequent project briefing meeting on March 24, 2010.

Together the three workshops provided the TI Team interactions with the appropriate range of resource and proponent experts. These experts were carefully identified to present, discuss, and debate the data, models, and methods that together form the basis for assuring that the CBR of the TDI have been properly represented in the hazard model. Experts representing academia, government, and private industry participated. The TI Team also reached out to a wide range of experts as they developed the database and performed the integration activities to develop the SSC model. The Panel participated throughout this process, and is satisfied that the TI Team fully engaged appropriate experts to accomplish the goals of a SSHAC Guidance. 


\section{Integration}

Consistent with the SSHAC Guidance, integration is the process of assessing the CBR of the TDI and representing the assessment in the SSC model. Informed by the evaluation process, the integration process includes representation of the range of defensible methods, models, and interpretations of the larger technical community together with new models and methods developed by analyses during the evaluation and integration process.

For the CEUS SSC Project, development of the earthquake catalog, methods for assessing and representing maximum earthquake magnitudes, and methods for earthquake recurrence assessment continued during the integration process. The Panel reviewed all the analyses at various stages of development and provided comments and recommendations. The TI Team performed the integration process by means of eleven working meetings. Members of the Panel participated in most of these working meetings as observers or resource experts. The full Panel participated in the discussions during both feedback meetings and provided formal comments and recommendations following the meetings. We observed that the integration process was thorough and that it acceptably complied with the SSHAC Guidance. Based on our participation and observations we conclude that the integrated CEUS SSC Model appropriately represents the center, body, and range of current methods, models and technically defensible interpretations.

\section{PPRP Engagement}

Consistent with the SSHAC Guidance, the Panel was fully engaged in peer-review interactions with the TI Team and the Project Manager of the CEUS SSC Project throughout the entire project period - from development of the Project Plan in early to mid 2008 through production of the Final Project Report in mid to late 2011. ${ }^{5}$ The Panel provided both written and oral peerreview comments on both technical and process aspects at many stages of the Project's evolution. Key PPRP activities, leading up to this final report, have included:

- Review of the Project Plan.

- Formulation of a PPRP implementation plan, specifically for the CEUS SSC Project, to ensure adherence to the general guidance provided by SSHAC and NUREG-1563 for the scope and goals of a PPRP review.

- Involvement in each of the three Project workshops, including advising in the planning stage; participating collectively as a review panel during the workshop (and individually as resource experts when requested by the TI Team), providing timely comments on technical and process issues; and submitting a written report of the Panel's observations and recommendations following each workshop.

- Development and implementation of a process, together with the TI Team, to document the resolution of recommendations made in PPRP formal communications.

- Participation as observers (and occasionally as resource experts when requested by the TI Team) in eight of the TI Team's 11 working meetings.

- Peer-review and written comments, including several informal reports, on the TI Team's intermediate work products, particularly early versions of the CEUS SSC Model.

\footnotetext{
${ }^{5}$ See CEUS SSC Final Report: Section 2.5, Table 2.2-1, and Appendix I
} 
- Direct interaction with the TI Team and Project Manager in more than 20 teleconferences and four face-to-face briefings - in addition to the three workshops and eight working meetings of the TI Team noted above.

- Extensive, critical peer-review of the Project's 2010 Draft Report and 2011 Final Report.

The Panel, collectively and individually, fully understood the SSHAC Guidance for a structured participatory peer review and the requirements for a Level 3 assessment process; had full and frequent access to information and interacted extensively with the TI Team and Project Manager throughout the entire project; provided peer-review comments at numerous stages; and, as documented within the Final Project Report, was fully engaged to meet its peer-review obligations in an effective way.

\section{Project Report}

The SSHAC Guidance makes clear that adequate documentation of process and results is crucial for their understanding and use by others in the technical community, by later analysis teams, and by the project sponsors. The Panel understood what was needed to conform to the SSHAC requirements, and it was committed to ensuring that the documentation of technical details associated with the CEUS SSC Model in the Project Report was clear and complete. The Panel was equally committed to ensuring the transparency of process aspects of the project, both in implementation and in description in the Project Report.

The Panel provided lengthy compilations of review comments (see Appendix I of the Project Report) for both the 2010 Draft Report and the 2011 Final Report. These included hundreds of comments, categorized as general, specific, relating to clarity and completeness, or editorial. The massive amount of detail provided by the TI Team in the Project Report and the intensiveness of the Panel's review comments both reflect great diligence and a mutual understanding by the TI Team and the PPRP of the thoroughness and high quality of documentation expected in the Project Report.

The Project Manager and the TI Lead provided review criteria to the Panel for both the draft and final versions of the Project Report. The criteria for reviewing the Draft Report ${ }^{6}$ covered the range of technical and process issues consistent with requirements of the SSHAC Guidance, including draft implementation guidance (see footnote \#4). Key criteria, among others, include sufficiency of explanatory detail; adequate consideration of the full range of data, models, and methods - and the views of the larger technical community; adequate justification of the data evaluation process, logic-tree weights, and other technical decisions; proper treatment of uncertainties; and conformance to a SSHAC Level 3 assessment process. To be clear, the PPRP is charged with judging the adequacy of the documented justification for the CEUS SSC Model and its associated logic-tree weights. The TI Team "owns" the Model and logic-tree weights.

Criteria for reviewing the Final Report focused on reaching closure to comments made on the Draft Report and ensuring that no substantive issues remained unresolved. To that end, among its many review comments on the Final Report the Panel identified "mandatory" comments, which the TI Team was required to address in the final version of the Project Report.

\footnotetext{
${ }^{6}$ See PPRP report dated October 4, 2010, in Appendix I of CEUS SSC Final Report
} 
The Panel made thorough, extensive efforts in its documented reviews of the 2010 Draft Report and the 2011 Final Report (as well as in many related interactions with the TI Team) to ensure a high-quality Project Report that fully meets SSHAC requirements for clear, complete, and transparent documentation of all aspects of the CEUS SSC Project. We are pleased to confirm that implementation of the CEUS SSC Project fully conformed with the SSHAC Guidance and that the resulting CEUS SSC Model properly meets the SSHAC goal of representing the center, body, and range of technically-defensible interpretations.

This concludes our PPRP Final Report for the CEUS SSC Project.

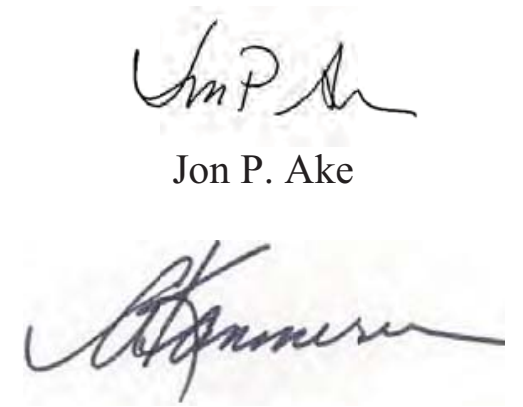

Annie M. Kammerer

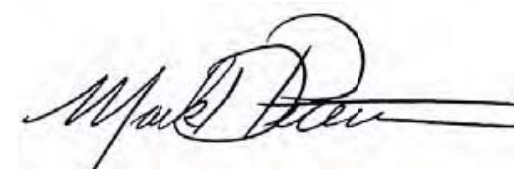

Mark D. Petersen

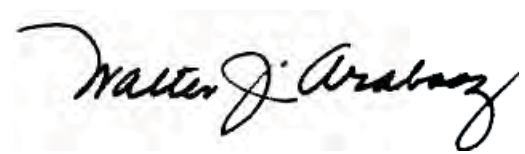

Walter J. Arabasz

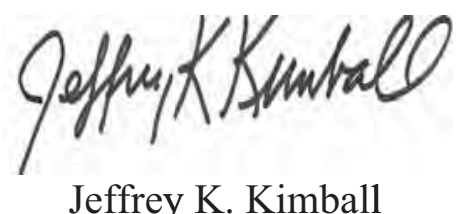

Jeffrey K. Kimball

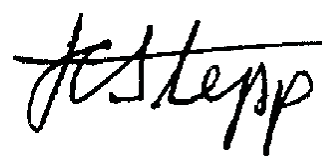

J. Carl Stepp

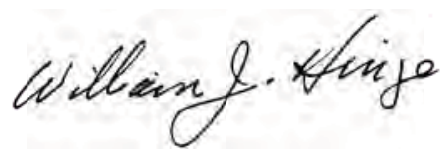

William J. Hinze

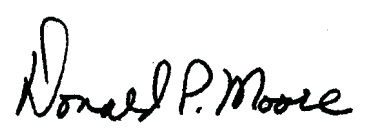

Donald P. Moore

Copy:

Lawrence A. Salomone

Kevin J. Coppersmith

Brent Gutierrez 


\section{PROJECT ACKNOWLEDGMENTS}

This study was sponsored by the Electric Power Research Institute (EPRI) Advanced Nuclear Technology Action Plan Committee, the U.S. Department of Energy (DOE) Office of Nuclear Energy and Office of the Chief of Nuclear Safety, and the U.S. Nuclear Regulatory Commission (NRC) Office of Nuclear Regulatory Research. Technical experts from the DOE, NRC, U.S. Geological Survey, Defense Nuclear Facility Safety Board, industry, and academia participated in the study as part of the Technical Integration (TI) Team or as members of the Participatory Peer Review Panel (PPRP). Any statements, opinions, findings, conclusions, or recommendations expressed in this material are those of the authors and do not necessarily reflect those of the participating or sponsoring agencies.

Jeffrey F. Hamel was the EPRI Advanced Nuclear Technology Program Manager. Lawrence A. Salomone of Savannah River Nuclear Solutions, LLC, served as the Project Manager for the study. Kevin J. Coppersmith of Coppersmith Consulting Inc., served as the lead for the TI Team. J. Carl Stepp of Earthquake Hazards Solutions, and Walter J. Arabasz, Research Professor Emeritus of Geology and Geophysics at the University of Utah, served as Co-chairmen for the PPRP. The entire Central and Eastern United States Seismic Source Characterization Project Team and their roles are discussed in Section 2 and are shown on the project oganization chart (Figure 2.3-1) of the report.

The authors of the report wish to acknowledge the contributions of the following people: the resource experts who participated in Workshop 1, the proponent experts who participated in Workshop 2, and the technical experts who provided valuable insights, perspective, and references throughout the study. The names of all these contributors are listed in Table 2.2-2.

In addition, the authors of the report appreciate the support of Geraldine Moore-Butler as administrative assistant and Nancy L. Sutherland as technical editor for the project. This report was assembled at AMEC. 
Page intentionally left blank 


\section{SPONSORS' PERSPECTIVE}

This report describes a new seismic source characterization model for the Central and Eastern United States (CEUS) for use in probabilistic seismic hazard analysis (PSHA) for nuclear facilities. PSHA has become a generally accepted procedure for supporting seismic design, seismic safety and decision making for both industry and government. Input to a PSHA consists of seismic source characterization (SSC) and ground motion characterization (GMC); these two components are necessary to calculate probabilistic hazard results (or seismic hazard curves) at a particular geographic location.

The 1986 Electric Power Research Institute and Seismicity Owners Group (EPRI-SOG) study included both an SSC and GMC component. Recent applications for new commercial reactors have followed U.S. Nuclear Regulatory Commission (NRC) regulatory guidance (RG 1.208) by using the EPRI-SOG source model as a starting point and updating it as appropriate on a sitespecific basis. This CEUS SSC Project has developed a new SSC model for the CEUS to replace the SSC component of the EPRI-SOG study.

The CEUS SSC Project was conducted using a Senior Seismic Hazard Analysis Committee (SSHAC) Level 3 process, as described in the NRC publication, Recommendations for Probabilistic Seismic Hazard Analysis: Guidance on Uncertainty and Use of Experts (NUREG/CR-6372). The goal of the SSHAC process is to represent the center, body, and range of technically defensible interpretations of the available data, models, and methods. The CEUS SSC model is applicable to any site within the CEUS and can be used with the EPRI 2004/2006 GMC model to calculate seismic hazard at any site of interest. Long-term efforts to replace the EPRI 2004/2006 GMC model with the Next Generation Attenuation Relationships for Central and Eastern North America obtained from the NGA-East Project is scheduled for completion in 2014.

The updated CEUS SSC model provides industry and government with the following: a new model for the commercial nuclear industry to perform PSHAs for future reactor license applications; the NRC to support its review of early site permit (ESP) and construction and operating license (COL) applications; and the U.S. Department of Energy (DOE) to support modern PSHAs to meet design and periodic review requirements for its current and future nuclear facilities. Specific benefits of the model are as follows:

- Consistency: For many sites, seismic sources at distances up to $300 \mathrm{~km}$ (186 mi.) or more significantly contribute to hazard at some spectral frequencies. Consequently, seismic hazard models for many sites have significant geologic overlap. If done separately, there is a likelihood of conflicting assessments for the same regions. A regional source model allows for consistent input into a PSHA. An updated conceptual SSC framework that provides a 
consistent basis for identifying and characterizing seismic sources in the CEUS has been developed. The NRC will no longer need to review each time each applicant's regional SSC model when the accepted CEUS SSC model is used. This will avoid lengthy review of the regional SSC model in ESP and COL applications for sites within the CEUS that use the accepted regional CEUS SSC model to develop its site-specific SSC model.

- Stability: This CEUS SSC model was developed using the accepted state-of-practice SSHAC methodology that involved the following tasks:

- Development of a comprehensive database and new tools for documenting the data consideration process.

- Multiple workshops to identify applicable data, debate alternative hypotheses, and discuss feedback.

- Multiple working meetings by the Technical Integration (TI) Team to develop the SSC model and fully incorporate uncertainties.

- Technical advancements in a number of areas, such as developing a uniform earthquake catalog, developing an updated approach for assessing maximum magnitude, compiling data evaluation tables, incorporating paleoseismic data, and using spatial smoothing tools.

- Participatory peer review, including four panel briefings, multiple interactions, and periodic formal feedback.

- Proper documentation of all process and technical aspects of the project.

Experience has shown that stability is best achieved through proper and thorough characterization of our knowledge and uncertainties, coupled with the involvement of the technical community, regulators, and oversight groups.

- Greater Longevity: An explicit goal of the SSHAC methodology is to represent the center, body, and range of the technically defensible interpretations of the available data, models, and methods. Using the SSHAC process provides reasonable assurance that this goal has been achieved. Representing the center, body, and range of interpretations at the time of the study means that as new information is acquired and various interpretations evolve as a result, the current thinking at any point is more likely to be addressed in the study. As new information becomes available, an existing SSC will require periodic reviews to evaluate the implications of the new findings. The need for updates to a particular study is now better understood as a result of findings of the CEUS SSC Project sensitivity studies to determine the significance of source characteristics.

- Cost and Schedule Savings: The CEUS SSC model can be used to perform a PSHA at any geographic location within the CEUS. It is applicable at any point within the CEUS, subject to site-specific refinements required by facility-specific regulations or regulatory guidance. Having stable, consistent input into a regional PSHA will reduce the time and cost required to complete a commercial nuclear site's ESP or COL licensing application, prepare a DOE site's PSHA, and develop design input for new commercial and DOE mission-critical nuclear facilities. 
- Advancement of Science: The CEUS SSC Project provides new data, models, and methods. This information was shared at three workshops with international observers as a means to provide technology transfer for application in other regions. The CEUS SSC earthquake catalog, which merges and reconciles several catalogs and provides a uniform moment magnitude for all events, and the CEUS SSC paleoliquefaction database provide a new baseline for future research and updates. New approaches used in this project for spatial smoothing of recurrence parameters, assessment of maximum magnitude, and systematical documentation of all data considered and evaluated also benefit future research and PSHA updates.

The sponsors of the CEUS SSC Project are utilities and vendors on the EPRI Advanced Nuclear Technology Action Plan Committee, the DOE Office of Nuclear Energy, the DOE Office of the Chief of Nuclear Safety, and the NRC Office of Nuclear Regulatory Research. Technical experts from the DOE, NRC, U.S. Geological Survey (USGS), and Defense Nuclear Facility Safety Board (DNFSB) participated in the study as part of the TI Team or as members of the Participatory Peer Review Panel (PPRP).

The product of the CEUS SSC Project is a robust peer-reviewed regional CEUS SSC model for use in PSHAs. This model will be applicable to the entire CEUS, providing an important baseline for future research and updates. The CEUS SSC Project demonstrates that a SSHAC Level 3 approach can achieve the goals of considering the knowledge and uncertainties of the larger technical community within a robust and transparent framework. The value of the new CEUS SSC model has been enhanced by the participation of key stakeholders from industry, government, and academia who were part of the CEUS SSC Project Team.

Looking forward, the NRC will publish NUREG-2117 (2012), Practical Implementation Guidelines for SSHAC Level 3 and 4 Hazard Studies that provides SSHAC guidance on the need to update a regional model. The guidance covers updating both regional and site-specific assessments. It addresses the "refinement" process of starting with a regional model and refining it for site-specific applications. 
Page intentionally left blank 


\section{ABBREVIATIONS}

AD anno domini (in the year of the Lord)

AFE annual frequency of exceedance

AIC Akaike information criterion

ALM Alabama-Louisiana-Mississippi (zone of possible paleoseismic features)

AM Atlantic Margin (seismotectonic zone)

AHEX Atlantic Highly Extended Crust (seismotectonic zone)

ANSS U.S. Advanced National Seismic System

ANT Advanced Nuclear Technology

APC Action Plan Comittee

BA Blytheville arch

BC before Christ

BCFZ Big Creek fault zone

BFZ Blytheville fault zone

BL Bootheel lineament

BMA Brunswick magnetic anomaly

BP before present

BPT Brownian passage time

BTP Branch Technical Position

CAD computer-aided design 
CBR center, body, and range

CCFZ Crittenden County fault zone

CDZ Commerce deformation zone

CENA Central and Eastern North America

CERI Center for Earthquake Research and Information

CEUS Central and Eastern United States

CFZ Commerce fault zone

CFR Code of Federal Regulations

CGL Commerce geophysical lineament

CGRGC Cottonwood Grove-Rough Creek graben

CI confidence interval

CNWRA Center for Nuclear Waste Regulatory Analysis

COCORP Consortium for Continental Reflection Profiling

COCRUST Consortium for Crustal Reconnaissance Using Seismic Techniques

COL combined construction and operating license

COLA combined operating license application

COMP composite prior, composite superdomain

CON contemporary (with earthquake occurrence)

COV coefficient of variation

CPT cone penetration test

CVSZ Central Virginia seismic zone

D\&G Dewey and Gordon (1984 catalog)

DEM digital elevation model 


\begin{tabular}{ll} 
DNFSB & Defense Nuclear Facilities Safety Board \\
DOE & U.S. Department of Energy \\
DWM & Division of Waste Management \\
ECC & Extended Continental Crust \\
ECC-AM & Extended Continental Crust-Atlantic Margin (seismotectonic zone) \\
ECC-GC & Extended Continental Crust-Gulf Coast (seismotectonic zone) \\
ECFS & East Coast fault system \\
ECFS-C & East Coast fault system—central segment \\
ECFS-N & East Coast fault system—northern segment \\
ECFS-S & East Coast fault system—southern segment \\
EC-SFS & East Coast-Stafford fault system \\
ECMA & East Coast magnetic anomaly \\
ECRB & East Continent rift basin \\
ECTM & Eastern Canada Telemetered Network \\
E[M $]$ & expected moment magnitude listed in the CEUS SSC catalog for an earthquake \\
ENA & eastern North America \\
EP & Eau Plain shear zone \\
EPRI & Electric Power Research Institute \\
EPRI-SOG & Electric Power Research Institute-Seismicity Owners Group \\
ERM & Eastern rift margin \\
ERM-N & Eastern rift margin-north \\
ERM-RP & Eastern rift margin—river (fault) picks \\
ERM-S & Eastern rift margin—south \\
\hline
\end{tabular}


ERM-SCC Eastern rift margin—south/Crittenden County

ERM-SRP Eastern rift margin—south/river (fault) picks

ERRM Eastern Reelfoot Rift Margin

ESP early site permit

ESRI Environmental Systems Research Institute

ETSZ Eastern Tennessee seismic zone

EUS Eastern United States

FAFC Fluorspar Area fault complex

FGDC Federal Geographic Data Committee

$\mathrm{ft} \quad$ foot or feet

FTP file transfer protocol

$\mathrm{ft} / \mathrm{s} \quad$ feet per second

$\mathrm{ft} / \mathrm{yr} \quad$ feet per year

FWLA $\quad$ Fugro William Lettis \& Associates

FWR Fort Wayne rift

$\mathrm{Ga} \quad$ billion years ago

GC Gulf Coast

GCVSZ Giles County, Virginia, seismic zone

GHEX Gulf Coast Highly Extended Crust (seismotectonic zone)

GIS geographic information system

GLTZ Great Lakes tectonic zone

GMC ground-motion characterization (model)

GMH Great Meteor Hotspot (seismotectonic zone)

cxii 


$\begin{array}{ll}\text { GMPE } & \text { ground-motion prediction equation } \\ \text { GMRS } & \text { ground-motion response spectra } \\ \text { GPR } & \text { ground-penetrating radar } \\ \text { GPS } & \text { global positioning system } \\ \text { GSC } & \text { Geological Survey of Canada } \\ \text { Gyr } & \text { gigayears (109 years) } \\ \text { HF } & \text { Humboldt fault } \\ \text { HID } & \text { hazard input document } \\ \text { I } & \text { maximum intensity } \\ \text { IAEA } & \text { International Atomic Energy Agency } \\ \text { IBEB } & \text { Illinois Basin Extended Basement (seismotectonic zone) } \\ \text { IPEEE } & \text { Individual Plant Examination for External Events } \\ \text { IRM } & \text { Iapetan rifted margin } \\ \text { ISC } & \text { International Seismological Centre } \\ \text { ITC } & \text { informed technical community } \\ \text { ka } & \text { thousand years ago } \\ \text { K-Ar } & \text { potassium-argon } \\ \text { km } & \text { kilometer(s) } \\ \text { km }{ }^{2} & \text { square kilometer(s) } \\ \text { kijec } & \text { kilometers per second } \\ \text { thousand years }\end{array}$


LDO Lamont-Doherty Earth Observatory (catalog)

LHS Latin hypercube sampling

LLNL Lawrence Livermore National Laboratory

$\ln (\mathrm{FA}) \quad$ logarithm of felt area (with felt area measured in $\mathrm{km}^{2}$ )

LS least squares

LSA La Salle anticlinal belt

LWLS locally weighted least squares

m $\quad$ meter(s)

M magnitude

M, $\mathrm{M}_{\mathrm{W}} \quad$ moment magnitudes

Ma million years ago

MAR Marianna (RLME source)

$\mathrm{m}_{\mathrm{b}} \quad$ body-wave magnitude (short period)

$\mathrm{m}_{\mathrm{bLg}} \quad$ body-wave magnitude determined from higher-mode $\left(\mathrm{L}_{\mathrm{g}}\right)$ surface waves

$\mathrm{M}_{\mathrm{C}} \quad$ coda magnitude

MCMC Markov Chain Monte Carlo

$\mathrm{M}_{\mathrm{D}} \quad$ duration magnitude

MESE Mesozoic and younger extended crust

MESE-N Mesozoic-and-younger extended crust or Mmax zone that is "narrow"

MESE-W Mesozoic-and-younger extended crust or Mmax zone that is "wide"

mi. $\quad$ mile(s)

mi. $^{2} \quad$ square mile(s)

MIDC midcontinent

cxiv 


\begin{tabular}{|c|c|}
\hline MidC & Midcontinent-Craton (seismotectonic zone) \\
\hline Mfa & felt-area magnitude \\
\hline $\mathrm{M}_{\mathrm{L}}$ & local magnitude \\
\hline $\mathrm{M}_{\max }, \mathrm{Mmax}$ & maximum magnitude \\
\hline MMI & modified Mercalli intensity \\
\hline $\mathrm{mm} / \mathrm{yr}$ & millimeters per year \\
\hline $\mathrm{M}_{\mathrm{N}}$ & Nuttli magnitude \\
\hline $\mathrm{M}_{\mathrm{o}}$ & Scalar seismic moment \\
\hline MRS & Midcontinent rift system \\
\hline $\mathrm{m} / \mathrm{s}$ & meters per second \\
\hline $\mathrm{M}_{\mathrm{S}}$ & surface-wave magnitude \\
\hline MSF & Meeman-Shelby fault \\
\hline \multicolumn{2}{|l|}{$\mathrm{M}_{\mathrm{w}}$} \\
\hline Myr & million years \\
\hline NAD83 & North American Datum of 1983 \\
\hline NAP & Northern Appalachian (seismotectonic zone) \\
\hline $\mathrm{Nd}$ & neodymium \\
\hline NEDB & National Earthquake Database \\
\hline NEI & Nuclear Energy Institute \\
\hline NEIC & National Earthquake Information Center \\
\hline $\mathrm{NF}$ & Niagara fault zone \\
\hline NMESE & -Mesozoic and younger extended crust \\
\hline
\end{tabular}

NMESE-N Mesozoic-and-younger extended crust or Mmax zone that is "narrow" 
Abbreviations

NMESE-W Mesozoic-and-younger extended crust or Mmax zone that is "wide"

NMFS New Madrid fault system

NMN New Madrid North fault

NMS New Madrid South fault

NMSZ New Madrid seismic zone

NN New Madrid north (fault segment as designated by Johnston and Schweig, 1996)

NOAA National Oceanic and Atmospheric Administration

NPP nuclear power plant(s)

NR Nemaha Ridge

NRC U.S. Nuclear Regulatory Commission

NRHF Nemaha Ridge-Humboldt fault

NSHMP National Seismic Hazard Mapping Project

NW New Madrid west (fault segment as designated by Johnston and Schweig, 1996)

OKA Oklahoma aulacogen (seismotectonic zone)

OKO Oklahoma Geological Survey Leonard Geophysical Observatory (catalog)

OSL optically stimulated luminescence

$\mathrm{P}_{\mathrm{a}} \quad$ probability of activity (of being seismogenic)

PEZ Paleozoic Extended Crust (seismotectonic zone)

PGA peak ground acceleration

PM Project Manager

PPRP Participatory Peer Review Panel

PSHA probabilistic seismic hazard analysis

PVHA probabilistic volcanic hazard analysis 


\begin{tabular}{ll} 
RCG & Rough Creek graben \\
RF & Reelfoot fault \\
RFT & Reelfoot thrust (fault) \\
RLME & repeated large-magnitude earthquake (source) \\
RR & Reelfoot rift zone \\
RS & Reelfoot South (fault segment) \\
SA & spectral acceleration \\
SCL & St. Charles lineament \\
SCML & south-central magnetic lineament \\
SCR & stable continental region \\
SCSN & South Carolina Seismic Network \\
SEUS & Southeastern United States (catalog) \\
SEUSSN & Southeastern United States Seismic Network \\
SGFZ & Ste. Genevieve fault zone \\
SHmax & maximum horizontal stress, compression, or principal stress \\
SLR & St. Lawrence rift (seismotectonic zone) \\
SLTZ & Spirit Lake tectonic zone \\
SLU & Saint Louis University (catalog) \\
SNM & Sanford et al. (2002 catalog) \\
SOG & Seismicity Owners Group \\
SPT & standard penetration test \\
SRA & Stover, Reagor, and Algermissen (1984 catalog) \\
SRTM & Shuttle Radar Topography Mission \\
\hline
\end{tabular}


SSC seismic source characterization

SSE safe shutdown earthquake

SSHAC Senior Seismic Hazard Analysis Committee

Str\&Tur Street and Turcotte (1977 catalog)

SUSN Southeastern United States Network

TC technical community

TFI technical facilitator/integrator

TI technical integration

USGS U.S. Geological Survey

USNSN U.S. National Seismograph Network

UTC Coordinated Universal Time

$\mathrm{V}_{\mathrm{P}} / \mathrm{V}_{\mathrm{S}} \quad$ ratio of $\mathrm{P}$-wave velocity to $\mathrm{S}$-wave velocity

WES Weston Observatory (catalog)

WIPP Waste Isolation Pilot Project

WQSZ Western Quebec seismic zone

WRFZ White River fault zone

WUS Western United States

WVFS Wabash Valley fault system

WVSZ Wabash Valley seismic zone

WWSSN World-Wide Standardized Seismograph Network 